ESTRUTURA E MANEJO DE UMA FLORESTA DE VÁRZEA DO ESTUÁRIO AMAZÔNICO

DOMINGOS SÁVIO MOREIRA DOS SANTOS MACEDO Engenheiro Florestal

Orientador: Prof. Dr. Virgilio Mauricio Viana

Dissertação apresentada à Escola Superior de Agricultura " Luiz de Queiroz ", da Universidade de são Paulo, para obtenção de título de Mestre en Ciências Área de Concentração : Ciências Florestais.

P I R A C I C A B A

Estado de São Paulo - Brasil

Março - 1996 
Dados Internacionais de Catalogação na Publicação (CIP)

DIVISÃO DE BIBLIOTECA E DOCUMENTAÇẪO - Campus "Luiz de Queiroz"/USP

Macedo, Domingos Sávio Moreira dos Santos

Estrutura e manejo de uma floresta de várzea do estuário amzônico / Domingos Sávio

Moreira dos Santos Macedo. - - Piracicaba, 1996.

117 p. : il.

Dissertação (mestrado) - - Escola Superior de Agricultura Luiz de Queiroz, 1996.

Bibliografia.

1. Ecossistema florestal 2. Floresta - Manejo I. Titulo

CDD 634.9 
ESTRUTURA E MANEJO DE UMA FLORESTA DE VÁRZEA DO ESTUÁRIO AMAZÔNICO

DOMINGOS SÁVIO MOREIRA DOS SANTOS MACEDO

Aprovada em: 05.09.96

Comissão julgadora:

Prof. Dr. Virgílio M. Viana

Dr. Anthony B. Anderson

ESALQ/USP

Banco Mundial

Dr. Garo Batmanian

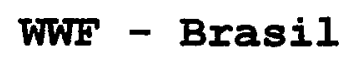

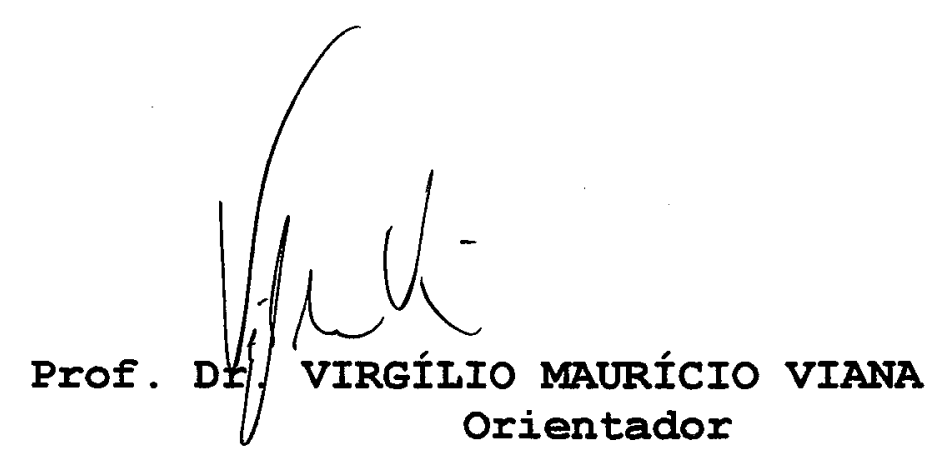


À memória de

Élio Moreira dos Santos Pena, um pioneiro... 


\section{Agradecimentos}

A realização deste trabalho contou com o apoio institucional do Museu Paraense Emílio Goeldi, Departamento de Botânica, em Belém-PA e Departamento de Ciências florestais da ESALQ/USP, Piracicaba-SP. Foram obtidos junto ao World Wildlife Fund-US financiamentos para a condução das viagens de campo, análise dos dados e material de consumo (grants \#9569 e \#OA48). Foram recebidas bolsas de estudo pela FAPESP - Fundação de Amparo à Pesquisa do Estado de São Paulo (proc. \#92/1559-3) e CAPES - Coordenação de Aperfeiçoamento de Pessoal de Nível Superior.

- local para a realização deste estudo foi cedido pelas Industrias TREVO da Amazônia com sede em Belém-PA.

- apoio das comunidades vizinhas localizadas no furo do Cacau, no município de Gurupá-PA, foi de grande importância no sentido de busca de informações e seleção das melhores áreas para a execução dos trabalhos de campo. Gostaria de expressar o meu agradecimento à familia de Coarací Nunes que durante todo o período da minha ausência em campo a $3.500 \mathrm{~km}$ de distância, foi - responsável pela manutenção do experimento, e que soube como ninguém entender qual a verdadeira finalidade do trabalho e que considero neste momento uma pessoa perfeitamente capacitada para a difusão das técnicas de manejo empregadas neste trabalho. Aos demais parceiros de trabalho de campo, especialmente "Tia Velha" e "Paxiúba" também extendo os agradecimentos.

Me considero como uma pessoa de muita sorte na minha carreira profissional por ter sido orientado por pesquisadores de extrema capacidade de trabalho e visão científica, e talvez de mais sorte ainda por tê-los como grandes amigos que são os Drs. Anthony B. Anderson e Virgilio M. Viana.

Me dedico já sete anos de pesquisas na Amazônia, e devo a este grande prazer aos meus queridos amigos Anna Fanzeres $e$ Igor Mousasticoshvily Jr.

Aos colegas de curso, professores e funcionários da universidade que me apoiaram na realização do trabalho, especialmente Edson Higashi, Nadja Lepsch, André Dias e Vítor.

À minha familia, que à distância, sempre torceu para o sucesso do meu trabalho na Amazônia.

À minha querida Laurinha por toda sua dedicação e paciência durante as fases da sua e da minha dissertação. 


\section{INDICE}

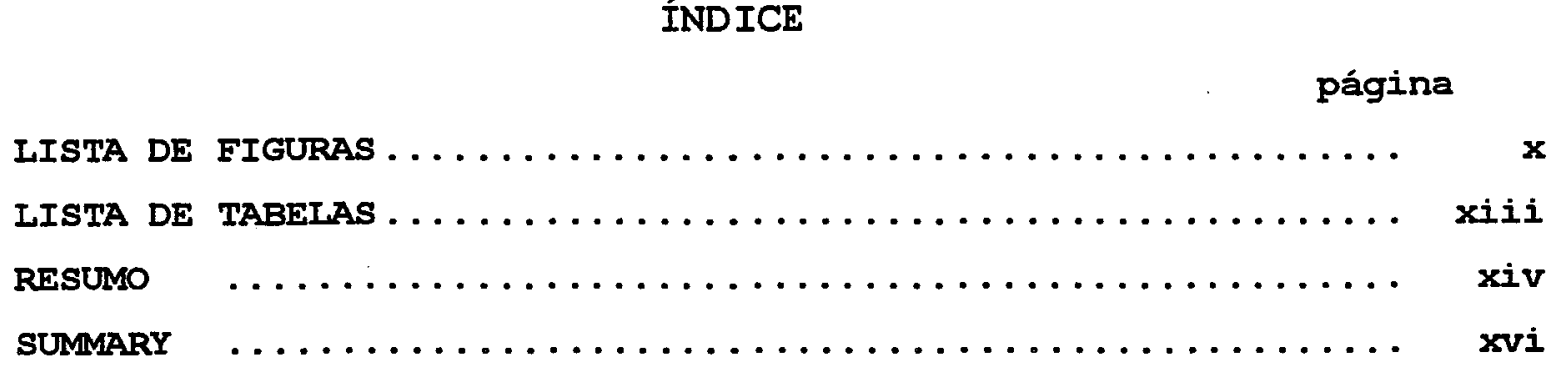

Capitulo I

Estrutura e funcionamento de uma floresta de várzea do estuário amazônico

1. Introdução $\ldots \ldots \ldots \ldots \ldots \ldots \ldots \ldots \ldots \ldots \ldots \ldots \ldots \ldots \ldots \ldots$

2. o local de estudo......................... 3

3. Fatores que afetam a estrutura e funcionamento das florestas de várzea do estuário ........................ 5

3.1. As florestas de várzea e os períodos de inundação ... 5

3.2. Estrutura física e química dos solos das várzeas .... 6

3.3. A luz e os processos regenerativos nas florestas .... 8

4. Objetivos da pesquisa....................... 9

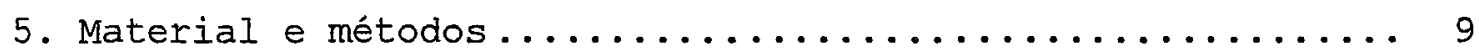

5.1. Solo ................................ 9

5.2. Monitoramento do lençol freático ................ 10

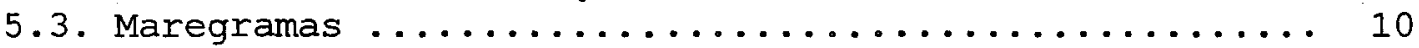

5.4. Caracterização de regime de luz ............... 11

6. Resultados e discussão........................ 11

6.1. Estrutura física e química do solo ............... 11

6.2. Lençol freático: Oscilações entre periodos de menor e maior drenagem do solo .................. 12

6.3. O regime das marés: As diferenças entre as épocas de inundação para inverno e verão ............... 15

6.4. O regime de luz em uma floresta de várzea .......... 16

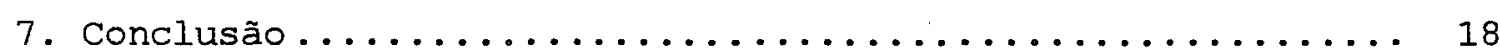

8. Bibliografia............................... 19 
Plantio de enriquecimento de Virola surinamensis (Rol.) Warb. numa floresta de várzea sob diferentes intensidades de luz situações topográficas

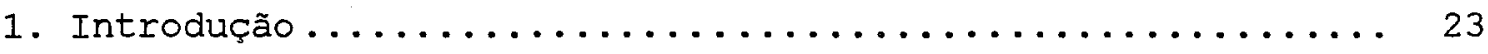

1.1. O Problema .......................... 23

1.1.1. Baixa produtividade em função das técnicas de manejo utilizadas .................. 24

1.1.2. Aspectos legais e operacionais .......... 25

1.2. Hipóteses ............................. 25

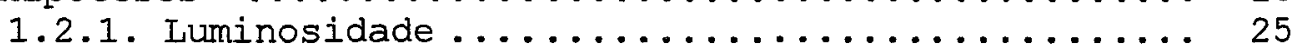

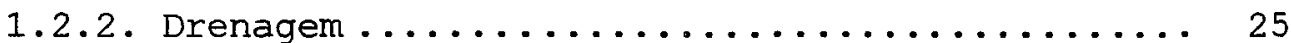

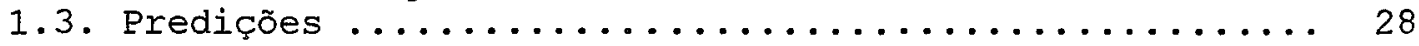

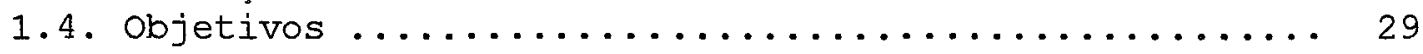

2. Material e métodos........................... 29

2.1. o local de estudo ......................... 29

2.2. Intensidades de exploração: Tratamentos de abertura das

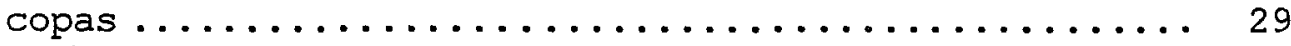

2.3. O sistema de enriquecimento ................ 31

2.4. Medições: Classes de porcentagens de luz ......... 33

2.5. Levantamento topográfico .................. 34

3. Resultados e discussão ..................... 34

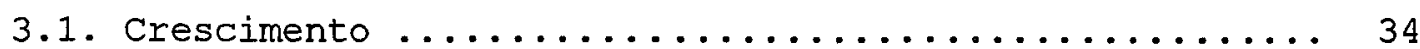

3.1.1. Em diferentes regimes de luz ............ 34

3.1.2. Em diferentes situações topográficas ....... 38

3.1.3. Interação: Luz x Topografia ............ 39

3.2. Sobrevivência ....................... 40

3.2.1. Em diferentes regimes de luz ........... 40

3.2.2. Em diferentes situações topográficas ........ 42

3.2.3. Interação: Luz x Topografia ............ 42

4. Conclusão ........................... 43

5. Bibliografia........................... 45 


\section{Comportamento inicial da regeneração natural numa floresta de várzea sob diferentes intensidades de exploração}

1. Introdução........................... 48

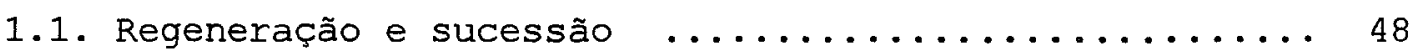

1.2. O problema ............................ 49

1.2.1.A exploração seletiva: Técnica não sustentável . . 49

1.3. Hipóteses e predições ................... 50

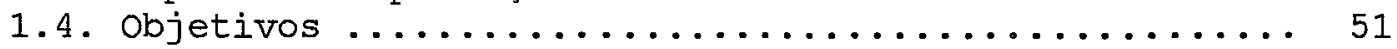

2. Material e métodos ......................... 51

2.1. o local de estudo ........................ 51

2.2. Intensidades de exploração: Tratamentos ......... 51

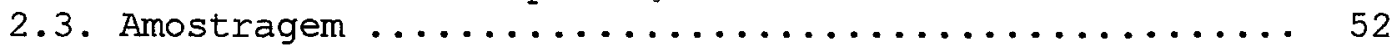

2.4. Identificação das espécies $\ldots \ldots \ldots \ldots \ldots \ldots \ldots \ldots \ldots \ldots$

2.5. Estrutura da regeneração ................ 54

3. Resultados e discussão ...................... 55

3.1. Relação entre $\circ$ número de espécies e $\circ$ número de parcelas ............................ 55

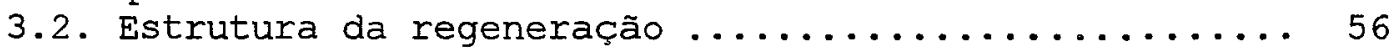

3.2.1. Composição florística .................. 56

3.2.2. Grupos de espécies: padrões de recrutamento em função da abundância e frequência

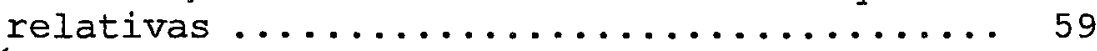

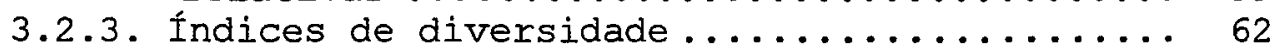

3.3. Influência das intensidades de exploração na composição das espécies.................. 64

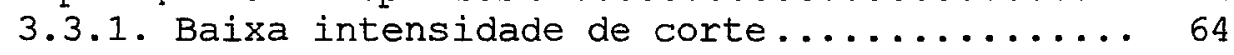

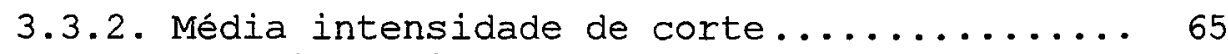

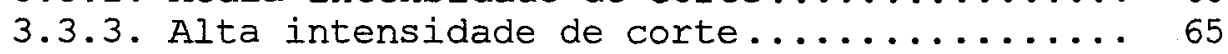

4. Conclusão ................................ 69

5. Bibliografia.......................... 72

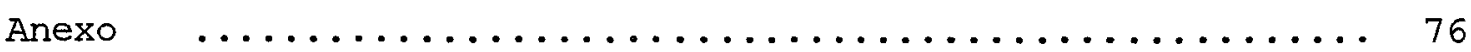




\section{Capítulo IV}

\section{Estudo do Impacto de diferentes intensidades de exploração numa floresta de várzea do estuário amazônico}

1. Introdução ................................. 80

1.2. o problema do manejo em florestas tropicais ....... 80

1.3. Hipóteses e predições ..................... 81

1.4. objetivos ............................. 82

2. Material e métodos ........................... 82

2.1. o local de estudo ....................... 82

2.2. Amostragem ......................... 82

2.2.1. Tamanho e forma da amostragem ........... 82

2.2.2. Relação entre 0 número de espécies e 0 número

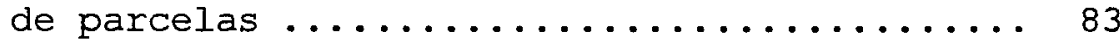

2.3. Inventário: Coleta e identificação das espécies .... 84

2.4. Tratos silviculturais .................... 84

2.4.1. Seleção e marcação das árvores ............ 84

2.4.2. Espécies selecionadas ................ 84

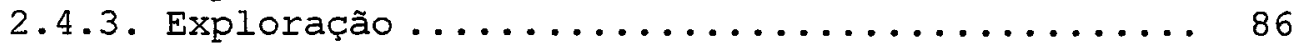

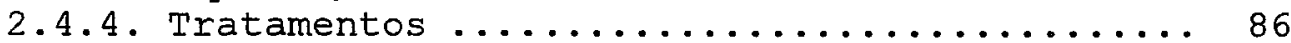

2.5. Estrutura da floresta .................... 87

2.5.1. Composição florística ............... 87

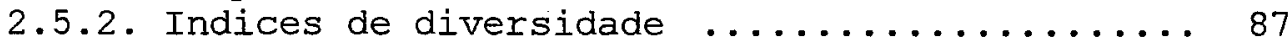

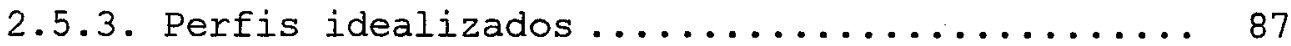

2.6. Avaliação econômica ..................... 87

3. Resultados e discussão .......................... 88

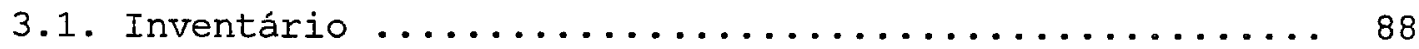

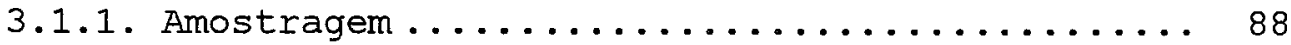

3.1.2. Estrutura da floresta ................. 90

3.1.3. Diversidade de espécies em florestas de várzea amazônica: futuras fontes de comparação ..... 91

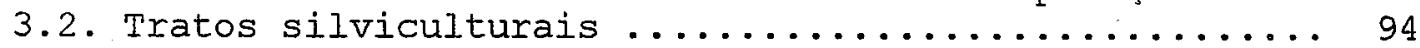

3.2 .1 . Exploração ....................... 94

3.2.1.1. Distribuição diamétrica ......... 94

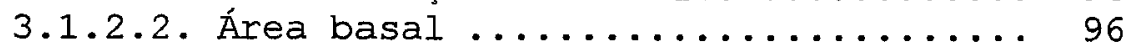

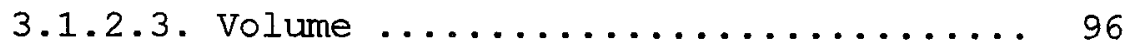

3.3. Danos em função da exploração ................... 97

3.4. Levantamento dos custos dos tratamentos ........... 108

4. Conclusão.................................... 110

5. Bibliografia............................. 111

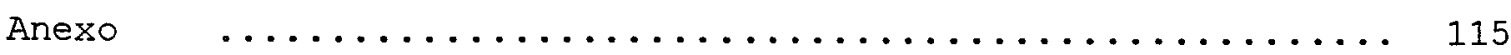




\section{LISTA DE FIGURAS}

Capitulo I

\section{página}

Figura 1: Localização da área de estudo em relação à região do estuário amazônico.............................. 4

Figura 2-A: Representação do transecto 1 (200m ao longo da floresta) em relação às características físicas e químicas do solo e oscilação do nível do lençol freático (médias anuais).

Figura 2-B: Representação do transecto 2 (200m ao longo da floresta) em relação às características físicas e químicas do solo e oscilação do nível do lençol freático (médias anuais).

Figura 3:Série temporal da oscilação do nivel da maré de 1982 a 1988 coletadas pela CIA DOCAS do pará e fornecidos pelo Projeto "Programa Estuário", Depto. de Bot6anica, Museu Goeldi, Belém-PA .............................

\section{Capítulo II}

Figura 1 : Comparação do desempenho de virola aos 8 e 10 anos, sob sombra, manejada à pleno sol em relação aos incrementos de (A) diâmetro, (B) altura e o volume por ha............... 26

Figura 2: Representação idealizada da predição quanto ao crescimento da virola a uma maior ou menor incidência de luz. o ponto intermediário representa o crescimento ótimo ..... 27

Figura 3: Representação idealizada da predição do crescimento da virola em função de cada local. o ponto de maior crescimento representa a drenagem ótima para a espécie. . . 28

Figura 4: Distribuição das parcelas na área de estudo...... 30 Figura 5: Níveis de luminosidade para os diferentes tratamentos $\left(\frac{\circ}{8}\right)$

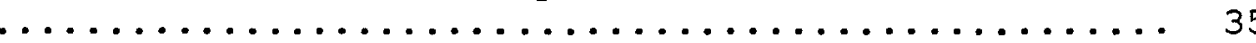

Figura 6: Altura (m)das mudas por tratamento, por classes de luz

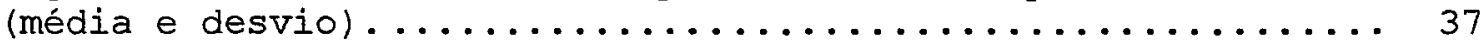

Figura 7: Altura (m) das 100 maiores mudas por tratamento (média e desvio).............................. 37

Figura 8: Número de mudas com incremento por tratamento..... 38 Figura 9: Representação do nível topográfico estabelecido para

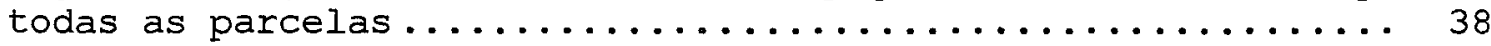

Figura 10: Altura(m) das mudas em função da interação entre luz e topografia................................. 40

Figura 11: Mortalidade de mudas por tratamento........... 41

Figura 12: Relação entre a porcentagem de luz de mudas mortas e

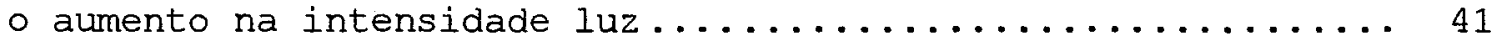

Figura 13: Porcentagem de mudas mortas para topografia alta e baixa 
Capítulo III

página

Figura 1: Desenho esquemático do tamanho e forma das parcelas

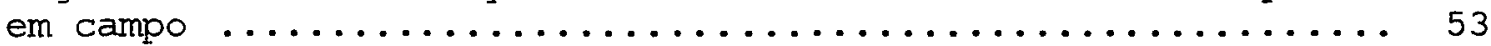

Figura 2: Médias por tratamento da porcentagem de entrada de luz, resultante das aberturas das copas durante a exploração

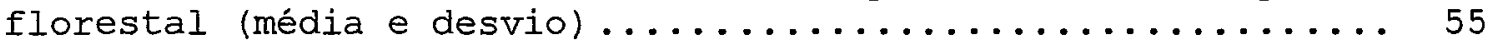

Figura 3: Número de espécies em função do aumento de parcelas $\left(4 \mathrm{~m}^{2}\right)$, calculadas para os tratamentos I, II, III e IV ........57

Figura 4: Distribuição das famílias botânicas identificadas no local de estudo e sua distribuição para cada tratamento..... 58

Figura 5: Proporção do número de famílias, gêneros e espécies em relação a cada tratamento ........................ 59

Figura 6: A - Abundância e frequência de: árvores, arbustos e cipós, nos quatro tratamento.......................60

Figura 6: B - Abundância e frequência de: ervas, palmeiras e gramíneas, nos quatro tratamento .....................61

Figura 7: Comportamento da regeneração natural de algumas espécies por tratamento: bases para uma classificação preliminar quanto a grupos de sucessão................. 68

Figura 8: Comportamento da regeneração natural de algumas espécies por tratamento: bases para uma classificação preliminar quanto a grupos de sucessão................ 68

Figura 9: Comportamento da regeneração natural de algumas espécies por tratamento: bases para uma classificação preliminar quanto a grupos de sucessão................. 68

\section{Capítulo IV}

página

Figura 1: Relação espécie/área de todas as parcelas

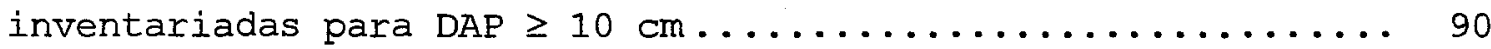

Figura 2: Relação do número de espécies e números de indivíduos para a floresta em estudo......................... 92

Eigura 3: A - Número de individuos ( $\mathrm{n} / \mathrm{ha}$ ) por classe de DAP, antes da exploração; B - Número de individuos (n/ha) por classe de DAP, após a exploração .................. 95

Figura 4: Análise de variância da área basal (m2/ha), antes e depois da aplicação dos tratamentos ................ 96

Figura 5.1: Mapa da distribuição espacial de todas as árvores inventariadas para o tratamento 1, parcela 12, como exemplo de área não explorada............................... 98 
Figura 5.2: Mapa da distribuição espacial de todas as árvores inventariadas para 0 tratamento 2, parcela 8, como exemplo de retirada de $25 \%$ de área basal ....................... 99

Figura 5.3: Mapa da distribuição espacial de todas as árvores inventariadas para o tratamento 3, parcela 9, como exemplo de retirada de $50 \%$ de área basal ...................... 100

Figura 5.4: Mapa da distribuição espacial de todas as árvores inventariadas para o tratamento 4, parcela 10, como exemplo de retirada de 75 o de área basal...................... 101

Figura 6.1: Perfil da vegetação, referente ao tratamento 1, parcela 12, como exemplo de área não explorada............ 102

Figura 6.2: Perfil da vegetação, referente ao tratamento 2, parcela 8, como exemplo de retirada de 25\% de área basal..... 103

Figura 6.3: Perfil da vegetação, referente ao tratamento 3, parcela 9, como exemplo de retirada de 50\% de área basal.... 104

Figura 6.4: Perfil da vegetação, referente ao tratamento 4, parcela 10, como exemplo de retirada de 75\% de área basal.... 105 Figura 7: Médias em porcentagem dos danos e árvores exploradas para cada tratamento ........................... 107

Figura 8: Relação dos todos os itens e seus respectivos gastos para cada tratamento envolvendo a derrubada, limpeza e plantio de enriquecimento ............................ 108 


\section{LISTA DE TABELAS}

\section{página}

\section{Capitulo II}

\section{página}

Tabela 1: Distribuição do total das mudas em função das cinco classes de luz para todos os tratamentos................ 36

\section{Capitulo III}

página

Tabela 1: Médias de área basal, abundância e número de espécies por tratamento para avaliar a homogeneidade da área experimental. Valores calculados pelo programa SAS (Ronald \& Smith, 1984) ............................... 52

Tabela 2: Relação dos índices de riqueza e heterogeneidade de espécies calculados para os vários tratamentos........... 63

Tabela 3.1: Valores do coeficiente de similaridade de Jaccard, obtidos pelo pelo procedimento SIMQUAI (Rohlf, 1990), utilizando-se matriz de presença (1) e ausência (0), de familias nos quatro tratamentos....................... 64

Tabela 3.2: Valores do coeficiente similaridade de Jaccard, obtidos pelo pelo procedimento SIMQUAL (Rohlf, 1990), utilizando-se matriz de presença (1) e ausência (0), de gêneros

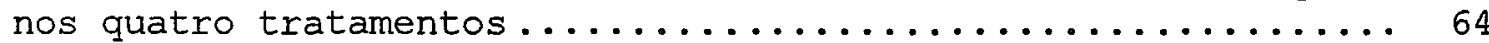

\section{Capitulo IV}

\section{página}

Tabela 1: Relação das espécies selecionadas para 0 monitoramento da regeneração natural. ............... 85

Tabela 2: Relação da área basal $\left(\mathrm{m}^{2} /\right.$ parcela de 0.49$)$ e resultados do do número suficiente de parcelas........... 89

Tabela 3: Valores mínimos para amostragem em cada parcela de 0.49 ha, levando-se em consideração o aumento da área a cada

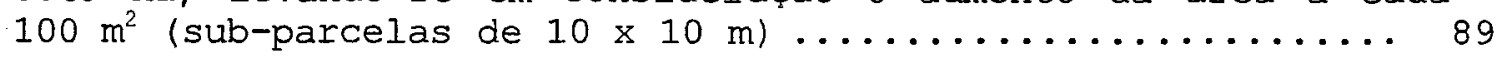

Tabela 4: Valores do coeficiente de similaridade de Jaccard, obtidos pelo procedimento SIMQUAL (Rohlf, 1990), para as parcelas dos tratamentos 1, 2, 34, respectivamente......... 93

Tabela 5: Médias da área basal ( $\left.\mathrm{m}^{2} / \mathrm{ha}\right)$; número de individuos ( $\mathrm{n} / \mathrm{ha}) ;$ e número de espécies, antes da execução dos

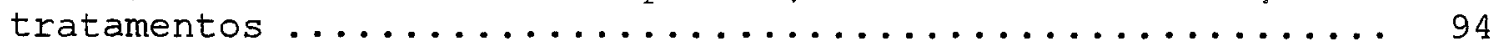

Tabela 6: Médias do volume de madeira extraido por tratamento. 97

Tabela 7: Cálculo de índices de heterogeneidade e de riqueza para a caracterização do efeito da exploração em relação a diversidade de espécies na floresta.................. 108 


\title{
ESTRUTURA E MANEJO DE UMA FLORESTA DE VÁRZEA DO ESTUÁRIO AMAZÔNICO
}

\author{
Autor: DOMINGOS SÁVIO MACEDO \\ Orientador: Prof. Dr. VIRGÍLIO MAURÍCIO VIANA
}

\section{RESUMO}

- estudo está dividido em quatro capítulos. o Capítulo I fornece algumas informações ecológicas básicas sobre a estrutura e funcionamento de florestas de várzea do estuário amazônico, principalmente em relação aos regimes periódicos de inundação das várzeas de maré e suas influências sobre o meio biofísico. Nos capítulos seguintes são apresentados resultados que poderão servir como base ecológica para o manejo deste ecossistema. Sob várias intensidades de manejo florestal, o estudo enfoca o impacto sobre a vegetação arbórea (Capítulo IV) e regeneração natural de plântulas (Capítulo III); e o crescimento de mudas de Virola surinamensis que foram plantadas na floresta (Capítulo II).

A área de estudo está localizada na foz do rio Amazonas, no Município de Gurupá, Estado do Pará (latitude 1²9's e longitude $51^{\circ} 38^{\prime} \mathrm{W}$ ).

Existem dois níveis de oscilação da maré na região do estuário: i) nível baixo de água abaixo do solo compreendendo os meses de julho a janeiro, o que praticamente coincide com o período menos intenso de chuva; e ii) nível alto de água nos meses de fevereiro a junho, coincindindo com os períodos de maior intensidade de chuva. O regime de inundações periódicas é - grande catalizador dos processos bióticos e abióticos das várzeas, acelerando os processos de renovação dos seus recursos.

$\mathrm{Na}$ metodologia adotada, foram instaladas 16 parcelas de 70 x 70 metros ( $0.49 \mathrm{ha}$ ), de forma quadrada, onde foi realizado um inventário de todos os indivíduos acima de $10 \mathrm{~cm}$ de DAP. Foram realizados 4 tratamentos com 4 repetições cada: i) testemunha (sem exploração: tratamento 1 - T1); ii) retirada de $25 \%$ da 
área basal a partir dos maiores diâmetros (tratamento 2 - T2); iii) retirada de 508 da área basal (tratamento 3 - T3); e iv) retirada de $75 \%$ da área basal (tratamento 4 - T4). Após a exploração foram instaladas sub-parcelas de 40 x 40 metros ( 0.16 ha) dentro das parcelas de 0.49 ha, ou seja, foi deixada uma bordadura de 15 metros para cada lado. Em seguida foi realizado um plantio de enriquecimento de Virola surinamensis (Rol.) Warb., perfazendo um total de 144 mudas por sub-parcela. $\mathrm{Na}$ mesma àrea das sub-parcelas foram instaladas microparcelas de 2 × 2 metros $\left(4 \mathrm{~m}^{2}\right)$, cruzando o centro das subparcelas.

As porcentagens médias de luz obtidas para os tratamentos foram: $5.6 \frac{\circ}{8}$ para $\circ \mathrm{T} 1 ; 13.5 \%$ para $\circ \mathrm{T} 2 ; 24.8 \%$ para $0 \mathrm{~T} 3$; $\mathrm{e}$ 40.1\% para o T4. Da mesma forma, a interação entre luz e topografia não exerceu efeitos significativos sobre $\circ$ crescimento das mudas de Virola surinamensis. A variação topográfica e a interação entre luz e topografia não teve efeito sobre a sobrevivência das mudas.

Houve um aumento do número de espécies e do número de individuos à medida qua aumentou o regime de luz. Tanto o índice de heterogeneidade de Shannon, como de riqueza de espécies Margalef), evidenciaram estas mudanças, principalmente com relação aos extremos (tratamentos 1 e 4 ).

- volume comercial por ha foi: $58.88 \mathrm{~m}^{3}$ (T2); $93.13 \mathrm{~m}^{3}$ (T3); e $136.86 \mathrm{~m}^{3}$ (T4). Os custos médios por metro cúbico/ha foram: US\$6.37 (T2); US\$5.80 (T3) e US\$5.46 (T2). Com relação às árvores danificadas foram observadas diferenças significativas entre T2 e T3 e T4. 


\title{
STRUCTURE AND MANAGEMENT OF A FLOODPLAIN FOREST IN THE AMAZON ESTUARY
}

\author{
Author: DOMINGOS S. MACEDO \\ Adviser: Prof. Dr. VIRGÍlIO MAURÍCIO VIANA
}

\section{SUMMARY}

This study is divided into four chapters. Chapter I provides ecological information about the structure and function of floodplain forests in the Amazon estuary, mainly in relation to periodic regimes of flooding and their influence on the biophysical environment.

The next chapters provide on ecological basis for management of this ecosystem. Under various forest management intensities, the study focuses on the impact on the structure of adult trees (Chapter IV); on the natural regeneration of seedlings (Chapter III); and on the growth of seedlings of Virola surinamensis that were planted within the forest (Chapter II).

The study site is located at the mouth of the Amazon river, in the municipality of Gurupá, Pará State, Brazil (latitude $0^{\circ} 47^{\prime} \mathrm{S}$ and longitude $51^{\circ} 37^{\prime} \mathrm{W}$ ).

Two levels of oscilation were found: i) low water level during July through January, at the same time as low levels of rainfall; and ii) high water level during February through June, at the same time as high levels of rainfall. The tidal regime is the great catalyst of biotic and abiotic activities in the floodplain forests, accelerating the renovation processes of its resources.

As part of the methodology utilized, 16 square plots measuring $70 \times 70$ meters $(0.49 \mathrm{ha})$ were defined, where a forest inventory was conducted in which all trees $\mathrm{DBH} \geq 10 \mathrm{~cm}$ were measured. Four treatments were applied with four replications each: i) without logging (control: treatment 1 - T1); 258 
removal of the basal area, beginning with the highest diameters (treatment 2 - T2), iii) removal of $50 \%$ of the basal area (treatment $3-T 3$ ), and iv) removal of $75 \%$ of the basal area (treatment $4-T 4$ ).

After the forest logging, subplots of $40 \mathrm{x} 40$ meters 10.16 ha) were placed inside the main plots of 0.49 ha, with a border of $15 \mathrm{~m}$ on each side. Then an enrichment planting was done using seedlings of Virola surinamensis (Rol.) Warb., with a total of 144 seedlings per subplot, within the subplots, microplots of 2 x 2 meters $\left(4 \mathrm{~m}^{2}\right)$ were placed crossing the center of the subplots.

The mean percentages of light (luminosity) obtained under the treatments were: $5.6 \frac{8}{\circ}$ (T1); $13.5 \%$ (T2); $24.8 \%$ (T3); and $40.1 \%(T 4)$. Likewise, the interaction between light and topography exerted no significant effect on seedling growth. Topographic variation, as well as the interaction between light and topography, exerted no effect on seedling mortality.

The number of species and individuals increased signicantly as light (luminosity) increased. In addition, the heterogeneity index of Shannon and the species richness index of Margalef reflected these changes, especially at the extremes ( $T 1$ and T4).

The comercial volume per ha: $58.88 \mathrm{~m}^{3}$ (T2); $93.13 \mathrm{~m}^{3}$ (T3); and $136.86 \mathrm{~m}^{3}$ (T4).

The mean costs per cubic meter per ha were: Us\$6.37 (T2); US\$5.80 (T3) and US\$5.46 (T4). In relation to trees damaged, statistical differences were found between $\mathrm{T} 2$ and $\mathrm{T} 3$ and $\mathrm{T} 4$. 


\section{Capítulo I}

\section{Estrutura e funcionamento de uma floresta de várzea do estuário amazônico}

\section{Introdução}

As várzeas ocorrem ao longo de toda a extensão do Rio Amazonas e ocupam cerca de $2 a$ 3\% de toda a área da Bacia Amazônica (Sombroek, 1984; Prance, 1980). Entretanto, existem diversas classificações com relação aos diferentes tipos de várzea, seja pela sua localização; pela composição química e cor da água dos rios e afluentes; pela flora e fauna; e pelos solos e biomassa (Prance, 1980; Pires, 1984; Morán, 1990; Ayres, 1993). As áreas de várzea compartilham, no entanto, características em comum, incluindo $\circ$ ciclo de enchente $e$ esvaziamento dos rios que, por sua vez, influi na flora, na fauna e nas estratégias das populações humanas (Morán, 1990). Para efeito de simplificação e melhor entendimento, este estudo considera pelo menos tres tipos de vegetação bem distintos, em relação a sua posição ao longo do curso do Rio Amazonas, assim distribuídos (Sioli, 1984):

Várzeas do alto Amazônas: Correspondem às áreas inundáveis mais altas situadas na região do alto Amazonas, acima da cidade de Manaus.

Várzeas do médio e baixo Amazônas: Localizam-se na região do baixo Amazonas entre as cidades de Manaus e Santarém.

Várzeas do estuário ou várzea de maré: Sujeitas às inundações diárias, resultantes de rio com influência das marés, que podem ser notadas até $1.000 \mathrm{~km}$ da foz do rio Amazonas. Na região do estuário observa-se grande irregularidade nas oscilações do nível da maré, sendo que a amplitude média das marés mais altas (fevereiro a abril) varia de 3,5 a 4 metros (Diegues, 1990). Neste estudo serão tratados aspectos referentes apenas a estrutura e funcionamento das florestas de várzea do estuário amazônico. 
Em função de complexos processos de adaptação ao regime de inundações, existem grandes diferenças na composição do número de espécies, na estrutura diamétrica e na altura dos indivíduos, comparado com as florestas de terra firme (Pires, 1972; Daly \& Hammond, 1989). Apesar de ser o tipo florestal com a maior concentração de população humana, as matas de várzea vêm se sustentando (resistindo) ao longo de séculos a contínuos ciclos extrativistas (Meggers, 1984), e são sem dúvida a grande base de sustentação econômica para as populações ribeirinhas tradicionais da Amazônia (Anderson \& Ioris, 1992).

Apesar do reconhecimento do seu potencial, pouco se sabe sobre as relações entre as espécies ali presentes com solos ricos em nutrientes e matéria orgânica, porém muito pobres em oxigênio devido a grande parte do tempo em que permanecem submersos (Jordan et al., 1978). As causas da dinâmica desta floresta permanecem incógnitas, como também, as razões que permitem as populações ribeirinhas sobreviverem ali a centenas de anos utilizando, sempre na dependência dos seus recursos naturais.

Este capítulo pretende fornecer informações ecológicas básicas que continuam pouco esclarecidas, com relação a estrutura e funcionamento de florestas de várzea do estuário amazônico. Nos capitulos seguintes pretende-se mostrar alguns resultados que poderão servir como base ecológica para recomendações sobre manejo das Várzeas inundáveis. Sob várias intensidades de manejo florestal, o estudo enfoca o impacto sobre a vegetação arbórea (Capitulo IV), a regeneração natural de plântulas (Capítulo III), - crescimento de mudas de Virola surinamensis que foram plantadas (Capitulo II). 
2. O local de estudo

A área de estudo está localizada na foz do rio Amazonas (Figura 1), no Município de Gurupá, Estado do Pará $\left(0^{\circ} 47^{\prime} \mathrm{S}\right.$ e longitude $51^{\circ} 37^{\prime} \mathrm{W}$ ).

A escolha do local foi feita principalmente em função da existência naquela região (Gurupá e municípios vizinhos) da maior área de plantios de enriquecimento com virola surinamensis na Amazônia brasileira, cerca de 4.800 ha (Anderson et al., 1992). Pode-se dizer também que é uma das áreas mais expressivas de reflorestamentos -- cerca de 17.650 ha -- em diferentes regimes de manejo com espécies nativas da Amazônia brasileira como andiroba (Carapa guianensis Aubl.), jutaí (Hymenaea oblongifolia Hub.), anoerá (Licania macrophylla Bth.) e pracuúba (Mora paraensis Ducke). Os plantios variam de mistos a puros, em situações a pleno sol e à sombra, com diferentes tipos de espaçamentos (Kanashiro \& Yared, 1991). É também uma região estratégica em termos sócio-econômicos, pois - local de estudo está situado a aproximadamente $175 \mathrm{~km}$ do projeto Jarí, $80 \mathrm{~km}$ da reserva extrativista do Cajarí, $101 \mathrm{~km}$ do porto de Macapá e $128 \mathrm{~km}$ de sede do Município de Gurupá, onde nos últimos anos vem servindo de palco de importantes iniciativas de desenvolvimento sustentável, envolvendo prefeituras, sindicatos rurais e ONGs.

A pluviosidade na região apresenta um índice anual de $3.000 \mathrm{~mm}$. As chuvas se concentram de janeiro a julho (cerca de $80 \%$ da precipitação anual). A região possui clima tropical úmido, segundo a classificação de Köeppen, entre os tipos Ami e Afi (Tancredi et al., 1986). A pedologia da região apresenta em sua maior extensão dois grandes grupos: solos hidromórficos gleizados e laterita hidromórfica. 


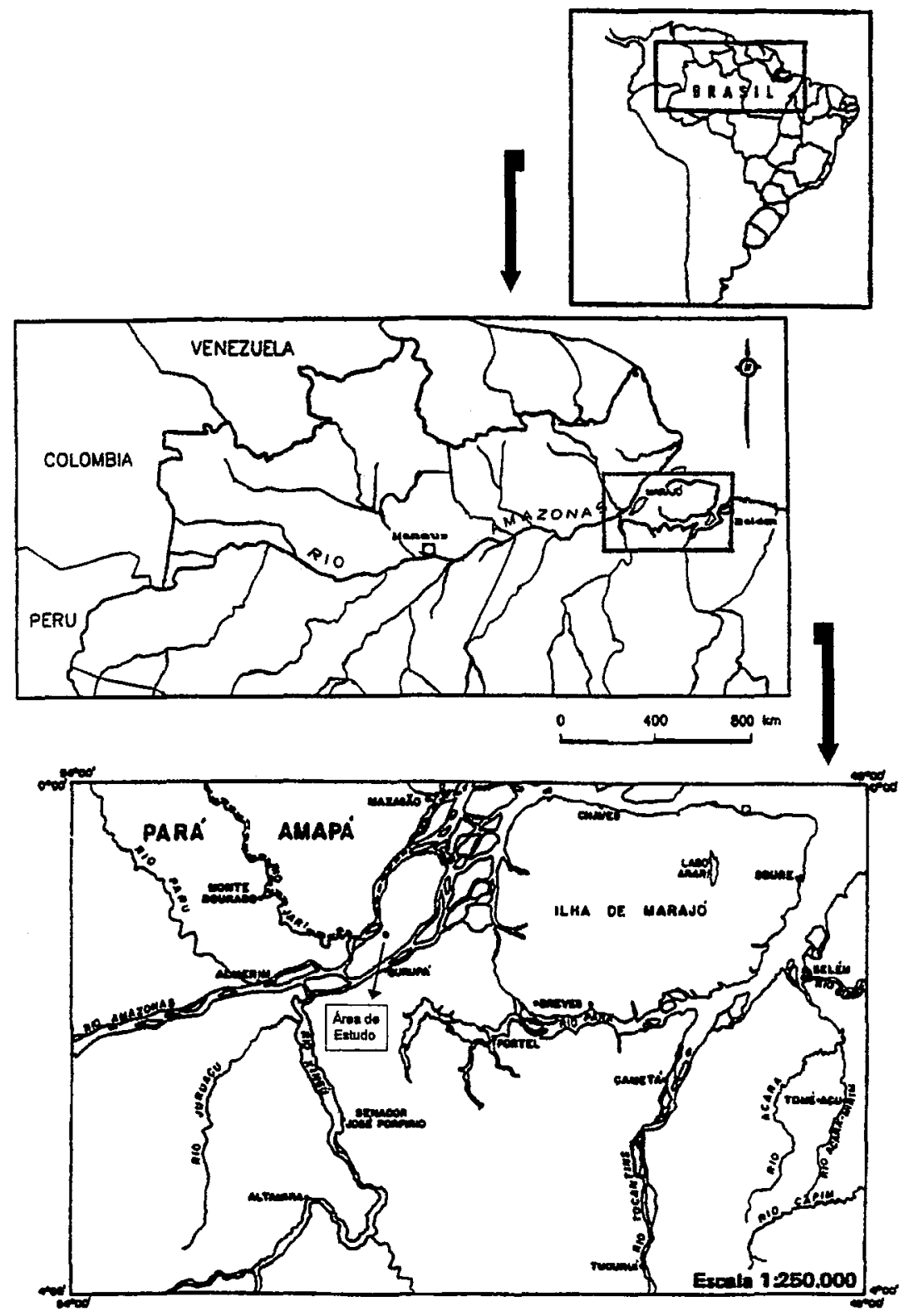

Figura 1: Localização da área de estudo em relação à região do estuário amazônico. 
Nas várzeas do estuário predomina uma floresta alta de várzea, recortada por pequenos igarapés, que no período das chuvas lançam suas águas no interior da mata. A região é ocupada por uma população que habita geralmente nas margens dos rios, onde é praticada agricultura (mandioca, arroz, cana, etc.), e extração de produtos como látex, cacau, frutas, e madeira, bem como caça e pesca (Morán, 1990).

3. Fatores que afetam a estrutura e funcionamento das florestas de várzea do estuário

3.1. As florestas de várzea e os períodos de inundação

A dinâmica da interação entre a água e solo é o principal processo que governa os sistemas de rios e as terras inundadas adjacentes. A alternância de períodos de avanço e retração da água em áreas inundadas é o principal fator que controla as adaptações da maioria dos componentes bióticos ali existentes (Bayley, 1995). Este regime é 0 responsável pelo aumento da produtividade biológica e pela manutenção da diversidade no sistema. Os principais componentes associados com este processo contínuo (anual e/ou diário) são as plantas, nutrientes, detritos e sedimentos (Sioli, 1984).

Um gradiente da composição biótica, nutrientes, e luz existentes ao longo desta zona de transição (aquática e terrestre) é denominada de várzea. As várzeas fazem parte do ecossistema de rios e terras alagadas que são inundadas e drenadas sucessivamente. Um acúmulo de matéria orgânica e nutrientes ocorre como resultado deste movimento (Furch, 1984).

Durante o período de alagamento, os nutrientes previamente mineralizados são dissolvidos. Mais nutrientes são dissolvidos nas águas ou associados com sedimentos suspensos são também adicionados oriundos do rio principal. Altas taxas de produção primária e decomposição também ocorrem durante a época de 
inundação, acelerando a produção da decomposição (Junk, 1984; Kozlowski, 1984).

3.2. Estrutura física e química dos solos das várzeas

Quando um solo é inundado, as trocas de gases entre o solo e - ar são drasticamente reduzidas. Logo após a ocorrência de uma inundação, microorganismos consomem praticamente todo o oxigenio na água e no solo (Ponnamperuma, 1984).

A pouca aeração do solo associada com inundações induz a um grande número de mudanças no solo e nas plantas que adversamente influem no seu crescimento. Conseqüentemente, algumas mudanças morfológicas podem aparecer, tais como a hipertrofia das lenticelas como também o aparecimento de tecidos aerenquimáticos, raízes adventíceas, e pneumatóforos (Jackson \& Drew, 1984).

A inundação de um solo desencadeia uma série de processos físicos, químicos e biológicos que influenciam profundamente a qualidade do solo e o crescimento das plantas. A natureza, os padrões e a extensão desses processos dependem das propriedades físicas e químicas do solo e da duração do período de alagamento (Kozlowski, 1984).

A inundação ou retenção da água em um solo virtualmente elimina 0 ar dos seus poros e limita a troca de gases para a difusão molecular no solo submerso. Este solo, entretanto, não é uniformemente desprovido de oxigênio. As concentações de $\mathrm{O}_{2}$ podem ser altas na superficie numa pequeníssima camada em contato com a água de superfície. Reduções drásticas de trocas gasosas entre o solo inundado e a atmosfera leva ao acúmulo de nitrogênio, dióxido de carbono, metano e hidrogênio na sua superficie(Ponnamperuma, 1984).

A temperatura em solos inundados afeta sobremaneira a velocidade e $\circ$ padrão das mudanças químicas e eletroquímicas iniciadas pela inundação, além da liberação de nutrientes, produção de toxinas e o crescimento das plantas (Kozlowski, 1984). 
Quando um solo drenado é inundado, os seus colóides absorvem água e o solo incha. A taxa de aumento da "sorção" e do volume nos solos minerais dependem da quantidade e do tipo de mineral de argila, e da natureza dos cátions trocáveis. Quanto maior a quantidade de argila, maior será $\circ$ inchamento do solo (Ponnamperuma, 1984).

À medida que a umidade aumenta, a coesão das lâminas de água ao redor das partículas do solo fazem elas se aderirem, tornando-o plástico. Quanto maior a quantidade de água, a coesão diminui drasticamente. Solos inundados têm pouca resistência ao deslizamento entre as partículas e também uma baixa compressão (Falesi, 1972; Sanchez, 1976).

A inundação modifica a estrutura do solo pela ruptura dos agregados. Esta ruptura reflete uma redução na coesão com o aumento da quantidade de água e desfloculação da argila, causados pelo inchamento irregular das partículas e a destruição dos agentes cimentantes (Gentry \& Lopez-Parodi, 1980).

Os valores de $\mathrm{pH}$ da maioria dos solos inundados das várzeas amazônicas está entre 6.7 e 7.2 (Sioli, 1984). Entretanto, se a quantidade de ferro reduzível é baixa, $\circ \mathrm{pH}$ pode não atingir valores acima de 5.0, principalmente depois de meses de inundação. Se a quantidade de matéria orgânica de um solo de $\mathrm{pH}$ alto é pequena, os valores podem chegar a valores de $\mathrm{pH}$ bem alcalinos (Furch, 1984).

Os cátions são encontrados nos colóides do solo com cargas negativas permanentes, residentes nas particulas e pelo pH dependente destas cargas negativas. Períodos de inundação podem aumentar a capacidade de troca de cátions de solos ácidos e diminuir em solos alcalinos. Da mesma maneira, as propriedades de troca de ânions são afetadas pelo aumento de $\mathrm{pH}$ em solos ácidos e pelo decréscimo de $\mathrm{pH}$ em solos alcalinos (Furch, 1984).

A decomposição de matéria orgânica é mais lenta em solos inundados do que em solos bem drenados, principalmente em locais -permanentemente inundados (Piedade et al., 1991).

Com relação à fertilidade, a restrição de entrada de oxigênio no solo, o inchamento dos colóides e a destruição da 
estrutura, reduzem drasticamente a taxa de respiração e a absorção de nutrientes pelas plantas, não havendo transferência interna de oxigênio para as raízes (Sanchez, 1976).

Solos inundáveis possuem basicamente três horizontes principais: um horizonte " $A$ " parcialmente oxigenado, na qual a matéria orgânica se acumula; um próximo horizonte em que há uma alternância de condições entre oxidação e redução; e um horizonte que sempre prevalece a redução. Quando o solo fica saturado por água, a oxidação da matéria orgânica é lenta e se acumula no horizonte " $A$ ". No horizonte seguinte, ferro e manganês são alternadamente reduzidos e oxidados. Durante a oxidação, o $\mathrm{Fe}$ e Mg são depositados em camadas denominadas de "mosqueado", em tons de ferrugem. O horizonte permanentemente inundado possui uma tonalidade azul-esverdeada devido a presença de compostos de ferro (Vieira, 1975).

\subsection{A luz e os processos regenerativos nas florestas}

Clareiras constituem um complexo recurso para $\circ$ estabelecimento e manutenção dos diversos tipos de florestas tropicais. Estas podem variar em tamanho e em frequiencias de ocorrência temporal e espacial (Denslow, 1980; Ewel, 1983). O sucesso de estratégias de regeneração é dependente dos padrões de distribuição e tamanho de clareiras (Baur, 1964; Whitmore, 1978).

Existem duas classes principais de regeneração: (i) espécies tolerantes à sombra, que persistem na forma de mudas suprimidas no sub-bosque até a abertura do dossel, quando ocorre um acelerado crescimento das mesmas; e (ii) espécies pioneiras, intolerantes à sombra, que germinam nas clareiras e crescem rapidamente (Brokaw, 1987).

- tamanho de clareiras tem vital importância para a sucessão florestal. Pequenas clareiras formadas por quedas de galhos, por exemplo, podem não proporcionar condições para o estabelecimento de espécies pioneiras. Ao contrário, se a clareira é grande o suficiente, é colonizada principalmente por estas espécies (Hartshorn, 1980). 
- ambiente criado pela radiação durante 0 dia em uma clareira é tipicamente caracterizado por um período de radiação solar direta interrompido por períodos de radiação difusa (Ackerly \& Bazzaz, 1995). A forma da abertura do dossel abaixo de uma única planta gera uma marcada heterogeneidade espacial na distribuição angular da radiação incidente. A localização e tamanho da abertura do dossel dependem do tamanho da clareira, altura e distribuição da vegetação circundante. Uma planta colonizando uma localização periférica de uma clareira recebe muito mais luz de uma única direção do que de outra, devido a uma assimetria da abertura do dossel acima (Chazdon \& Pearcy, 1991).

A regeneração pode ocorrer de sementes que germinam depois da queda de árvores ou de mudas que estavam presentes no subbosque antes da queda (Newell et al., 1993). As espécies que melhor exploram a luz disponível depois da queda de uma árvore são aquelas que persistem mais tempo no sub-bosque até a abertura do dossel (Newell et al., 1993).

4. Objetivos da pesquisa

I. Acompanhar a oscilação do nível do lençol freático ao longo dos períodos de maior e menor preciptação no local de estudo;

II. Descrição do tipo de solo que compõem uma floresta de várzea periodicamente inundada;

III.Caracterização do regime de luz no interior da floresta.

5. Material e métodos

5.1. Solo

Para a caracterização do solo da área de estudo foram estabelecidos transectos de 200 metros ao longo da floresta a partir de dois pontos distintos: (i) um curso d'água (igarapé), e (ii) um paraná ou furo. Foram abertas trincheiras $(1,5 \times 1,5 \times 1,5$ 
metros) a cada 50 metros ao longo de cada transecto, perfazendo um total de 10 trincheiras abertas (5 em cada linha).

Procedeu-se a descrição do perfil do solo de cada trincheira, obtendo-se as caracteristicas morfológicas dos horizontes (Lemos \& Santos, 1984). As amostras foram secas ao ar livre no mesmo local de coleta para posterior análise química e física em laboratório. As amostras foram retiradas no período de menor precipitação anual da região (setembro e outubro), época em que apenas as áreas mais baixas da floresta são inundadas pelas marés.

\subsection{Monitoramento do lençol freático}

Para acompanhar a oscilação do nível do lençol freático no local de estudo, foram utilizadas as mesmas 10 trincheiras para a coleta de solo nos dois transectos, no sentido curso d'águafloresta. Em cada trincheira foi colocada uma régua graduada em centímetros, possuindo altura superior ao da profundidade da trincheira $(1,5 \mathrm{~m})$.

Para a retirada dos dados foi estabelecida a seguinte freqüência de medições: a cada mês foram marcadas todas as épocas de mudança de lua, ou seja, lua cheia, minguante, nova e crescente. No dia de cada mudança, fornecido por um calendário, foram retiradas duas medições: a primeira referente ao horário de maré cheia (pré-a-mar), e a segunda referente a maré seca (baixamar). o período de medição foi de 12 meses (julho/93 a junho/94).

\subsection{Maregramas}

Os dados referentes ao monitoramento do nível das marés no porto de Belém, coletados diariamente pela Companhia Docas do Pará, foram obtidos pelo projeto "Usos Tradicionais da Terra como Base para Desenvolvimento Sustentável no Estuário Amazônico" (Departamento de Botânica do Museu Goeldi, Belém-PA). Os dados são referentes a um período de 7 anos (1982 a 1988), que, apesar de serem coletados em anos anteriores a este trabalho, são de 
importância fundamental para ilustrar o esquema de oscilação do regime anual de marés na região do estuário amazônico.

5.4. Caracterização de regime de luz

Dentro das parcelas testemunhas, utilizadas para o estudo de diferentes intensidades de manejo que serão referidas nos capitulos seguintes, foi estabelecida uma malha de pontos para obtenção da quantidade média de luz que incide naturalmente em uma floresta de várzea não perturbada. Em cada uma de 4 parcelas de 0,49, foram obtidos 144 pontos. Em cada um destes pontos, foram tomadas duas leituras (a um metro uma da outra), utilizando-se de um luxímetro eletrônico de escala variável em lux/Fc.

As medições foram feitas em dias de céu aberto com ausência de nuvens sempre no período de 12 às 14 horas de cada dia, na época de menor precipitação anual na região (agosto a outubro). No início e no fim da medição de cada parcela foi retirada a intensidade máxima de luz em local aberto (clareira) para referência no cálculo dos valores relativos de luz.

\section{Resultados e discussão}

\subsection{Estrutura física e química do solo}

As áreas de várzea localizadas na região do estuário são caracterizadas por dois tipos de solos: (i) hidromórficos gleyzados eutróficos e distróficos, e (ii) hidromórficos indiscriminados eutróficos e distróficos (BRASIL, DNPM - PROJETO RADAM, 1974).

A classificação encontrada no local de estudo, segundo as análises de laboratório, foi de um solo do tipo gley pouco húmico e eutrófico. Podemos encontrar várias características típicas neste solo, tais como a presença de camadas de deposição recente, mal drenadas (altura média do lençol: $39.8 \mathrm{~cm}$ acima do nível do mar, $s d=15.69$ ), fortemente ácidas (média do $\mathrm{pH}: 4.52$, sd = 
0.22 ), pouco profundas (profundidade média: $57.5 \mathrm{~cm}, \mathrm{sd}=11.99$ ) e de textura argilosa dominante $(55.18$, sd $=3.94)$. Em todos os locais onde procedeu-se a coleta, foi encontrada a presença de mosqueados amarelos, avermelhados dentro do perfil, conseqüência da redução dos compostos férricos a ferrosos, ou da oxidação a férricos conforme a oscilação do lençol freático (Vieira, 1988).

Foram encontrados nos perfis a presença de três horizontes: A: $20.1 \mathrm{~cm}$ de profundidade média (sd $=6.3$ ) e $1.81 \%$ de teor de matéria orgânica ( $\mathrm{sd}=1.53$ ); $\mathrm{C}_{1 \mathrm{~g}} \mathrm{com} 37.1 \mathrm{~cm}$ de profundudade média $(\mathrm{sd}=10.26)$ e $0.25 \%$ de teor de matéria orgânica (sd = 0.10); e $\mathrm{C}_{2 g}$ com 0.22 s de teor de matéria orgânica (sd $=0.06$ ).

Com relação à presença de raízes, foi observada uma maior concentração no horizonte superficial, com a densidade de raízes grossas e finas decrescendo abruptamente nos horizontes subseqüentes. Em média, existe maior concentração do sistema radicular nos primeiros $50 \mathrm{~cm}$ do solo.

Foi observada diferença estatística entre os diversos pontos de coleta de solo $(50,100,150$ e $200 \mathrm{~m})$ somente em relação a quantidade de argila. Para as quantidades de areia e silte, matéria orgânica, capacidade de troca de cátions, e o de saturação de bases (V\&) nos três horizontes, não houveram diferenças estatisticas (Figuras 2-A e 2-B).

6.2. Lençol freático: Oscilações entre períodos de menor e maior drenagem do solo

Nos 12 meses quando foi medida a oscilação do nível do lençol freático (julho/93 a junho/94), foi feita uma comparação das médias entre os níveis mínimo e máximo (Prob > 0.001). Ficou evidente que existem dois niveis de oscilação: nível baixo de água $(99.8 \mathrm{~cm}$ abaixo do solo, sd $=30.76)$, compreendendo os meses de julho a janeiro, o que praticamente coincide com o período menos intenso de chuva; e nível alto de água $(20.3 \mathrm{~cm}$ acima do solo, sd =3.1), compreendendo os meses de fevereiro a junho, coincidindo com os períodos de maior intensidade de chuva (Figuras 2-A e 2-B). 


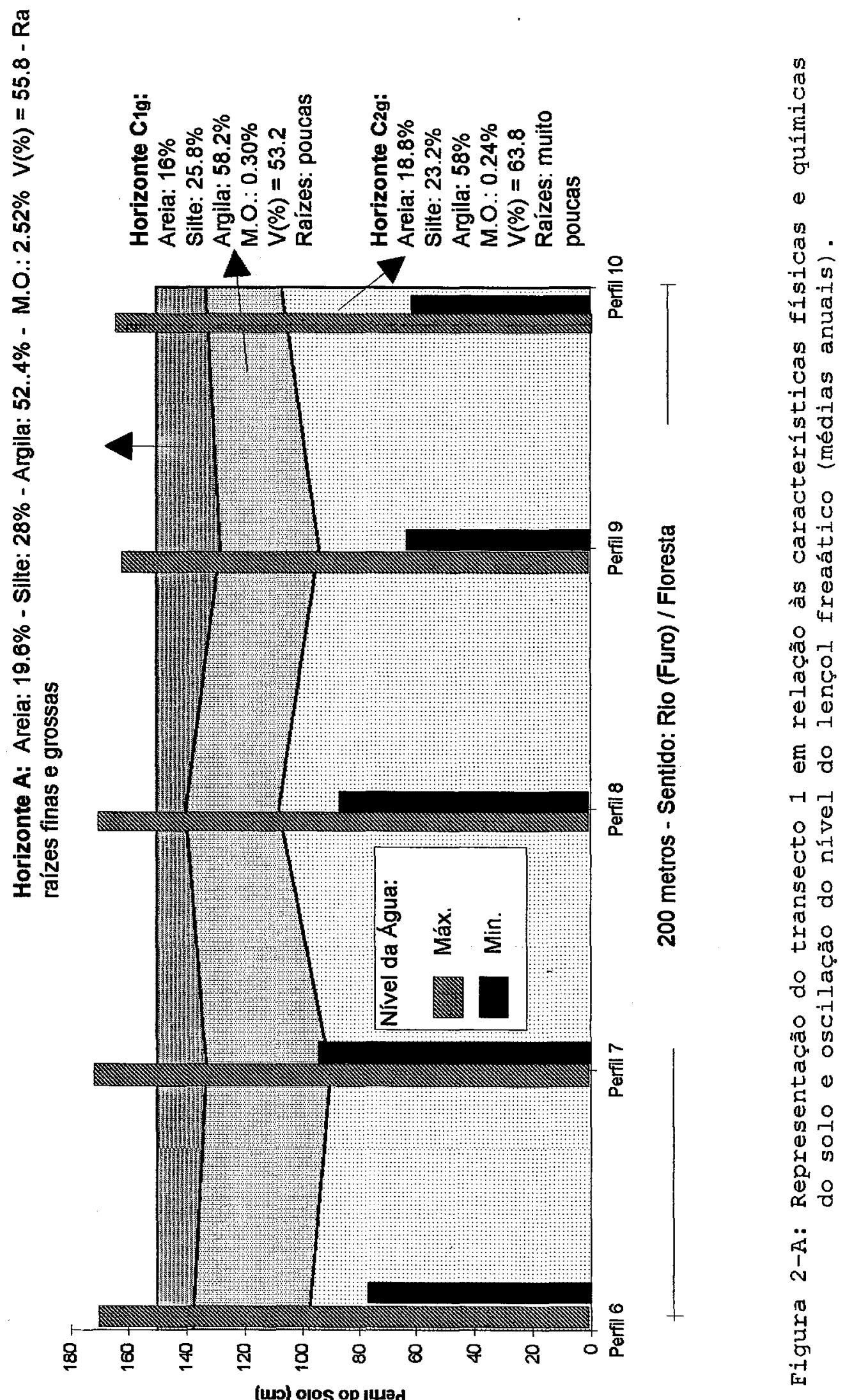




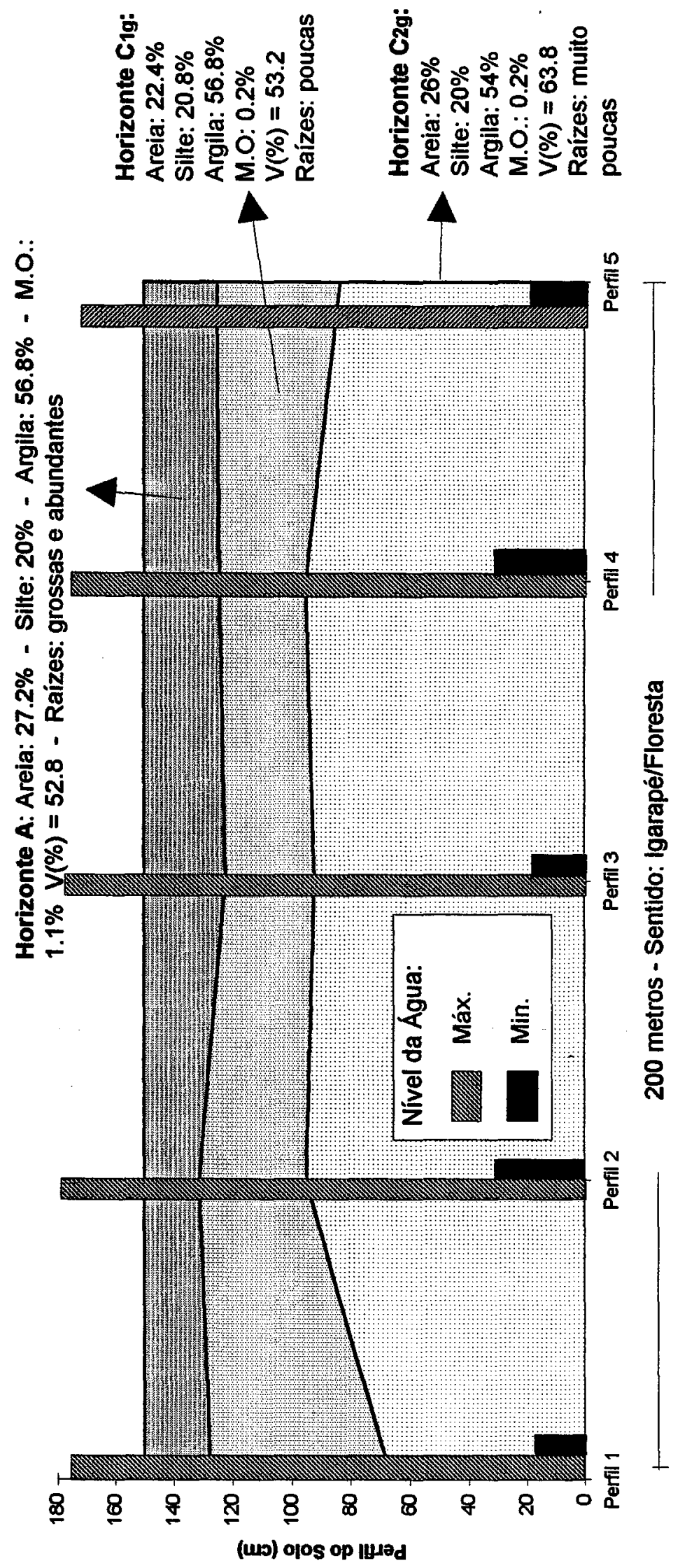

웅

告

(1)

0

年

学

(2)

0

-

记

岑是

(])

ن

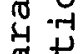

U

, 104

잉

U.

(1)

近

통

$\sim \stackrel{0}{5}$

얻

U 0

of 0

ర

点

욤

o

$\circ$ ?

0

$\pi$

임ㅇ

on

()

Q

叫

$\ddot{p}$

N

章 
A preocupação de obter dados para caracterizar mudanças do nível do lençol ao longo do ano, como também para saber o período de maior permanência do nível da água próxima à superfície do solo dentro da floresta, poderia esclarecer alguns pontos chaves de como proceder no manejo florestal das várzeas. Estes resultados serviram também para enumerar alguns pontos que ainda levantam muita discussão, tais como: (i) De que forma as enchentes influenciam os processos de ocorrência, germinação e crescimento das espécies componentes das várzeas? (ii) Como ocorre a adaptação das espécies às condições adversas como a baixa taxa de oxigenação dos solos?

Obter respostas a essas questões é de grande interesse para a silvicultura das espécies de importância econômica das várzeas do estuário, principalmente em locais onde pretende-se conduzir plantios de enriquecimento com estas espécies.

Na área de estudo, com relação as diferenças do nível do lençol freático ao longo do ano, podemos afirmar que nas épocas onde há maior concentração das chuvas, a permanência de água acima do nível do solo é quase constante e o escoamento é menor, principalmente nas épocas de lua cheia (denominadas de "lançantes" pelos habitantes da região).

Nesta época, o nível da água acima do solo permanece praticamente inalterado, mesmo com as interferências diárias das marés baixas. Entretanto, nas épocas de lua nova, ainda dentro dos períodos mais chuvosos, há um período de regularização da vazão de água dentro da mata. Ou seja, apesar do nível da água ser grande devido ao período concentrado das chuvas, existe um escoamento de água temporário (dois períodos de 6 horas por dia) durante a lua nova (denominada de "pacuema").

6.3. O regime das marés: As diferenças entre as épocas de inundação para inverno e verão

Como já foi citado anteriormente, existem na região dois períodos bem diferentes em relação ao nível da água no interior do solo. O estudo da série de dados referente à oscilação dos níveis de maré observados no porto de Belém, também localizado no 
estuário, confirma a tendência de encontrarmos dois períodos distintos ao longo do ano (Figura 3). Na base desses dados, podemos fazer algumas afirmações sobre a relação entre estas oscilações freqüentes do nível da água e e ecologia das espécies das várzeas do estuário. A primeira é com relação às estratégias de dispersão de sementes. Quase que na sua totalidade as espécies vegetais utilizam a água como principal agente de dispersão de suas sementes, que são levadas a grande distância pela extensa rede de rios, paranás e igarapés que ocorrem na região. As marés são o elemento chave neste processo, em função da alternância diária no nível da água, principalmente nos períodos mais concentrados das chuvas (fevereiro a maio). A segunda, é a estabilidade dos processos de renovação da floresta. O movimento das marés é sem dúvida o combustível para a manutenção do contínuo processo de exploração que as várzeas vêm sofrendo até os dias de hoje, devido ao constante intercâmbio de nutrientes e material genético, o que normalmente não ocorre tão intensivamente nas florestas altas de terra firme.

\subsection{O regime de luz em uma floresta de várzea}

A intensidade média de luz que incide dentro da floresta de várzea fechada é de $6.55 \%$, sd $=2.96$. O valor encontrado não difere muito se comparado com outros levantamentos em florestas tropicais (Chazdon \& Pearcy, 1991).

- sub-bosque é bem limpo, podendo-se observar processos de sucessão apenas nas clareiras mais recentes, causadas principalmente pela ação dos ventos e tempestades que causam a derrubada das árvores maiores. Apesar de apresentarem raízes tabulares (sapopemas), estas árvores são extremamente suceptíveis a queda devido ao seu sistema radicular ser superficial. No Capítulo III, uma atenção especial será dada ao comportamento desta floresta, quando sujeita a diferentes intensidades de exploração e a um conseqüente aumento na quantidade de luz em relação aos processos de regeneração natural. 


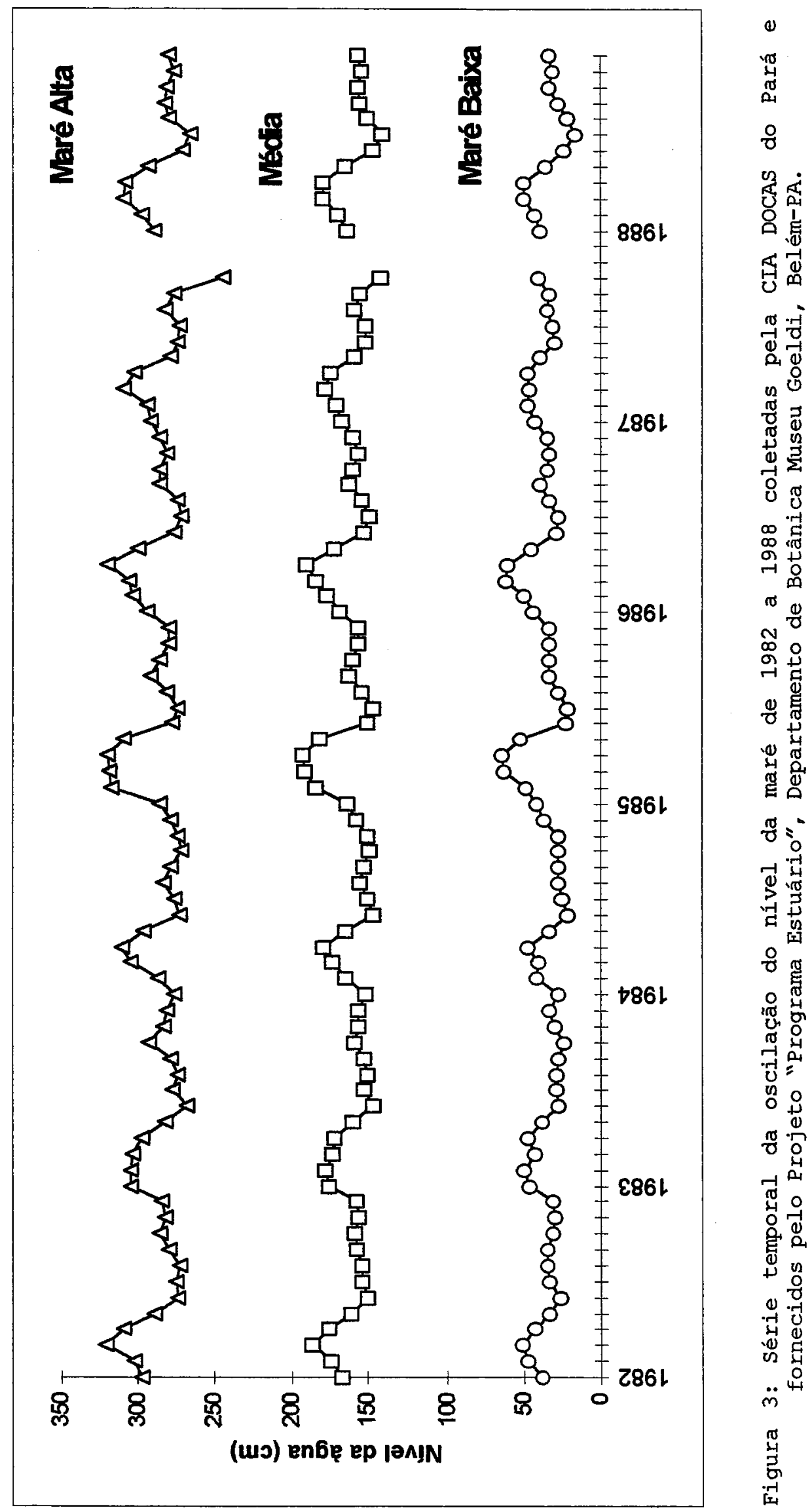


7. Conclusão

As várzeas do estuário amazônico possuem características marcantes quanto ao seu meio biofísico. Este estudo identificou que os solos permanecem três meses do ano com a altura do lençol freático acima e nove meses em média $0.4 \mathrm{~m}$ abaixo do nível do solo. Os solos são diretamente influenciados pelas alterações dos níveis das máres que alternam dois períodos diários de vazante e enchente durante todo $\circ$ ano, e pelo regime das chuvas na região (fevereiro a abril). Estas mudanças e evidenciam dois periodos bem nítidos com relação ao nível de água no curso dos rios e conseqüentemente no interior das várzeas do estuário amazônico.

Existem dois níveis de oscilação do lençol freático:

nível baixo de água abaixo do solo compreendendo os meses de julho a janeiro, o que praticamente coincide com o período menos intenso de chuva; (ii) nível alto de água compreendendo os meses de fevereiro a junho, coincidindo com os períodos de maior intensidade de chuva.

$0 \mathrm{pH}$ do solo se caracterizou como fortemente ácido com uma média de 4,52, com sua profundidade média não passando de $57,5 \mathrm{~cm}$ e possui textura argilosa dominante em todos os horizontes com valores médios de 55,18. Possui um elevado teor de matéria orgânica no seu horizonte superficial, com valores médios de 1,81\%, e com maior concentração de raizes nos primeiros $25 \mathrm{~cm}$ de profundidade. A classificação encontrada foi de um solo do tipo gley pouco húmico eutrófico, não diferindo da classificação de solo para locais de várzea do estuário amazônico (RADAM, 1974; Vieira, 1988). A intensidade média de luz que incide dentro da floresta em estudo foi de $6.55 \%$. Este valor representa uma floresta pouco perturbada.

Para as várzeas do estuário, o regime de inundações periódicas tem um papel chave na composição química e física dos solos que com outros fatores como a luz influi nas estratégias de sobrevivência da flora, fauna e das populações humanas dependentes dos seus recursos naturais. 


\section{Bibliografia}

Ackerly, D.D. \& F.A. Bazzaz. 1995. Seedling crown orientation and interception of diffuse radiation in tropical forest gaps. Ecology, 76(4): 1134-46.

Anderson, A.B.; Mousasticoshvily, I. \& Macedo, D.S. 1992. Impactos ecológicos e sócio-econômicos da extração seletiva de virola no estuário amazônico: Implicações para políticas florestais brasileiras. Relatório final a WWF-US. Rio de Janeiro. 52p.

Anderson, A.B. \& Ioris E.M. 1992. Valuing the rain forest: Economic strategies by small-scale forest extractivists in the Amazon estuary. Human Ecology, 20(3):337-69.

Ayres, J.M. 1993. As Matas de Várzea do Mamirauá. CNPq/Sociedade Civil Mamirauá. Brasilia, DF. Vol. 1. 123 p.

Baur, G.N. 1964. The ecological basis of rain forest management. New South Wales, Australia: Forestry Comission.

Bayley, P.B. 1995. Understanding large river-floodplain ecosystems. Bioscience, 45(3):153-58.

BRASIL. DNPM - PROJETO RADAM. Folha SA, 22 Belém, Rio de Janeiro. 1974. vol (5). (Levantamento de recursos Naturais).

Brokaw, N.V.L. 1987. Gap-phase regeneration of three pioneer tree species in a tropical forest. Journal of Ecology, 75:919.

Chazdon, L.R \& Robert W. Pearcy. 1991. The importance of sunflecks for forest understory plants. Bioscience, $41(11): 760-66$.

Daly, D.C. \& Ghillean T. Prance. 1989. Brazilian Amazon. In: Floristic inventory of tropical countries. Campbell, D.G. \& Hammond, D. Editors. N. York. NYBG/WWE. 401-26.

Denslow, J.S. 1980. Gap partitioning among tropical rain forest. Biotropica, suppl. 47-55.

Diegues, A.C.S. 1990. Inventário de áreas úmidas no Brasil. Versão preliminar. In: Programa de pesquisa e conservação de áreas úmidas no Brasil. USP/UICA/F. Ford. p. 145-64.

Ewel, J. 1983. Succession. In: Tropical rain forest ecosystems: Structure and function. Edited by Golley, F.B. Elsevier. Amsterdam. p. 217-23.

Falesi, I.C. 1972. Estudo atual dos conhecimentos sobre os solos da Amazônia brasileira. IPEAN, Minist. Agricultura. Bol. Técnico 54 .

Furch, K. 1984. Water chemistry of the Amazon basin: The distribution of chemical elements and freshwaters. In: The Amazon: limnology and landscape ecology of mighty tropical river and its basin. H. Sioli Editor. W. Junk Publishers. Boston. p.167-200. 
Gentry, A.H. \& Lopez-Parodi, J. 1980. Deforestation and increasead flooding of the upper Amazon. Science, 210: 135456.

Hartshorn, G.S. 1980. Neotropical forest dynamics. Biotropica, suppl. 23-30.499p.

Jackson, M.B. \& Malcolm C. Drew. 1984. Effects of flooding on growth and metabolism of herbarius plants. In: Flooding and Plant Growth. T.T. Koslowski, editor. Academic Press, Florida. p. $1-5$.

Jordan, C.F.; Medina, E. \& H. Klinge. 1978. Amazon escosystems. Their structure and functioning with particular emphasis on nutrients. Interciencia, 3(4):223-32.

Junk, W.J. 1984. Ecology of the várzea, floodplain of Amazonian whitewater rivers. In: The Amazon: limnology and landscape ecology of mighty tropical river and its basin. H. Sioli Editor. W. Junk Publishers. Boston. p.214-43.

Kanashiro, M. \& J.A.G. Yared. 1991. Experiências com plantios florestais na Bacia Amazônica. In: o Desafio das florestas tropicais. Curitiba, PR. UFPR/GTZ. p. 117-37.

Koslowski, T.T. 1984. Extend, Causes, and Impacts of flooding. In: Flooding and Plant Growth. T.T. Koslowski, editor. Academic Press, Florida. p. 1-5.

Koslowski, T.T. 1984. Responses of Woody Plants on Flooding. In: Flooding and plant growth. T.T. Koslowski, editor. Academic Press, Florida. p. 10-42.

Lemos, R.C. \& Dos Santos, R.D. 1984. Manual de descrição e coleta de solo no campo. SBCS/SNLCS. Campinas, SP. 45 p.

Meggers, B.J. 1984. The indigenous peoples of Amazonia, their cultures, land use and patterns and effects on landscape and biota. In: The Amazon: limnology and landscape ecology of mighty tropical river and its basin. H. Sioli Editor. W. Junk Publishers. Boston. p. 627-48.

Morán, E.F. 1990. A Ecologia humana das populações da Amazônia. Vozes, Petrópolis, RJ. 367 p.

Newell, E.A.; MCDonald, E.P.; Strain, B.R. \& Julie S. Denslow. 1993. Photosynthetic responses of Miconia species to canopy openings in a lowland tropical forest. Oecologia, 94:49-56

Piedade, M.T.F.; Junk, W.J. \& S.P. Long. 1991. The productivity of $\mathrm{C}_{4}$ grass Echinochloa polystachya on the Amazon floodplain. Ecology, 72: 1456-63.

Pires, J. M. 1972. Estudo dos principais tipos de vegetação do estuário do Amazonas.Tese de Doutorado. ESALQ/USP. Piracicaba. $183 \mathrm{p}$. 
Pires, J.M. 1984. The Amazonian forest. In: The Amazon: limnology and landscape ecology of a mighty tropical river and its basin. H. Sioli Editor. W. Junk Publishers. Boston. p. 581-602.

Ponnamperuna, F.N. 1984. Effects of Flooding on Soils.In: Flooding and Plant Growth. T.T. Koslowski, editor. Academic Press, Florida. p. 10-42.

Prance G.T. 1980. A terminologia dos tipos de florestas amazônicas sujeitas a inundação. Acta Amazonica, 10(3): 495504 .

Sanchez, P. 1976. Properties and Managements of soils in the Tropics. New York: Wiley-Interscience. $356 \mathrm{p}$.

Sioli, H. 1984. The Amazon and its main affluents: Hydrography, morphology of the river courses, and river types. In: The Amazon: limnology and landscape ecology of a mighty tropical river and its basin. H. Sioli Editor. W. Junk Publishers. Boston. p.127-66.

Sombroek, W.G. 1984. Soils of the Amazon region. In: The Amazon: limnology and landscape ecology of a mighty tropical river and its basin. H. Sioli Editor. W. Junk Publishers. Boston. p.521-36.

Tancredi, A.C. \& Serra, V.H. 1986. Hidrogeografia da região oriental da Ilha de Marajó. Relatórios de pesquisa, 11, IDESP. Belém, PA. 97 p.

Vieira, L. S. 1975. Manual da ciência do solo. Ed. Ceres. São Paulo, SP. 464 p.

Vieira, L.S.; Dos Santos, P.C.T \& M. N. Vieira. 1988. Solos: propriedades, classificação e manejo. MEC/ABEAS, Brasilia, $\mathrm{DF} .154 \mathrm{p}$.

Whitmore, T.C. 1978. Gaps in the forest canopy. In: P.B. Tomlinson \& M.H. Zimmermann, ed. Tropical trees as living systems. Cambridge University Press. New York. p. 639-55. 


\section{Capítulo II}

Plantio de enriquecimento de Virola surinamensis (Rol.) Warb. numa floresta de várzea sob diferentes intensidades de luz e situações topográficas

\section{Introdução}

1.1. O Problema

As florestas alagadas ocupam cerca de $3,3 \times 10^{6} \mathrm{~km}^{2}$ em todo o mundo, e encontram-se distribuídas desde latitudes mais altas até os trópicos, oscilando entre áreas costeiras até locais montanhosos. Estas florestas contribuem significativamente para a produtividade de áreas pesqueiras da costa litorânea e ao longo de estuários; regulam a qualidade de 'runoff' e influenciam nas reservas de água das bacias hidrográficas (Lugo et al., 1988). Na Amazônia brasileira, as várzeas ocupam cerca de 2 a $3 \frac{0}{8}$ da área total, acompanhando a hidrografia do rio Amazonas (Sombroek, 1984; Prance, 1980). A existência de uma topografia plana e uma distribuição sazonal das chuvas contribui para a grande extensão de áreas alagadas. Estas áreas alagadas podem se extender até dezenas de quilômetros em cada um dos lados dos grandes rios (Sioli, 1984; Kubitzky, 1994).

$\mathrm{Na}$ região do estuário amazônico, a pressão sobre os recursos florestais vem esgotando algumas espécies de grande importância na economia local, e ameaça a própria sobrevivência das populações ribeirinhas da região (Uhl, 1990; Barros \& Uhl, 1995). A exploração seletiva de Virola surinamensis (Rol.) Warb. se intensificou nas últimas três décadas, fazendo com que a virola se tornasse a segunda espécie mais exportada pela indústria madeireira até meados de 1990 na Amazônia (Mousasticoshvily, 1992). A floresta de várzea do estuário amazônico -- o habitat natural da virola -- vem sofrendo constantes intervenções através dos anos, e a dimensão de suas árvores e o seu potencial regenerativo vem decrescendo num ritmo acelerado (Macedo \& Anderson, 1994). Desta forma, os sistemas silviculturais de regeneraçãa natural, empregados 
atualmente nas florestas tropicais (Evans, 1982; Baur, 1968), não terão muito sentido de utilização.

- esgotamento local de virola é uma consequencia (i) do corte das árvores abaixo do limite permitido por lei, (ii) falta de fiscalização pelo órgão competente, (iii) do baixo aproveitamento das toras pelas serrarias da região, e (iv) da não reposição do seu estoque natural (Anderson et al., 1992). As experiências atuais com reflorestamento não estão refletindo - rápido crescimento que é característico da espécie (Schulz \& Rodrigues, 1966; Macedo \& Pina-Rodrigues, 1992). Como consequência, a baixa produtividade atual da virola em plantios de enriquecimento no estuário amazônico e a baixa rentabilidade das florestas de várzea já exploradas, devido à pequena abundância atual das espécies comerciais, se constituem no grande problema para o estabelecimento de uma política florestal para a região.

- avanço das fronteiras de exploração da virola, que praticamente se extendeu por toda a bacia do rio Amazônas (Mousastichosviliy, 1992; Barros, 1995), fez com que o parque industrial concentrado no estuário fosse desativado, gerando uma crise de mão-de-obra. Para a silvicultura da virola, houve um desestímulo de novos investimentos na região por parte das grandes indústrias, pois a reposição florestal ${ }^{1}$ teria que ser feita nas áreas onde as espécies estariam sendo exploradas, ou seja, no alto e médio Amazônas e alto Solimões.

1.1.1. Baixa produtividade em função das técnicas de exploração utilizadas

Os projetos de reflorestamento na região somam aproximadamente $17.7 \times 10^{3}$ ha (Kanashiro \& Yared, 1991). Estão incluidos neste total plantios de enriquecimento, homogêneos $e$ plantios mistos, que têm como objetivo principal a produção de madeira serrada. Virola surinamensis representa 26.38 deste total, mas a produtividade dos plantios é baixa, principalmente em função

1 Portaria $n^{\circ} 441$ de 09 de agosto de 1989. 
do desconhecimento da dinâmica da espécie. Na Figura 1 é feita uma comparação do desempenho da espécie em três situações diferentes de plantio aos 8 e 10 anos. Os plantios a pleno sol e à sombra foram realizados no estuário (Anderson et al., 1992) e o plantio sob manejo silvicultural foram obtidos de Schulz \& Rodriguez (1966).

\subsubsection{Aspectos legais e operacionais}

A extração seletiva não se embasa no manejo para uma produção contínua de madeira, onde os individuos com características desejáveis são extraídos na sua totalidade. Consequentemente, esta extração está acarretando uma perda irrecuperável de grande parte do patrimônio genético das espécies de interesse comercial atual (Olfield, 1988). As florestas de várzea, apesar de menos representativas em comparação com as florestas de terra firme, têm ainda grande participação e competitividade no mercado da região, principalmente devido ao custo de transporte ser muito baixo e ao mercado já tradicional das espécies mais conhecidas (Cruz, 1991; Barrros \& Uhl, 1995). 0 desperdício de matéria-prima bruta que ocorre, seja na área de extração, transporte fluvial (jangada) ou na indústria, tem sido uma grande barreira à utilização ordenada e integral do potencial madeireiro (Mousasticoshvily, 1992).

\subsection{Hipóteses}

Os principais fatores ambientais que governam os processos de crescimento das espécies em mata de várzea são (a) luz e (b) drenagem de solos. Através de sua influência sobre a regeneração natural e crescimento, estes fatores têm grande importância na estrutura e funcionamento, bem como na produtividade deste ecossistema, especialmente no caso da virola (Fanzeres, 1989).

\subsubsection{Luminosidade}

Em todas as florestas tropicais, a estrutura e a dinâmica da vegetação arbórea exercem forte influência sobre as 

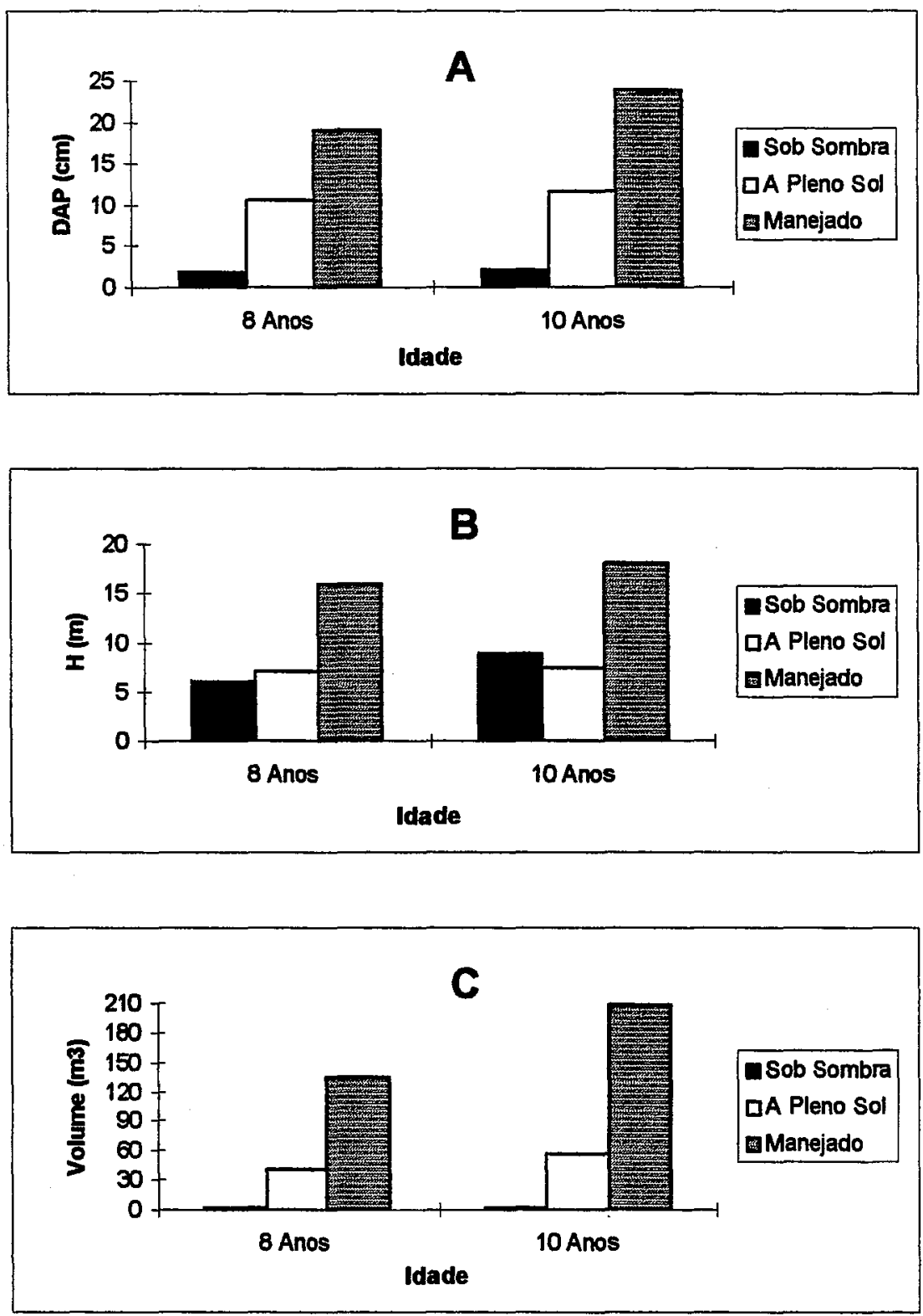

Figura 1: Comparação do desempenho de virola aos 8 e 10 anos, sob sombra, manejada à pleno sol em relação aos incrementos de (A) diâmetro, (B) altura e (C) volume por ha. 
variações espaciais e temporais de luz, que têm um papel chave na determinação da regeneração (Hartshorn, 1980; Viana, 1990; Molofsky \& Augspurger, 1992). Existem evidências que a interrelação entre as variações de luz e vegetação são especialmente importantes em matas de várzea (Schubart, 1983). Neste contexto, a virola é uma espécie típica de colonização de áreas perturbadas, onde a luminosidade é alta (Howe, 1990). As mudas desta espécie se desenvolvem preferencialmente nestes locais, devido à facilidade de dispersão de suas sementes e ao rápido crescimento (Howe \& Shupp, 1985).

A dispersão é influenciada pelas marés, que fazem oscilar - nível da água no interior das florestas de várzea, principalmente nos periodos mais chuvosos, quando os processos de regeneração e crescimento são altamente dinâmicos (Macedo \& Pina-Rodrigues, 1992). O crescimento da virola é maior em locais onde a ocorrência de luz é intensa no início e mais moderada na fase adulta (Fischer et. al., 1991). Desta forma, havendo maior incidência de luz, haverá maior crescimento em altura, diâmetro, e poda natural, até a espécie atingir níveis de dominância no interior da floresta (Figura 2).

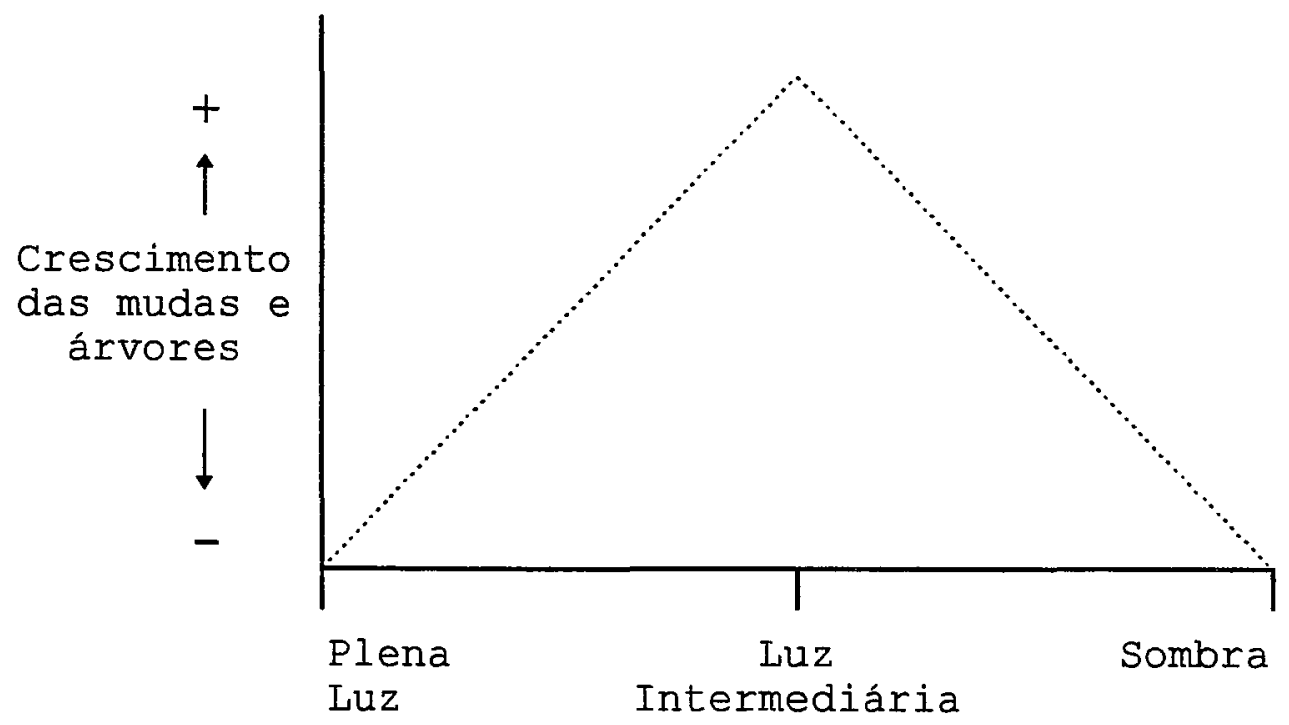

Figura 2: Representação idealizada da predição quanto ao crescimento da virola a uma maior ou menor incidência de luz. o ponto intermediário representa um crescimento ótimo. 


\subsubsection{Drenagem}

$\mathrm{Na}$ várzea do estuário amazônico, as inundações representam outro fator ecológico importante na determinação da natureza dos ecossistemas locais (Morán, 1990; Prance, 1980). Pequenas variações topográficas provocam grandes modificações na hidrologia e exercem um grande efeito no comportamento das espécies componentes das várzeas (Figura 3).

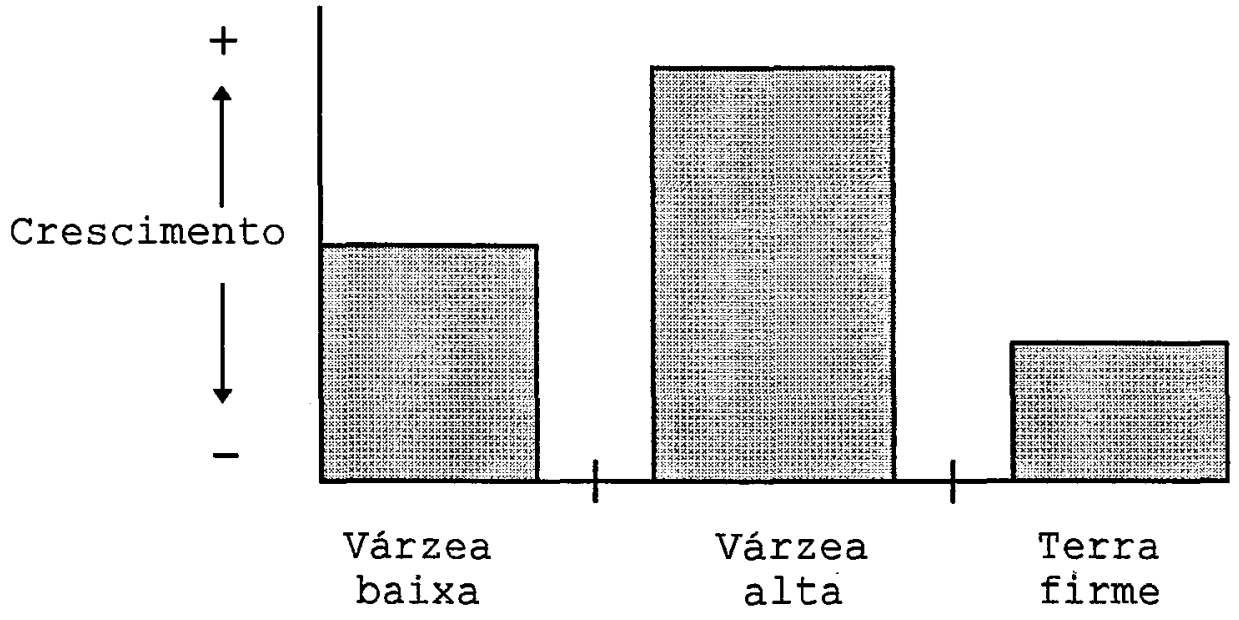

Figura 3: Representação idealizada da predição do crescimento da virola em função de cada local. O ponto de maior crescimento representa drenagem ótima para a espécie.

\subsection{Predições}

Havendo maior incidência de luz, haverá maior crescimento. Portanto, a liberação de luz dentro da floresta ao longo dos anos -- via técnicas de manejo silvicultural -- deve criar condições mais adequadas para o estabelecimento de plantios em florestas onde já sofreram algum tipo de exploração. A drenagem também influencia no crescimento da virola. Nos locais onde os solos são bem drenados o desenvolvimento da virola deve ser maior. 
Serão consideradas nesta pesquisa as seguintes predições:

\begin{tabular}{|c|c|c|}
\hline \multicolumn{2}{|c|}{ Principais Fatores } & $\begin{array}{c}\text { Crescimento } \\
\text { Muda (s } 5 \mathrm{~cm})\end{array}$ \\
\hline Luz & Pouca luz & Baixo \\
& Muita luz & Médio \\
& Luz intermediária & Alto \\
\hline Drenagem & Solo pouco drenado & Baixo \\
& Solo bem drenado & Alto \\
\hline
\end{tabular}

1.4. Objetivos

Testar os efeitos das variações de luz, em conjunto com variações de drenagem dos solos de várzea associadas à mudanças na topografia, sobre o estabelecimento de mudas de virola.

2. Material e métodos

2.1. O local de estudo.

Vide descrição na seção 2 do Capítulo I (pág. 3) e Figura 1 (pág. 4).

2.2. Intensidades de exploração: Tratamentos de abertura das copas

Dentro de uma área explorada de 7,84 ha, foi implantado um sistema de enriquecimento utilizando mudas de Virola surinamensis (Figura 4). Foram criadas quatro situações de abertura do dossel, partindo-se de uma condição inicial oriunda de uma floresta não explorada (tratamento 1); seguida pela retirada de 25\%, 50\% e 75\% da área basal das árvores adultas (tratamentos 2,3 e 4, respectivamente). O corte das árvores foi feito a partir das classes diamétricas superiores, levando-se em consideração a densidade por espécie. Levou-se também em consideração a distribuição espacial das árvores para a obtenção de uma liberação das copas o mais regular possível. 


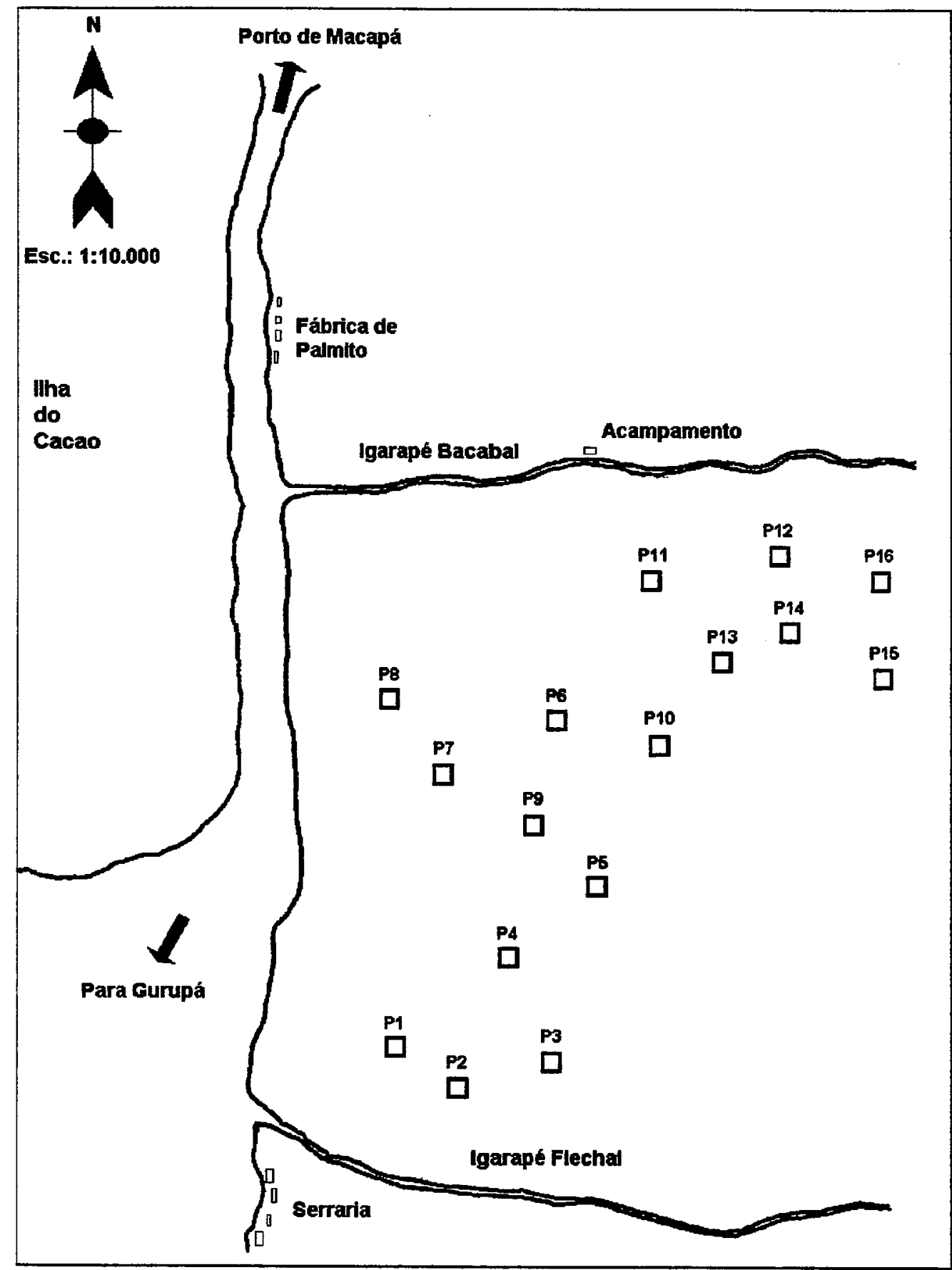

Figura 4: Distribuição das parcelas na área de estudo. 


\subsection{O sistema de enriquecimento}

Para cada nível de retirada de área basal foram utilizadas quatro parcelas quadradas de 0,49 ha $(70 \times 70$ metros), totalizando 1,96 ha de area explorada. A área plantada dentro de cada parcela foi de 0,16 ha totalizando 0,64 ha de área plantada, por tratamento. o esquema abaixo mostra o croqui das parcelas:

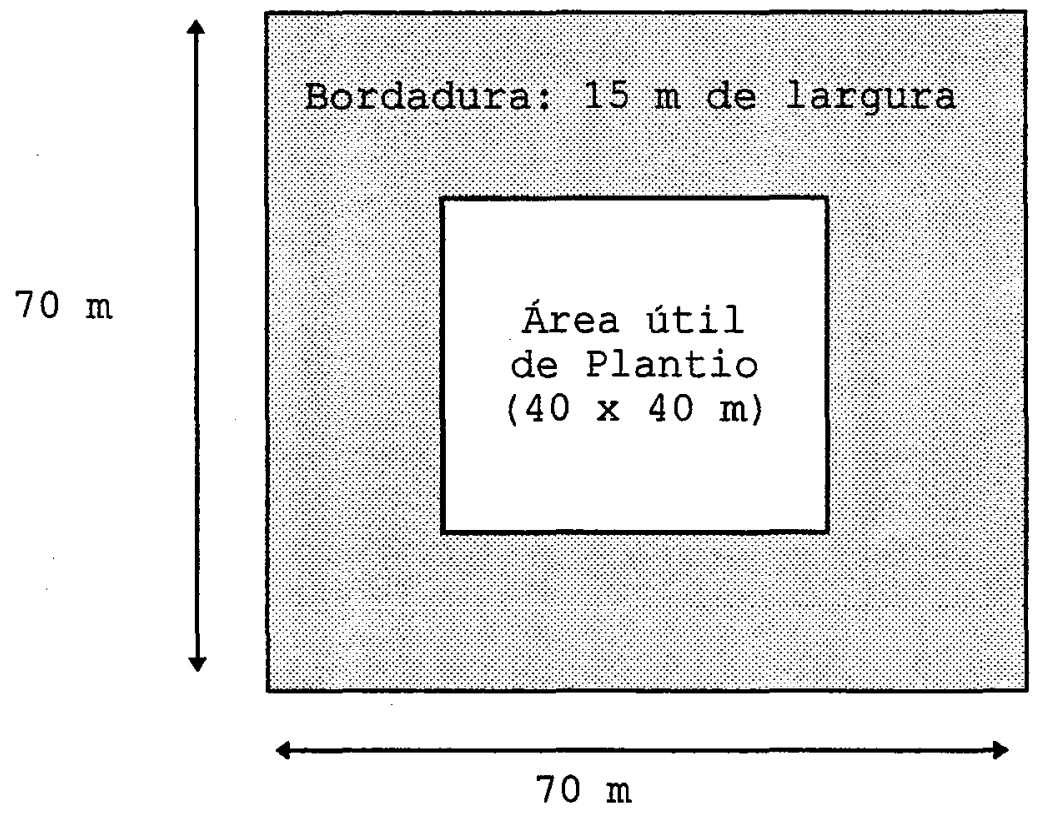

Foi utilizado o sistema de raiz nua para a produção das mudas de virola no plantio de enriquecimento dentro das parcelas. Este método foi o mais utilizado nos últimos anos em projetos de reflorestamento com Virola surinamensis no estuário (Lemos, 1974; Kanashiro \& Yared, 1991), e mostrou eficiência de operação e racionalização de custos (Macedo \& Pina-Rodriguez, 1992).

As sementes foram obtidas da maneira mais tradicional, ou seja, flutuando nos igarapés ao longo da floresta, da mesma maneira que eram coletadas pelas populações tradicionais, quando as sementes de virola possuíam valor econômico para a produção de saponina (cêra de ucuúba) entre 1930 e 1960 (Rodrigues, 1972). 
As sementes foram germinadas em sementeira suspensa, utilizando como substrato pó de serragem. Após o período de germinação (aproximadamente 15 dias), as plântulas com aproximadamente $10 \mathrm{~cm}$ foram classificadas, e foram eliminadas aquelas que não apresentavam boa forma da radicula.

A preparação do viveiro exigiu pouca mão-de-obra e material. Em um local situado a beira de um igarapé, retirou-se apenas as palmeiras e a vegetação rasteira, incluindo as raízes, gerando um nível de sombreamento de aproximadamente 50\%. Com a permanência da vegetação arbórea, foram feitos os canteiros no próprio solo dentro da floresta, com largura aproximada de um metro e comprimento de no máximo 20 metros.

A marcação do plantio nos canteiros foi feita com o auxílio de uma placa de compensado de aproximadamente $1 \mathrm{~m}^{2}$ perfurado a cada $10 \mathrm{~cm}$, totalizando uma densidade de 100 mudas $/ \mathrm{m}^{2}$ nos canteiros.

Após a perfuração do solo, foi feito o plantio das mudas repicadas da sementeira. Após três mesês, as mudas já estavam aptas ao plantio. Nesta fase houve nova seleção de mudas com altura variando de 25 a $50 \mathrm{~cm}$, que foram retiradas dos canteiros com auxílio de uma pá. As mudas receberam ainda um pequeno desbaste do sistema radicular antes de seguir para o plantio.

- plantio das mudas ocorreu no período das chuvas (fevereiro a março). o espaçamento utilizado foi a metodologia desenvolvida por Nelder (1973). Este método consiste de um desenho de espaçamento sistemático composto por um gride de pontos, baseado na propriedade, em que a área ocupada por cada planta muda numa forma consistente sobre as diferentes partes deste gride, conforme o esquema abaixo. 


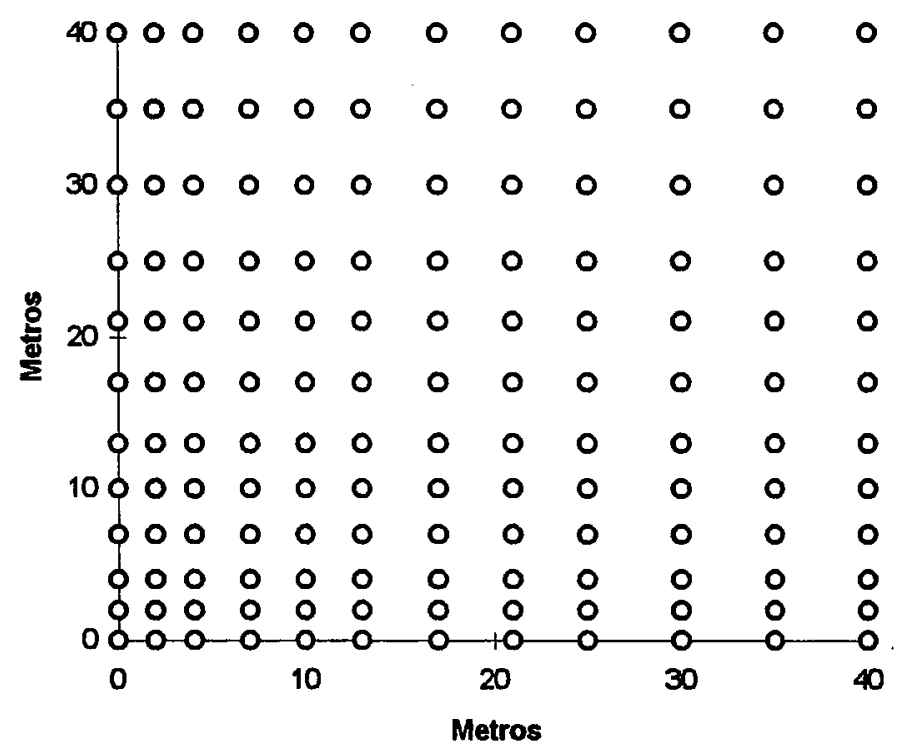

Este método de plantio possui vantagens como a diminuição da área experimental e redução dos custos de implantação, manutenção e tempo de medição das parcelas (Briscoe, 1990).

\subsection{Medições: Classes de porcentagem de luz}

Medições exatas da intensidade de luz que penetram no interior da floresta são difíceis de serem executadas. Haverá sempre diferenças em qualquer ponto, dependendo da hora do dia, da quantidade de nuvens e mesmo da época do ano (Pitt, 1969; Cersósimo, 1993). Para determinar a intensidade de luz solar, foi utilizado um luximetro. Nas parcelas de 40 x 40 metros deste estudo, foram alocados 144 pontos de medição, coincidindo com a posição de cada muda no interior das parcelas. Foram tomadas duas medições para cada ponto, com altura do aparelho situada sempre a 1 metro acima do solo. Antes e após à medição de cada parcela, foram retirados valores a pleno sol para obtenção dos valores máximos de luz. Estas medições foram feitas sempre no horário das 11:00 às 14:00 em dias de sol e céu limpo durante o período de verão amazônico (de agosto a setembro). 


\subsection{Levantamento topográfico}

As várzeas são terrenos alagados diariamente pelas marés normais. Nos locais mais baixos, a inundação pelas marés é constante, o que não acontece com as várzeas altas, que são atingidas apenas pelas marés de maior amplitude (Dubois, 1970). A virola tem mostrado melhor desempenho em solos com boa drenagem (Cruz, 1991). Para testar este fator, em cada parcela inventariada foi feito um levantamento taqueométrico ${ }^{2}$, estabelecendo-se uma malha de pontos a cada 10 metros, de onde retirou-se as quotas topográficas do terreno. Após a confeç̧ão dos mapas planialtimétricos, foram plotadas nestes mapas a posição de cada muda plantada no campo.

3. Resultados e discussão

\subsection{Crescimento}

3.1.1. Em diferentes regimes de luz

A intensidade de luz após a exploração em cada um dos tratamentos se caracterizou de maneira bem distinta. Foi observado um gradiente bem suave à medida que se intensificaram as aberturas na floresta (Figura 5). Em ordem crescente de porcentagem de luz foram obtidas as seguintes médias: 5.6\% para $\circ$ tratamento $1,13.5 \%$ para tratamento 2, $24.8 \%$ para $\circ$ tratamento 3 e $40.1 \%$ para $\circ$ tratamento 4. Foram encontradas diferenças significativas pelo teste $F$ entre os tratamentos $(F=24.11$, prob $<0.0001)$. Feita a comparação de médias dos tratamentos pelo teste de Duncan $(\propto=$ 0.05), foram obtidas quatro intensidades luminosas distintas, sendo confirmada desta maneira a caracterização dos diferentes regimes de luz em relação aos diferentes niveis de exploração (Figura 5).

\footnotetext{
2 Técnica utilizada para a confecção de mapas topográficos utilizandose um teodolito, aparelho dotado de um binóculo que faz vizadas a grandes distâncias, de onde se retira os angulos para o cálculo de área e nivelamento do terreno.
} 


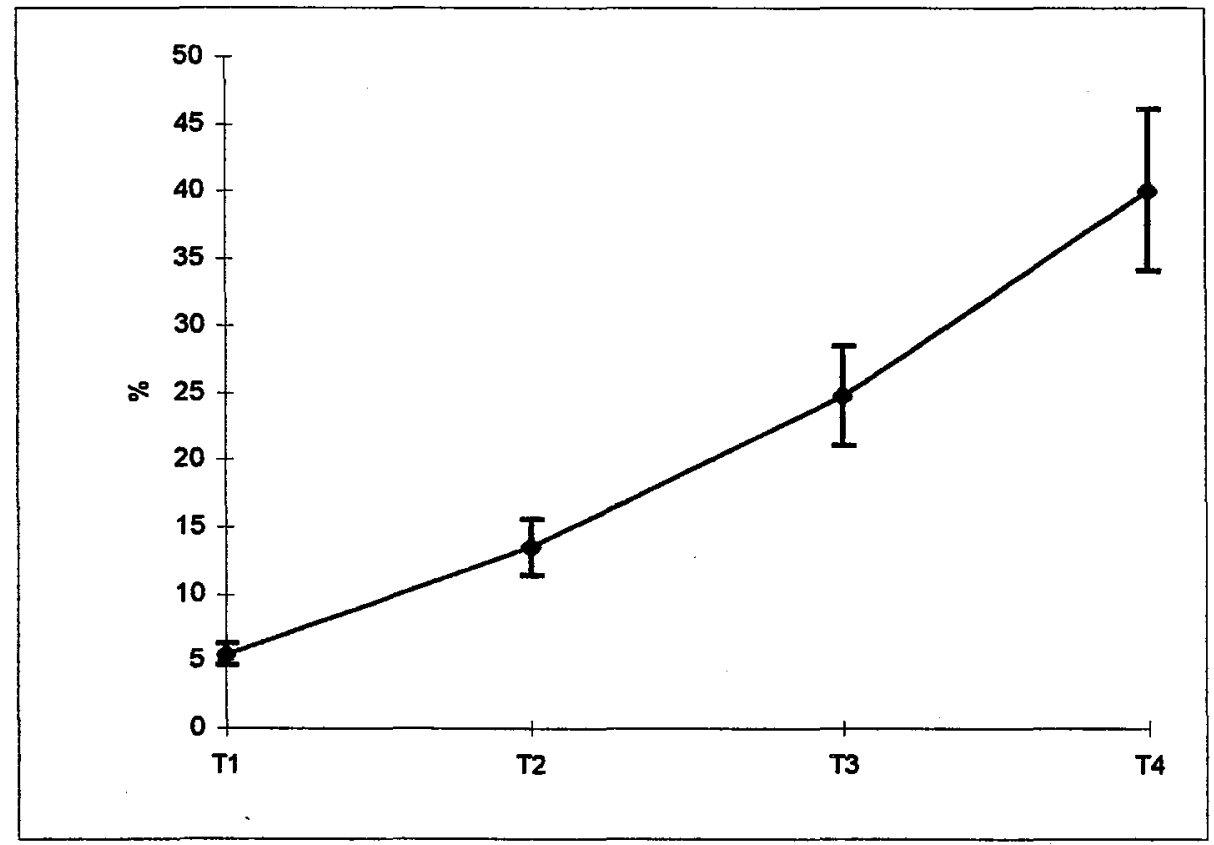

Figura 5: Níveis de luminosidade (8) para os diferentes tratamentos.

Com relação à frequência por classes de luz, no tratamento $1,33.9 \%$ de todas as mudas pertenceram à classe $I$ e apenas 3.3\% das mudas à classe $V$, enquanto no tratamento 4, 13.7\% pertenceram à classe I e 55.4 o à classe $V$ (Tabela 1 ). No tratamento onde foram observadas o maior número de clareiras (tratamento 4), a distribuição das mudas em relação às classes de luz foi bem mais uniforme. Após 24 meses de observações ( $\mathrm{n}=419$ ), foram observados 43\% para classe I, $12.7 \%$ para a classe II, $13.8 \%$ para a classe III, $10.7 \%$ para a classe IV e $19.8 \%$ para a classe V (Figura 6). 
Tabela 1: Distribuição do total das mudas em cinco classes de luz para todos os tratamentos.

\begin{tabular}{|c|c|c|}
\hline Classes de Luz & \% de Luz & Total de Mudas \\
\hline I & $0-19.9$ & 1.316 \\
\hline II & $20-39.9$ & 183 \\
\hline III & $40-59.9$ & 1499 \\
\hline IV & $60-79.9$ & 88 \\
\hline V & $>80$ & 150 \\
\hline
\end{tabular}

Com relação ao crescimento das mudas, na classe $V$ como era esperado, foi observada a maior média de crescimento $(0.4 \mathrm{~m})$ e 0 maior valor máximo $1.6 \mathrm{~m}$ (Figura 6). Para evidenciar melhor 0 desempenho das mudas em cada tratamento, utilizou-se os valores de crescimento das 100 mudas com maior altura (altura dominante). Foram obtidos os seguintes valores médios para cada tratamento após 24 meses: $0.21 \mathrm{~m}$ para T1, $0.44 \mathrm{~m}$ para T2, 0.66 para T3 e 0.72 para T4 (Figura 7 ).

Foram realizadas quatro medições ao longo de todo 0 experimento, compreendendo 24 meses de observações. Durante as medições da altura de crescimento foram observados alguns comportamentos em relação à arquitetura das mudas. O fato que chamou a atenção foi a queda do ponteiro. No tratamento sem abertura (testemunha) foi observado a maior ocorrência deste fenômeno, o que acarretou em crescimento negativo de algumas mudas. Na Figura 8 observa-se um decréscimo no número de mudas com crescimento negativo a medida em que há um aumento na incidencia de luz (tratamentos 2 e 3). Entretanto, no tratamento 4 (de maior abertura), houve um pequeno acréscimo no número de mudas com incremento negativo se comparado com o tratamento 3 . 


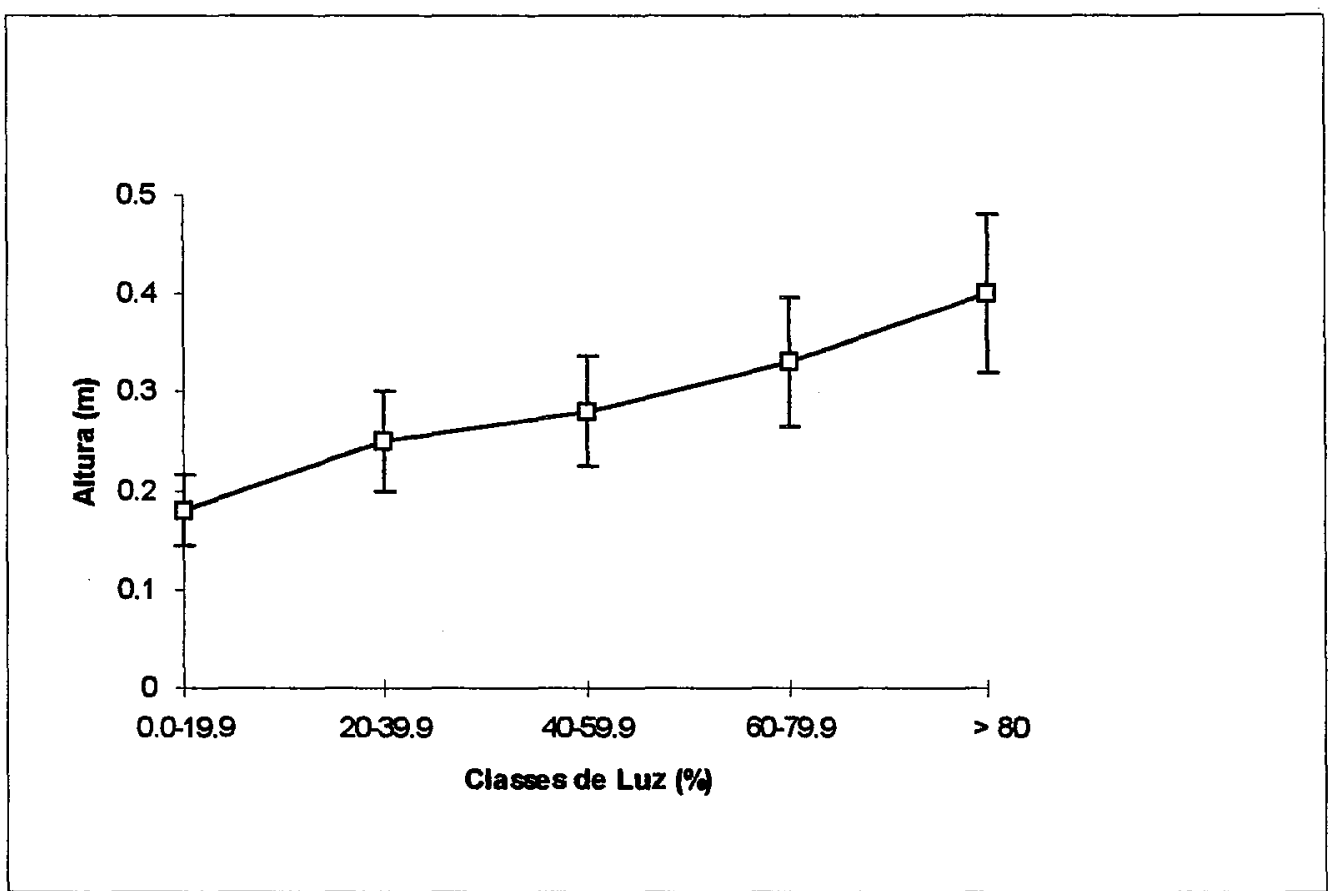

Figura 6: Altura (m) das mudas por tratamento (média e desvio padrão), por classes de luz.

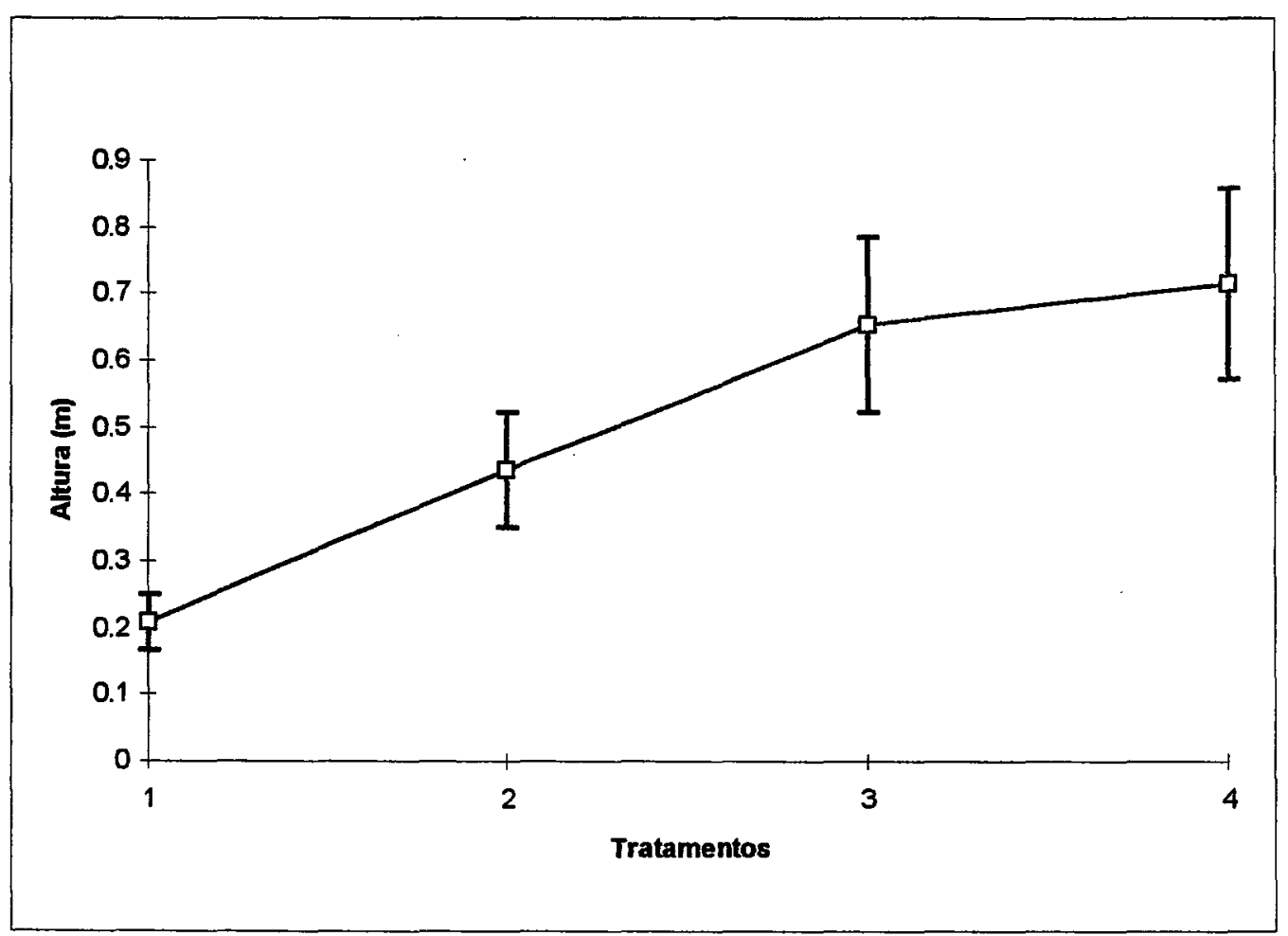

Figura 7: Altura das (m) das 100 maiores mudas por tratamento (média e desvio padrão) . 


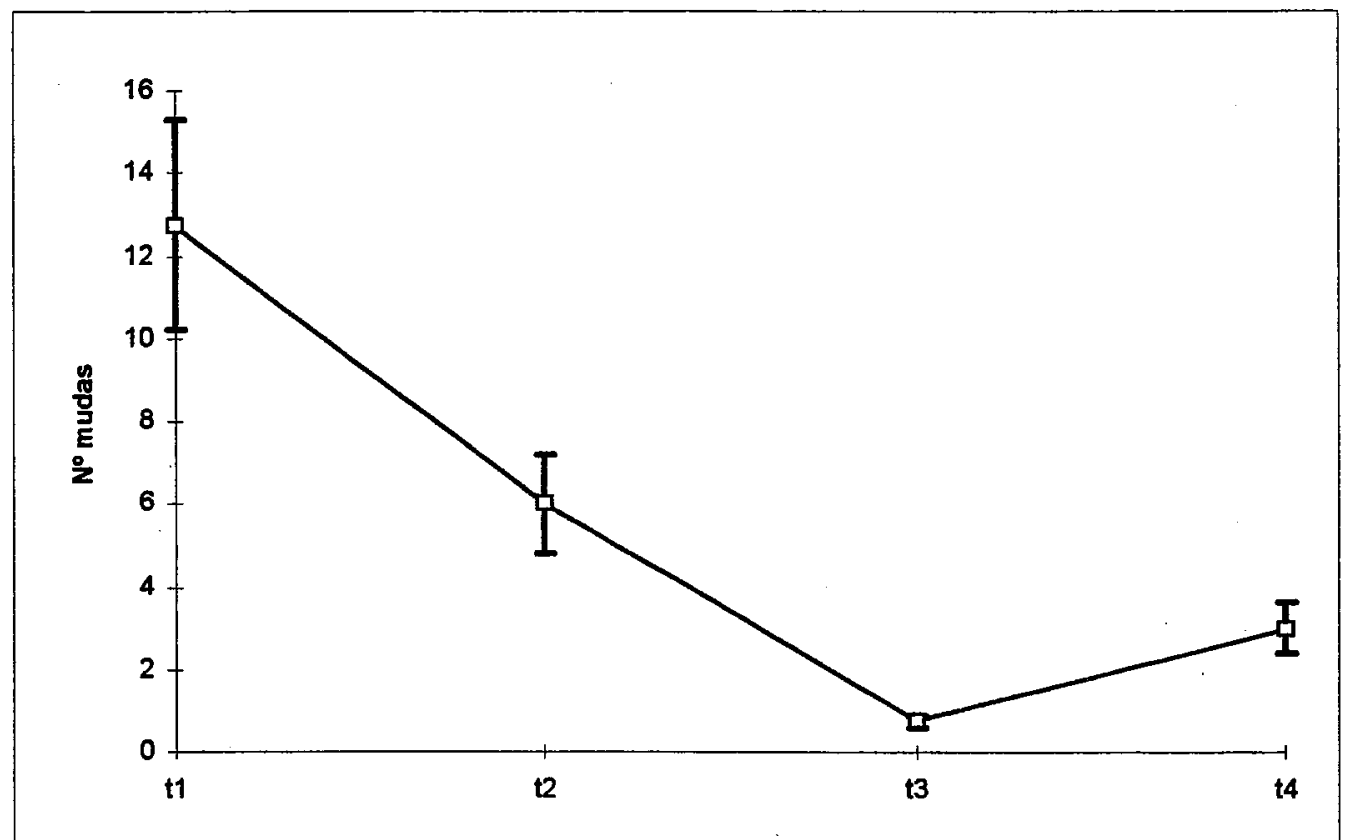

Figura 8: Número de mudas com incremento negativo por tratamento.

\subsubsection{Em diferentes situações topográficas}

Para a análise dos dados foram estabelecidas duas condições topográficas: (i) topografia alta e (ii) topografia baixa. o critério utilizado para esta diferenciação foi 0 cálculo da mediana $(1.63 \mathrm{~m})$, em função da cota topográfica mais alta $(2.43 \mathrm{~m})$ e a cota mais baixa $(1.11 \mathrm{~m})$, observada em todas as parcelas (Figura 9).

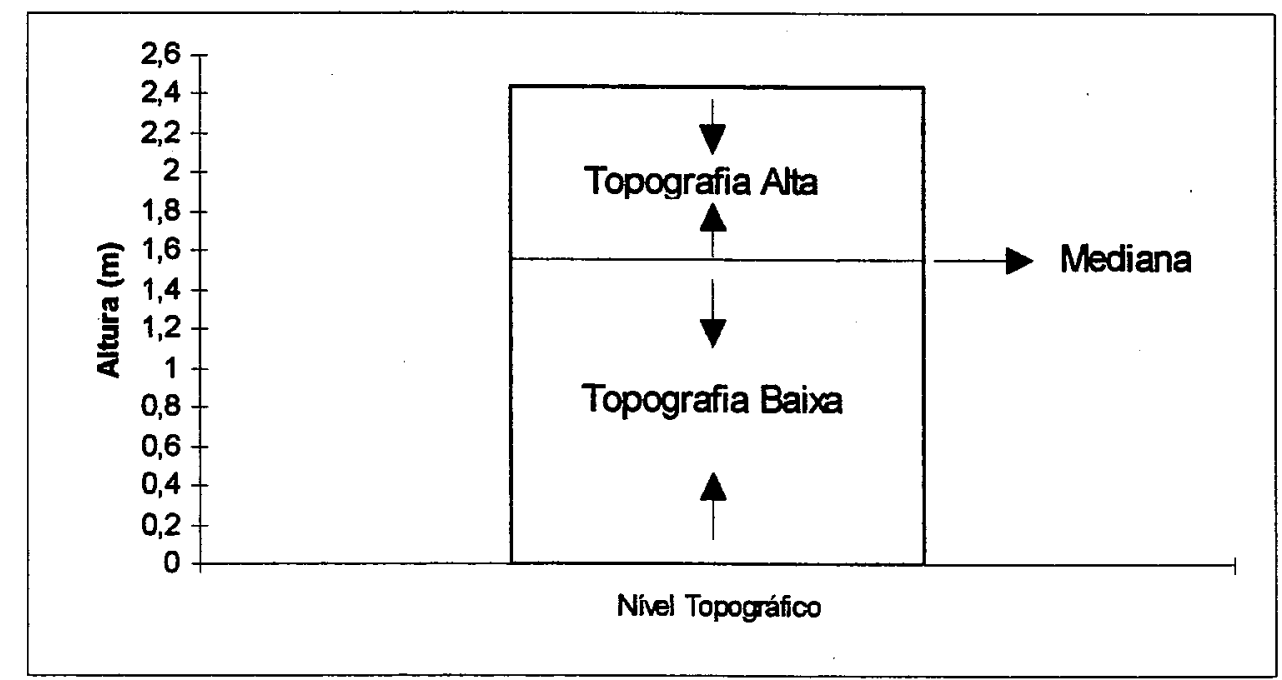

Figura 9: Representação do nivel topográfico estabelecido para todas as parcelas. 
Utilizando-se as médias por parcela das cotas alta e baixa, foi realizado um teste $t$, onde obteve-se diferença significativa para a classificação sugerida acima (Prob < 0.0001). Definidas então a existência entre áreas baixas e altas, pode-se avaliar o crescimento das mudas por classe topográfica e por tratamento, após 24 meses de experimento. Não foram observadas diferenças significativas no crescimento das mudas em relação às variáveis topográficas alta (média $=0.20 \mathrm{~m}$ ) e baixa (média $=0.23 \mathrm{~m}$ ) (Prob $>0.863)$. Comparadas as médias dos tratamentos pelo teste de Duncan ( $\alpha=0.05)$, não foram encontradas diferenças significativas para os tratamentos 1 e 2 , onde foram encontradas os seguintes valores médios de crescimento: $0.18 \mathrm{~m}$ e $0.07 \mathrm{~m}$, respectivamente. Já para os tratamentos 3 e 4 , foram encontradas diferenças significativas com as seguintes médias: $0.34 \mathrm{~m}$ e $0.29 \mathrm{~m}$, respectivamente.

\subsubsection{Interação: Luz $x$ topografia}

Para as variáveis luz e topografia, não foram obtidas diferenças significativas no crescimento das mudas (Prob) 0.4353). Apesar de ser esperada esta interação, o efeito das aberturas realizadas em função da exploração causou um maior crescimento das mudas à medida que aumentou a porcentagem de entrada de luz.

Analisando-se a Figura 10, pode-se observar duas situações distintas. Primeiro, para os tratamentos 1 e 2 houve maior crescimento das mudas nas áreas de topografia baixa. Este fato pode ser explicado pela pouca mudança no microclima no interior destas parcelas, pois não ocorreram muitas modificações na evapotranspiração. Segundo, para os tratamentos 3 e 4 foi observado um maior crescimento das mudas nas áreas mais altas (Figura 10). 


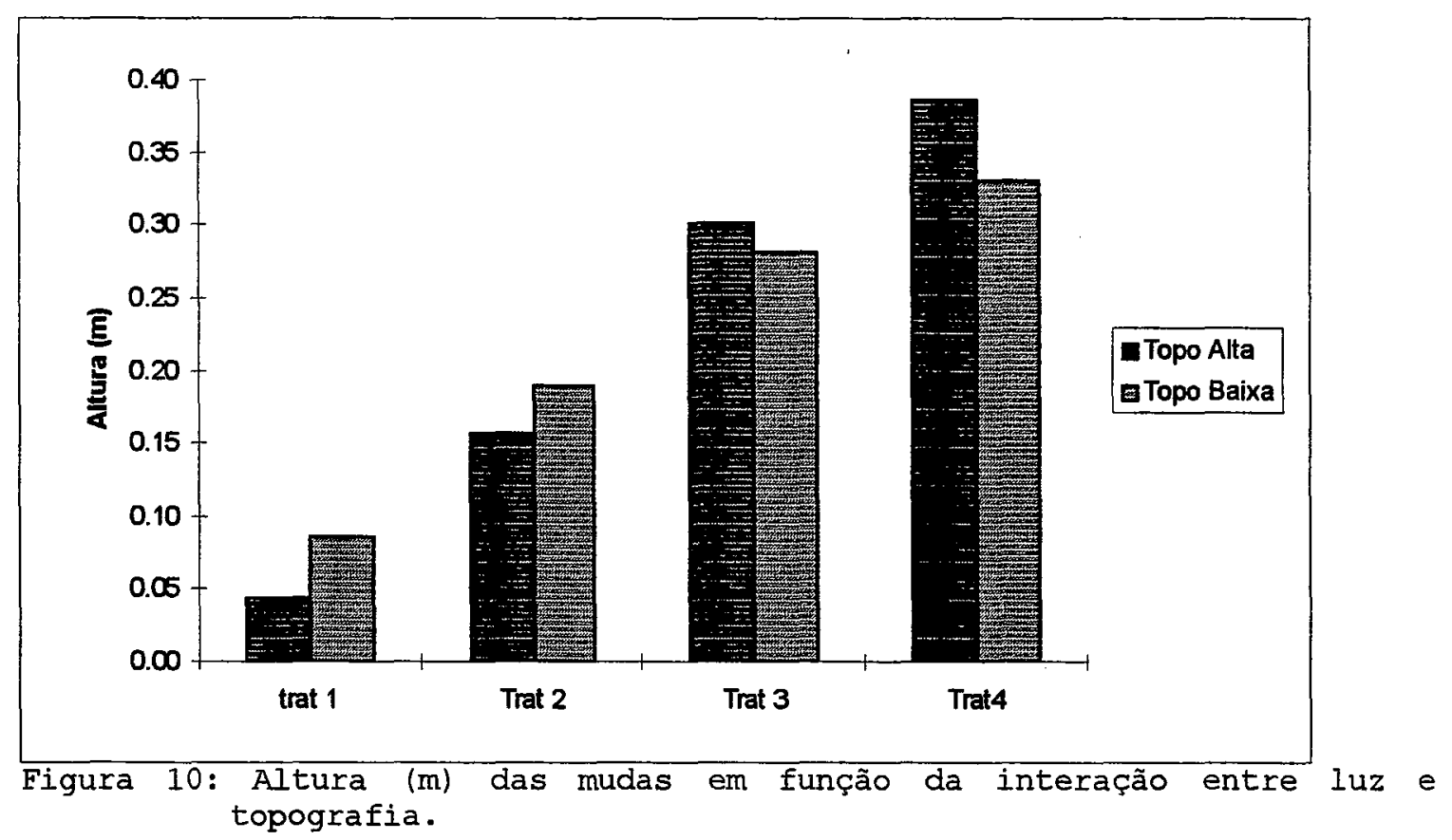

3.2. Sobrevivência

\subsubsection{Em diferentes regimes de luz}

Foram obtidos os seguintes valores médios para a mortalidade das mudas: $16.4 \%, \mathrm{sd}=6.32$ (T1); $15.88, \mathrm{sd}=2.36$ (T2); $19.58, \mathrm{sd}$ $=5.08(\mathrm{~T} 3) ;$ e $27.3 \frac{8}{\mathrm{r}} \mathrm{sd}=3.56(\mathrm{~T} 4)$.

Foram observadas diferenças significativas entre tratamentos, num nível crescente de mortalidade em função do aumento de luz, respeitando a ordem dos tratamentos (Prob < 0.0146). Entretanto, apenas o tratamento 4 diferiu em relação as médias dos outros tratamentos pelo teste Duncan $(\alpha=0.05)$ (Figura 11). Como foi observada uma tendência dos dados, foi efetuada uma análise de regressão linear simples, onde procurou-se correlacionar a porcentagem de entrada de luz com a porcentagem de mudas mortas. Na Figura 12, observa-se uma correlação positiva entre as variáveis anteriormente citadas. Obteve-se um coeficiente de correlação de 0.39 e significância na análise de variância (Prob $<0.009)$. 


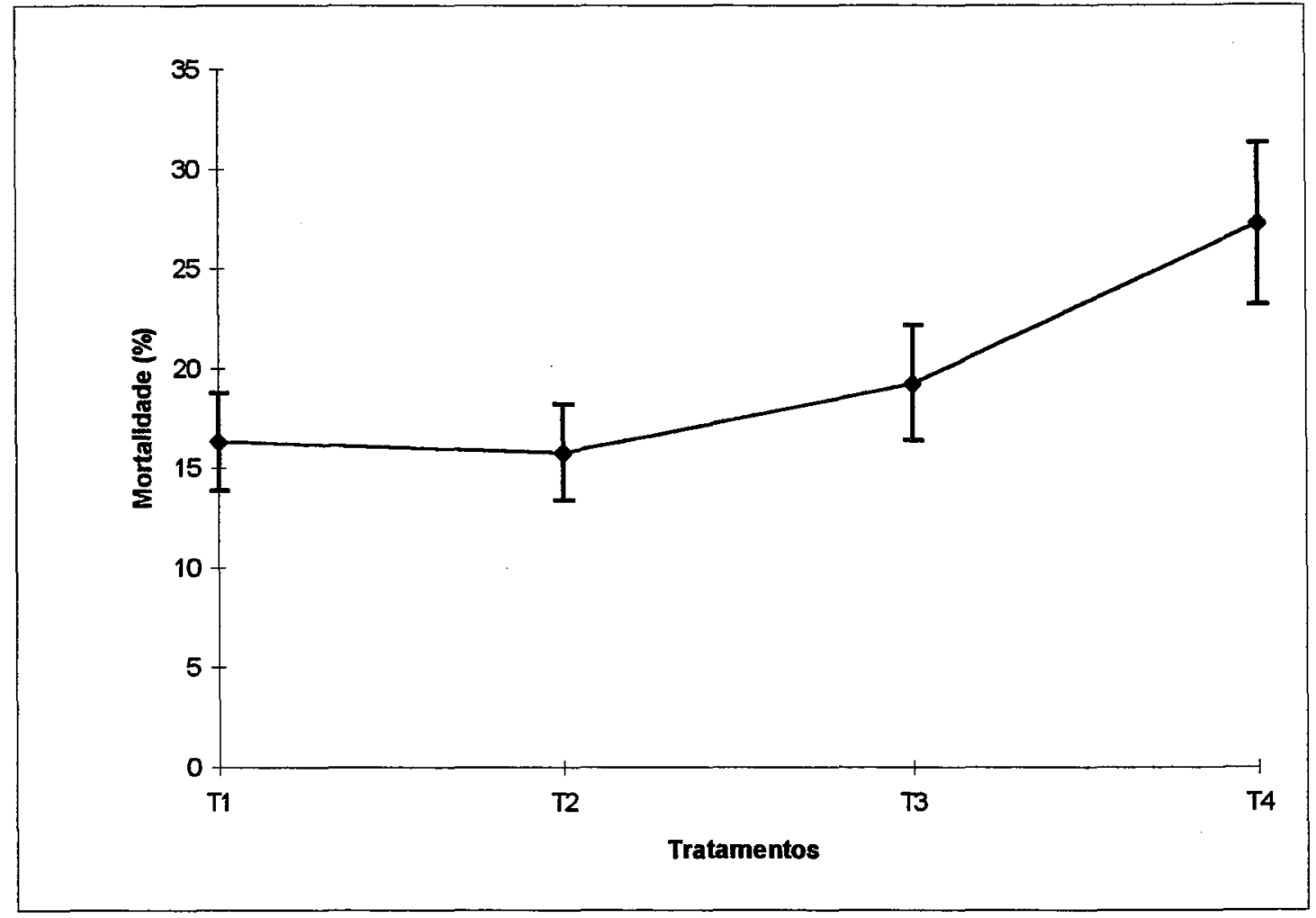

Figura 11: Mortalidade de mudas por tratamento (média e desvio padrão).

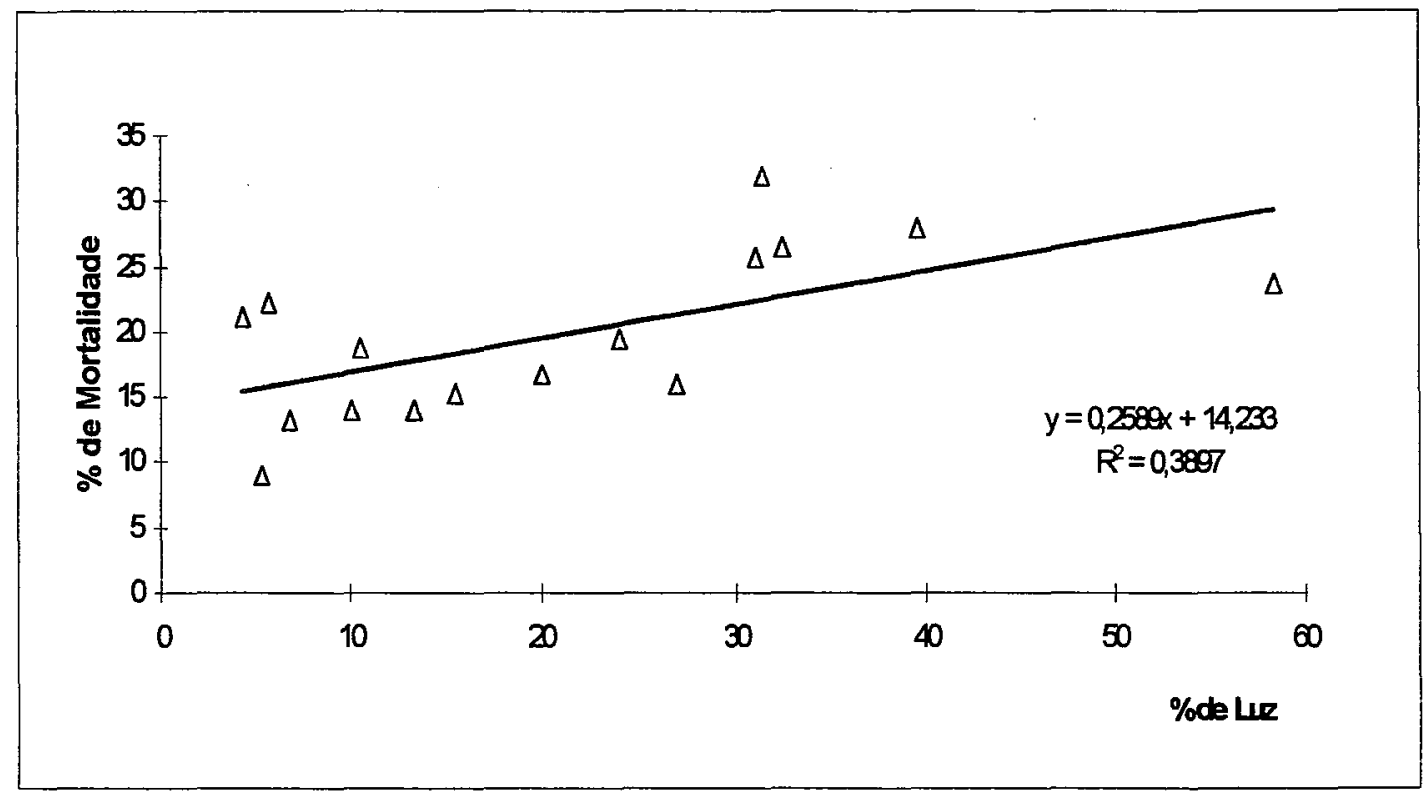

Figura 12: Relação entre a porcentagem de mudas mortas e o aumento na intensidade luz. 


\subsubsection{Em diferentes situações topográficas}

A variação topográfica não gerou diferenças significativas no número de mudas mortas (Prob > 0.5713). Portanto, a hipótese que longos períodos de alagamento poderiam afetar principalmente a fase inicial do plantio (pegamento das mudas) não foi sustentada. Cabe lembrar que o plantio foi efetuado na época mais chuvosa na região (fevereiro e março).

\subsubsection{Interação: Luz x topografia}

Considerando-se estes dois fatores, também não foram observadas diferenças significativas para a variável mortalidade das mudas (Prob > 0.7616). Entretanto, como foi observado para a variável crescimento, houve um aumento do número de mudas mortas à medida que aumentava a intensidade de luz (Figura 13). Exceto no tratamento 2, se observa que a mortalidade das mudas foi sempre maior nas áreas mais altas, o que nos leva a concluir que o efeito topográfico atua no desenvolvimento das mudas. Entretanto, os dados apresentados não demonstram que existe uma influência de um fator sobre o outro, após 24 meses de plantio.

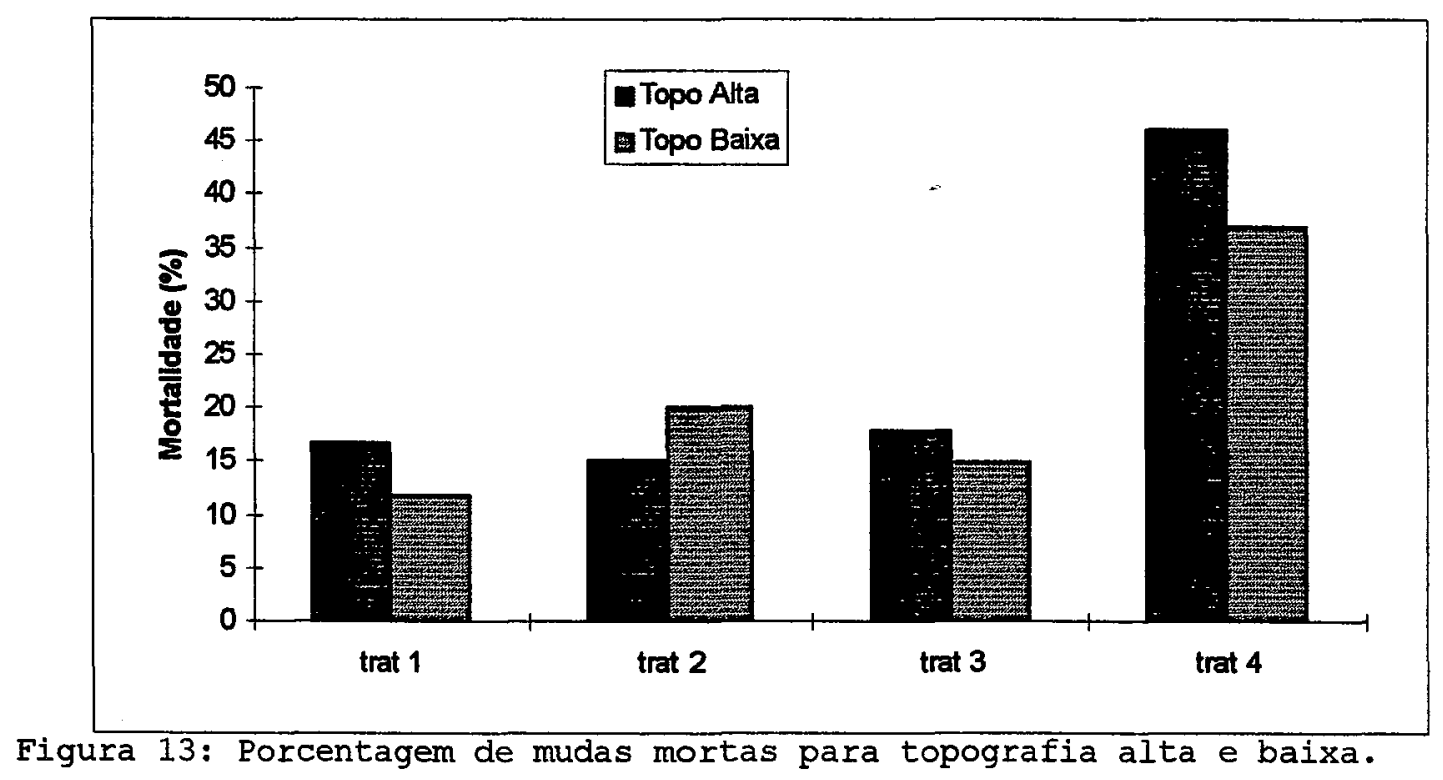


4. Conclusão

A intensidade de luz após a exploração em cada um dos tratamentos foi bem distinta. Observou-se um aumento da luminosidade à medida que se intensificaram as aberturas na floresta. Confirmou-se a hipótese inicial de que haveria maior crescimento das mudas nas áreas mais abertas.

Houve maior tendência de ocorrência de quebra de ponteiros nos locais mais fechados, acarretando incremento negativo de algumas mudas, o que pode indicar que a virola é uma espécie típica colonizadora de clareiras, como observado por Howe (1990) e Fisher et. al. (1991).

Comparados os efeitos do crescimento das mudas em relação a interação entre luz e topografia, não foram obtidas diferenças significativas, apesar de existir uma tendência de haver maior crescimento das mudas à medida que aumentou a porcentagem de entrada de luz. Não foi confirmada a hipótese inicial de que nos locais mais altos e com maior intensidade de luz haveria maior crescimento das mudas.

Com relação à sobrevivência das mudas, após 24 meses de observações, foi obtido uma maior porcentagem de mortalidade a medida que aumentou a intensidade de luz.

- efeito esperado de que longos períodos de alagamento afetariam a fase inicial do plantio (pegamento das mudas) não foi observado. A porcentagem de mortalidade das mudas foi abaixo de 25\%, o que para a silvicultura da espécie é um dado muito importante para o planejamento de projetos de enriquecimento neste tipo de floresta, implicando no dimensionamento dos viveiros, contratação de pessoal e planejamento de replantio que são atividades que oneram muito tais projetos. os tratamentos silviculturais mais adequados para a espécie implicam na prescrição de cortes de liberação na floresta. Esta técnica pode tornar disponível para o mercado regional uma grande variedade de produtos madeireiros e não madeireiros e incrementar o retorno econômico para as comunidades ribeirinhas. 
5. Bibliografia

Anderson, A.B.; Mousasticoshvily, I. \& Macedo, D.S. 1992. Impactos ecológicos e sócio-econômicos extração seletiva de virola no estuário amazônico: Implicações para politicas florestais brasileiras. Relatório final a WWF-US. Rio de Janeiro. 52p.

Barros A.C. \& C. Uhl. 1995. Logging along the Amazon River and Estuary: Patterns, problems and potencial. Forest Ecol. and Management, 77: 87-105.

Baur, G.N. 1968. The ecological basis of rain forest management. Forestry Commission of New South Wales, Sidney. 499 p.

Briscoe, C.B. 1990. Manual de ensayos de campo con arboles de usos múltiples. Winrock International, Arlington, VA. Manual no. 3. $143 \mathrm{p}$.

Cersósimo, L.F. 1993. Variações espaciais e temporais no estabelecimento de plântulas em trecho de floresta secundária em São Paulo, SP. Dissertação de Mestrado. Instituto de Biociências/USP. $195 \mathrm{p}$.

Cruz, E. C. da, 1991. Situação atual da silvicultura e do manejo florestal sustentado em áreas de várzea rivular. In: o desafio das florestas neotropicais. Curitiba. UFPr. Anais. p. 59-76.

Dubois, J., 1970. Características e distribuição geográfica das florestas naturais de folhosas no Brasil reflorestamento para produção de madeira de serraria: tendências e possibilidades. Silvicultura em São Paulo, 7:111-126.

Evans, J. 1982. Plantation forestry in the tropics. Oxford University Press. London. $472 \mathrm{p}$.

Fanzeres, A. 1989. Germinação e crescimento de Virola surinamensis (Rol.) Warb. em um ecossistema de várzea: base ecológica para recomendações técnicas. Relatório. 24 p.

Fisher, B.L.; Howe, F.H. \& Wright, J.S. 1991. Survival and growth of Virola surinamensis yearlings: Water augmentation in gap and understory. Oecologia, 86:292-297.

Hartshorn, G. S. 1980. Neotropical forest dynamics. Biotropica 12 (supl.) :23-30

Howe H.F.; Shupp, E.W. \& L.C. Westley. 1985. Early consequences of seed dispersal for a neotropical tree (Virola surimanensis). Ecology, 66(3):781-791

Howe, F. H. 1990. Survival and growth of juvenile virola surinamensis in Panama: effects of herbivory and canopy closure. J. of Tropical Ecology, 6:259-280. 
Kanashiro, M. \& J.A.G. Yared. 1991. Experiências com plantios florestais na Bacia Amazônica. In: o Desafio das florestas tropicais. Curitiba, PR. UFPR/GTZ. p. 117-37.

Kubstky, $K$ \& A. Zibursky. 1994. Seed dispersal in flood plain forests of Amazonia. Biotropica, 26(1): 30-43.

Lemos, J.M. 1974. Reflorestamento com Virola surinamensis (Ucuúba da várzea) na Ilha de Marajó. In: II CONGREsso FLORESTAL BRASIIEIRO. FIEP. Curitiba, PR. p. 110-113.

Lugo, A.E.; Brown S. \& M.M. Brinson. 1988. Forested wetlands in freshwater and salt-water environments. I.imnol. Oceanogr., $33(4$, part 2): 894-904.

Macedo, D. S. \& A. B. Anderson. 1993. Ecological impacts and policy implications of selective logging in the Amazon Estuary. Biotropica, 25(2): 151-163.

Macedo, D. S. \& Pina-Rodriguez, F.M. 1992. Manejo e conservação genética de Virola surinamensis no estuário amazônico. Relatório técnico submetido a WWF-US. $70 \mathrm{p}$.

Molofsky, J. \& C. K. Augspurger. 1992. The effect of leaf litter on early seedling establischment in a tropical forest. Ecology, 73(1): 68-77.

Morán, E.F. 1990. A Ecologia Humana das Populações da Amazônia. Vozes, Petrópolis, RJ. 367 p.

Mousasticoshvily Jr., I., 1992. Comercialização e industrialização da virola no estuário amazônico. Dissertação de Mestrado, Universidade Federal do Paraná, Curitiba. $140 \mathrm{p}$.

Nelder, J. A. 1973. New kinds of systematic designs for spacing experiments.Biometrics, September.

Oldfield, S. 1988. Rare tropical timbers. IUCN, Gland, Switzerland and Cambridge, UK. 48 p.

Pitt, J. 1969. Relatório ao Governo do Brasil sobre a aplicação de métodos silviculturais a algumas florestas da Amazônia. Belém. SUDAM. 1969. 245p.

Prance, G.T. 1980. A terminologia dos tipos de florestas sujeitas a inundação. Acta Amazonica, 10(3):495-504.

Rodriguez, W. A. A Ucuúba da várzea e suas aplicações. Acta Amazônica, 2(2):29-47. 1972.

Schubart, H.O.R. 1983. Ecologia e utilização das florestas. In: Salati et al. Amazônia: Desenvolvimento, integração e ecologia. São Paulo. Brasiliense/CNPq. 101-143.

Schulz, P.P.e P.I. Rodrigues, 1966. Forest plantation in Suriname. Revista Forestal Venezoelana, 9(14): 5-36. 
Sioli, H. 1984. The Amazon and its main affluents: Hydrography, morphology of the river courses, and river types. In: The Amazon: limnology and landscape ecology of mighty tropical river and its basin. H. Sioli Editor. W. Junk Publishers. Boston. p.127-66.

Sombroek, w.G. 1984. Soils of the Amazon region. In: The Amazon: limnology and landscape ecology of a mighty tropical river and its basin. H. Sioli Editor. W. Junk Publishers. Boston. p.521-36.

Uhl, C. 1990. Wood as an Economic catalyst to ecological change in Amazônia. In: Economic Catalysts to ecological change. 39th Annual conference. Center for Latin American Studies. Univ. of Florida. 177p.

Viana, M. V. 1990. Seed and seedling availability as a basis for management of natural forest regeneration. In: Alternatives to reforestation. Anderson, A.B. editor. Columbia Univ. Press. New York. 97-115p. 


\section{Capítulo III}

\section{Comportamento inicial da regeneração natural numa floresta de várzea sob diferentes intensidades de exploração}

1. Introdução

\subsection{Regeneração e sucessão}

Nas florestas tropicais o aumento na quantidade de luz associada à queda de árvores e consequente formação de clareiras é importante para a sobrevivência e crescimento das plantas, especialmente no sub-bosque com pouca incidência de luz (Denslow \& Diaz, 1990). Esta maior incidência de luz é comumente associada com o maior crescimento e decréscimo da mortalidade de muitas espécies típicas de pequenas clareiras (Forget, 1994).

A regeneração, sobrevivência e crescimento de plântulas de espécies arbóreas dependem da interação de fatores bióticos e abióticos do meio ambiente do interior da floresta, como intensidade luminosa, temperatura, umidade e fertilidade do solo, bem como de patógenos (Whitmore, 1978; Ewel, 1983; Khan et al., 1986; Vásquez-Yanes \& Orozco-Segovia, 1990).

A ocupação do espaço no interior da floresta em virtude da abertura da dossel é determinada pela presença de plântulas e arvoretas no local quando a clareira é formada e é, a princípio, uma função da abundância relativa e distribuição da regeneração pré-existente (Denslow, 1987).

A adaptação entre as espécies é variável a cada estágio de sucessão, como é o caso das espécies que se adaptam melhor durante as fases iniciais de sucessão, bem como, outras que dominam as fases mais adiantadas (Botkin \& Talbot, 1991). O desenvolvimento das florestas tropicais ocorre em longos períodos, e proporciona desta maneira, vàrios tipos de habitats, aumentando as chances para espécies cuja sobrevivência só ocorre em alguns estágios de sucessão (Brokaw, 1987). 
1.2. O problema

1.2.1. A exploração seletiva: Técnica não sustentável

De maneira geral, o impacto ecológico causado sobre a floresta, como um todo, depende da sua composição florística, da natureza e intensidade de exploração, e de espécies ou tipo de recurso que é explorado (Hutchinson, 1986; Uhl \& Vieira, 1989; Peters, 1994). A ocorrência de mortalidade excessiva da regeneração natural pode gerar um estoque inadequado de espécies desejáveis para o futuro (Martini et al., 1994). Outro aspecto negativo é que estes métodos reduzem as taxas de crescimento da floresta remanescente, fazendo com que os períodos entre os cortes sejam cada vez mais longos (Panayotou \& Ashton, 1992). Cada passo da exploração atual, incluindo a derrubada, arraste e extração, é uma fonte em potencial de dano que pode diminuir sériamente o valor da floresta explorada (Verríssimo et al., 1992 e 1995).

A alta diversidade de espécies madeireiras impõe restrições ecológicas no manejo das florestas tropicais (Hartshorn, 1989), como a baixa quantidade de volume obtida por unidade de área (Alder, 1992). Várias técnicas silviculturais tem sido testadas, como para enriquecer a regeneração natural e liberar as árvores suprimidas e/ou o plantio na forma de mudas (Baur, 1968; Evans, 1982). Entretanto, a devida atenção não é dada ao manejo das florestas tropicais, na base do conceito da dinâmica de clareiras (Oldeman, 1978; Hartshorn, 1980). O fato de que as espécies tradicionais e mais valiosas estão cada vez mais escassas, está fazendo com que o mercado atual de madeira se volte para as espécies dependentes deste tipo de manejo (light hardwoods), e que também possuem madeira de boa qualidade (De Camino, 1993).

A abundância e diversidade da regeneração de espécies arbóreas obtidas em virtude de aberturas artificiais simulando clareiras, estão demonstrando ótimas possibilidades de capacidade regenerativa em florestas tropicais (Bushbacher, 1990; synnott, 1992; Korning \& Balslev, 1994). 
1.3. Hipóteses e predições

Para a implantação de técnicas do "bom manejo" mais adequadas às florestas tropicais, são necessárias bases ecológicas sólidas, especialmente com relação às fases sucessionais das espécies de maior interesse econômico. Portanto, a hipótese deste estudo se baseia em que havendo este conhecimento, serão assegurados os processos de decisão dos tratamentos silviculturais mais adequados para o tipo de floresta a ser explorada, em função das espécies que dominam o seu estágio atual, e de espécies que podem ter sua importância em termos ecológicos e econômicos num futuro próximo.

\subsection{Objetivos}

Foram criadas quatro situações de manejo, desde a floresta sem nenhuma intervenção até abertura das copas das árvores adultas na forma de um ambiente bastante perturbado por uma exploração seletiva. Desta maneira, o gradiente que foi criado reflete uma floresta em diferentes estágios de sucessão e/ou recuperação. Espera-se que a resposta da regeneração natural das espécies componentes possa dar indicativos de como e em qual estágio de sucessão as espécies se estabelecem ou competem, principalmente pelo fator luminosidade. Com este experimento pretendeu-se conhecer melhor o esquema de sucessão deste tipo de floresta e fornecer informações para o manejo das suas espécies.

\section{Material e métodos}

2.1. O local de estudo

Vide descrição na seção 2 (pág. 3) e Figura 1 (pág. 4) do Capítulo I e Figura 4 do Capítulo II (pág. 29). 


\subsection{Intensidades de exploração: Tratamentos}

Foram estabelecidas parcelas de $4 \mathrm{~m}^{2}$ (2 $\mathrm{x} 2$ metros) para avaliar o comportamento da regeneração natural de três intensidades de manejo pré-existentes (após 24 meses), envolvendo a exploração seletiva de árvores acima de $30 \mathrm{~cm}$ de DAP (diâmetro acima do peito). Foram estabelecidas também parcelas em locais de floresta não explorada (Tratamento 1 ou T1), para efeito de comparação. As três intensidades de manejo são descritas abaixo:

(I) : retirada de $25 \%$ da área basal da floresta (Tratamento 2 ou T2);

(II): retirada de $50 \%$ da área basal da floresta (Tratamento 3 ou T3); e

(III) : retirada de 75\% da área basal da floresta (Tratamento 4 ou $\mathrm{T} 4)$.

Os tratamentos foram comparados estatisticamente (Tabela 1), utilizando uma amostragem da população adulta, ou seja, árvores com diâmetro maior ou igual a $10 \mathrm{~cm}$. Antes da exploração todos os locais amostrados não diferiram estatisticamente em relação a área basal, abundância, número de espécies e incidência de luz. Após a retirada das árvores -- respeitando os diferentes níveis de manejo -- as áreas foram consideradas estatisticamente distintas em relação as mesmas variáveis. Não houve redução no número de espécies após a aplicação dos tratamentos (Tabela 1).

Tabela 1: Médias da área basal, abundância e número de espécies por tratamanto para avaliar a homogeneidade da área experimental. Valores calculados pelo programa SAS (Ronald \& Smith, 1984).

\begin{tabular}{|c|c|c|c|}
\hline Tratamentos & $\begin{array}{c}\text { Área } \\
\text { Basal } \\
\left(\mathrm{m}^{2} / \mathrm{ha}\right)\end{array}$ & Abundância & Número de \\
$(\mathrm{n} / \mathrm{ha})$ & Espécies \\
\hline $\mathrm{T} 1$ & 26,918 & 438,25 & 32 \\
\hline $\mathrm{T} 2$ & 25,031 & 422,75 & 31 \\
\hline $\mathrm{T} 3$ & 27,938 & 423,75 & 35 \\
\hline $\mathrm{T} 4$ & 25,919 & 418,5 & 34 \\
\hline Valor F & $0,89 \mathrm{~ns}$ & $0,16 \mathrm{~ns}$ & $0,70 \mathrm{~ns}$ \\
C.V. (8) & 10,07 & 10,22 & 14,7 \\
Média & 26,4515 & 425,81 & 33 \\
\hline
\end{tabular}




\subsection{Amostragem}

- processo de amostragem obedeceu a seguinte sequência. Foram instaladas parcelas principais de forma quadrada e tamanho de 0,49 ha $(70 \times 70$ metros) para a abordagem da população adulta referentes às árvores com DAP $\geq 10 \mathrm{~cm}$. Dentro da parcela principal foram deixados 15 metros de bordadura em cada lado. A partir do centro da parcela principal foram estabelecidas 4 sub-parcelas de $40 \mathrm{~m}^{2}$ (2 $\times 20$ metros) que foram sub-divididas em 10 microparcelas de $4 \mathrm{~m}^{2}(2 \times 2 \mathrm{~m})$, totalizando 37 microparcelas (148 $\mathrm{m}^{2}$ ) para medição da regeneração natural em cada parcela principal. Para cada tratamento foram instaladas 4 parcelas principais, 16 subparcelas e 148 microparcelas. No total foram inventariadas 16 parcelas principais, 64 subparcelas e 592 microparcelas (Figura 1).

70 metros

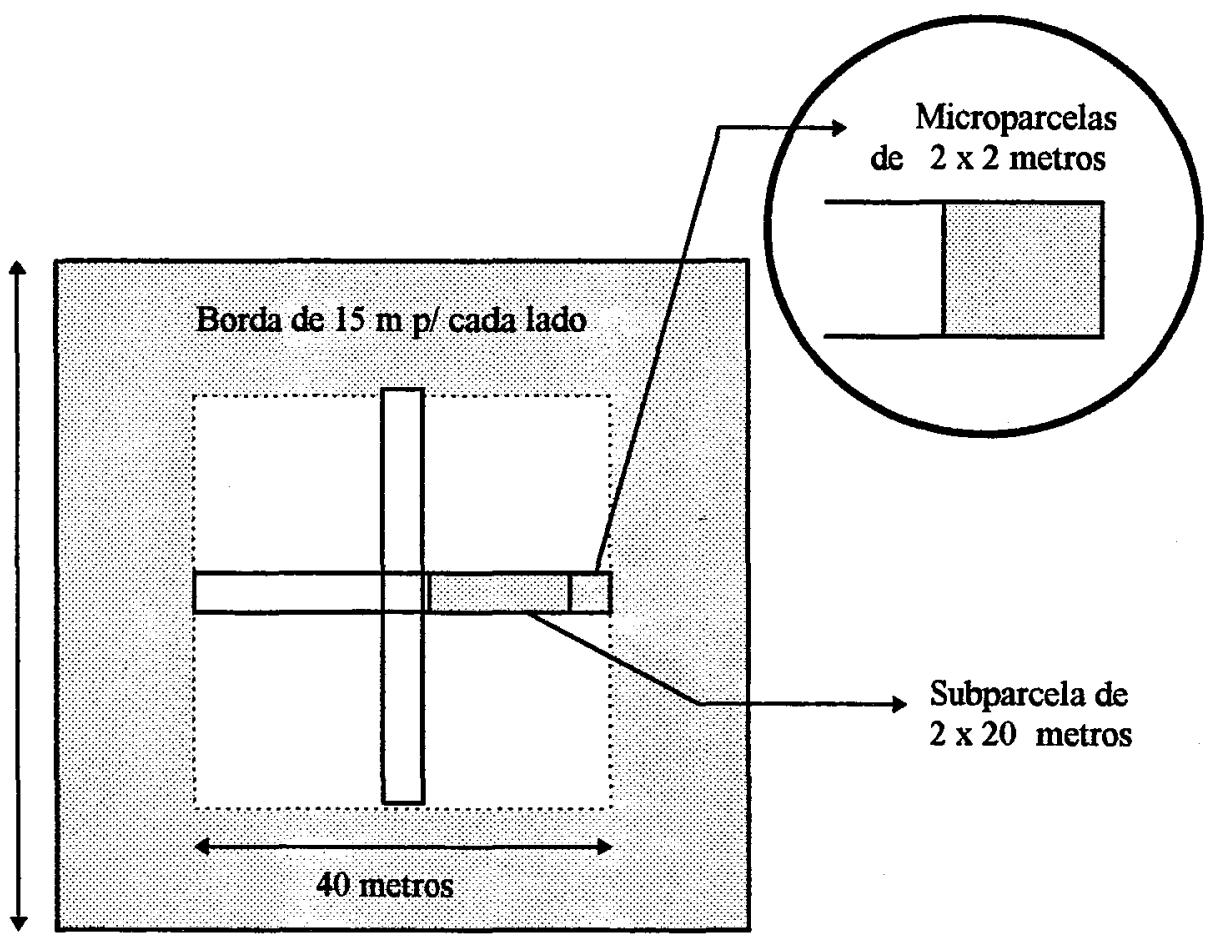

Figura 1: Desenho esquemático do tamanho e forma das parcelas em campo 


\subsection{Identificação das espécies}

Foram caracterizados todos os indivíduos entre $10 \mathrm{~cm}$ a 1,50 $\mathrm{m}$ de altura. No campo, os individuos foram classificados segundo as suas formas de vida: árvores, arbustos, cipós, ervas, palmeiras e gramíneas (Ewel, 1982; Lopez, 1993), como primeiro passo para interpretação do gradiente de luz e seus efeitos na composição da regeneração natural das espécies após 2 anos de exploração. A coleta e posterior identificação botânica foi feita por técnicos do Departamento de Botânica do Museu Paraense Emilio Goeldi, em Belém.

\subsection{Estrutura da regeneração}

Foram calculadas a abundância e frequência (Hosokawa, 1986; Lamprecht, 1990) de todas as espécies identificadas. Com os resultados obtidos do cálculo da abundância e frequência relativas, foram somadas todas as porcentagens referentes à estas duas variáveis para todas as espécies em função dos seus grupos, por tratamento. Para o cálculo da diversidade foram obtidos os seguintes indices:

- Índice de Margalef $\left(D_{M g}\right)$ : É definido como um índice de riqueza de espécies, combinando 0 número de espécies identificadas $(S)$ e o número de indivíduos somados de todas as espécies (N) (Magurran, 1987).

$$
\mathrm{D}_{\mathrm{Mg}}=\frac{(\mathrm{S}-1)}{\ln \mathrm{N}}
$$

- Indice de Shannon $\left(H^{\prime}\right)$ : índice de heterogeneidade, onde, $\mathrm{Pi}$ é a relação entre o número de indivíduos da espécie (ni) e o número total de indivíduos $(\mathrm{N})$ ou seja $\mathrm{Pi}=\mathrm{ni} / \mathrm{N}$. Este índice se baseia na abundânca proporcional de espécies (Southwood, 1978; Dias, 1993):

$$
\mathbf{H}^{\prime}=-\sum \mathrm{Pi}^{*} \ln \mathrm{Pi}
$$

- Indice de similaridade de Jacquard: Este índice é a proporção do número de unidades amostrais onde duas espécies 
ocorrem em relação ao número total de unidades amostrais onde no mínimo uma das espécies é encontrada (Ludwig \& Reynolds, 1988):

$$
I J=\frac{j}{(a+b-j)}
$$

Para o cáculo utiliza-se um determinado número de amostras $(a, b, c, \ldots, n)$ de uma população de espécies com as suas frequências conhecidas. O Indice é calculado dividindo-se o número de espécies comuns entre duas parcelas $(J)$ pelo número de espécies em cada parcela descontado o número de espécies comuns entre ambas.

3. Resultados e discussão

3.1. Relação entre $\circ$ número de espécies e $\circ$ número de parcelas

Em função dos diferentes níveis de exploração e consequente abertura da floresta, foi criado um gradiente de intensidades de luz (Figura 2), que desencadeou processos de recrutamento mais ou menos avançados em função do tamanho das clareiras que foram abertas. Os niveis médios de entrada de luz para os tratamentos 1 , 2,3 e 4 foram respectivamente: $5.6 \%$, 13.5\%, $24.8 \%$ e $40.1 \%$, onde encontraram-se diferenças significativas entre os mesmos $(P<$ $0.0001)$.

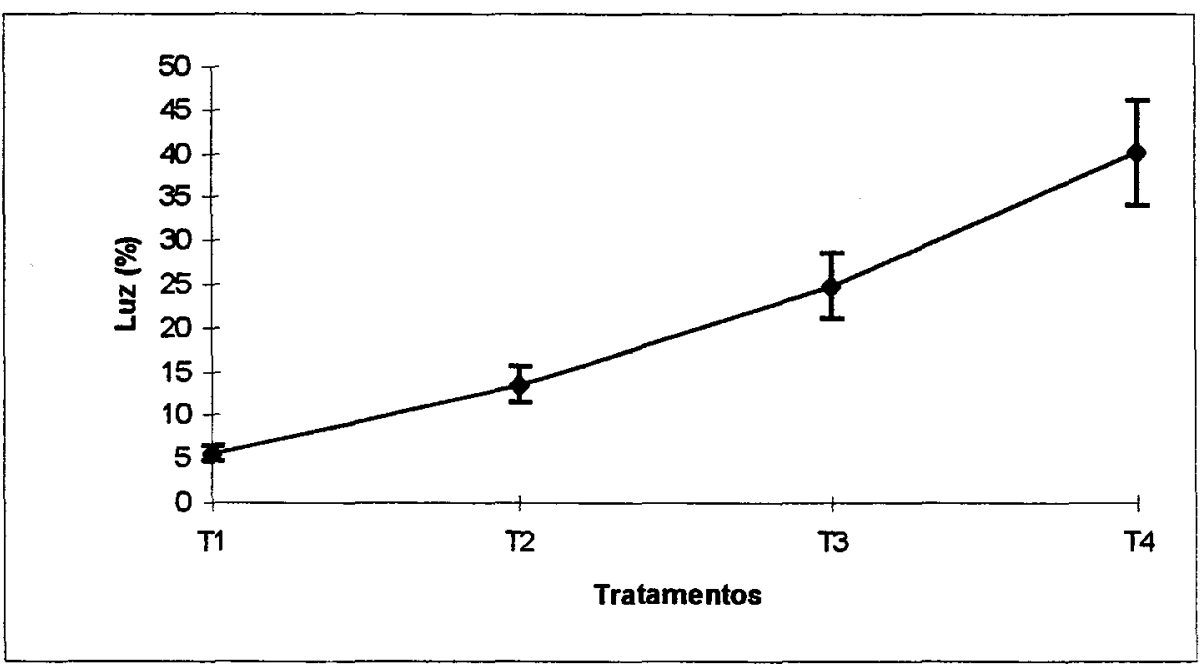

Figura 2: Médias por tratamento da porcentagem de entrada de luz, resultante da abertura das copas durante a exploração florestal (média e desvio padrãol. 
- número de individuos variou entre parcelas e tratamentos. As curvas de espécie/área mostraram uma tendência de estabilidade com o aumento da área amostrada, indicando suficiência de amostragem para todos os tratamentos (Figura 3). Para os quatro tratamentos, o número mínimo necessário de parcelas de $4 \mathrm{~m}^{2}$ para cada tratamento foi de $102\left(408 \mathrm{~m}^{2}\right)$ no $\mathrm{T} 1,124\left(496 \mathrm{~m}^{2}\right)$ no $\mathrm{T} 2,130$ $\left(520 \mathrm{~m}^{2}\right)$ no $\mathrm{T} 3$ e $93\left(372 \mathrm{~m}^{2}\right.$ ) no $\mathrm{T} 4$. Em cada curva (Figura 3) é destacado $\circ$ ponto em que um aumento de área equivalente a $10 \%$ da área amostrada corresponde a um aumento no número de espécies equivalente a 108 do total de espécies da amostra (0osting, 1951; Barros, 1986). Entretanto, houve um ligeiro acréscimo do número de espécies após a obtenção destes pontos, mostrando que existe um aumento contínuo de espécies novas à medida que a amostragem é aumentada.

\subsection{Estrutura da regeneração \\ 3.2.1. Composição florística}

As famílias Leguminosae e Arecaceae (palmeiras) tiveram o maior número de espécies em todos os tratamentos. Além destas duas famílias foram também representativas as familias polypodiaceae (tratamentos 1, 2 e 3), Bignoniaceae (tratamento 1), Maranthaceae (tratamentos 2 e 3), Euphorbiaceae (tratamentos 2 e 4) e Rubiaceae (tratamentos 2, 3 e 4) (Figura 4). As palmeiras contribuiram com $10.8 \%, 6.4 \frac{8}{\%}, 7.18$ e $6.3 \%$ do total de espécies para os tratamentos $1,2,3$ e 4, respectivamente. 0 tratamento 3 contribuiu com 0 maior número de famílias $(n=38)$, gêneros $(n=83)$ e espécies ( $n$ = 99). Os tratamentos 1 e 2 obtiveram valores próximos, caracterizando-se por possuirem um número menor de espécies, ficando o tratamento 4 como intermediário (Figura 5). 


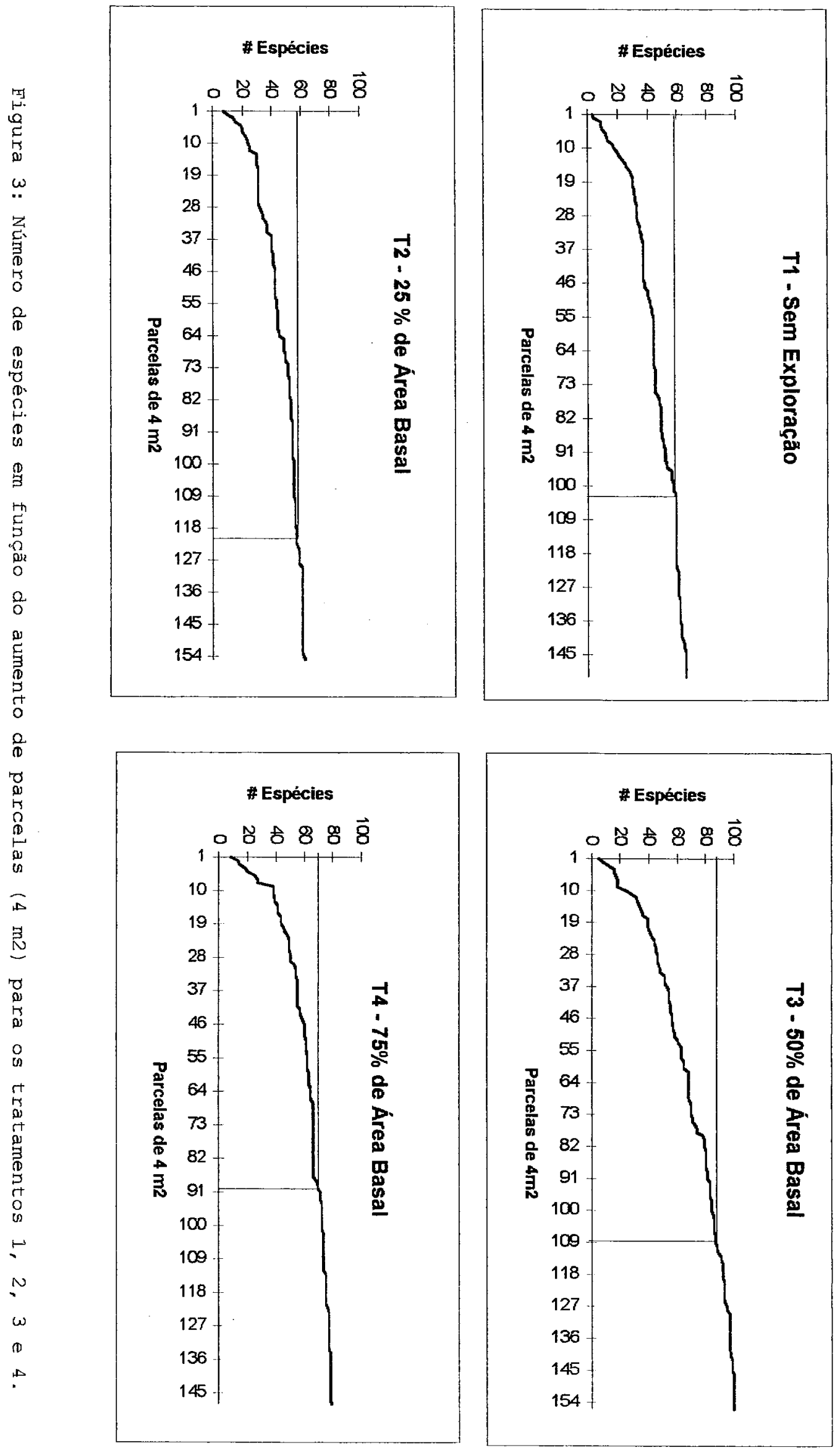




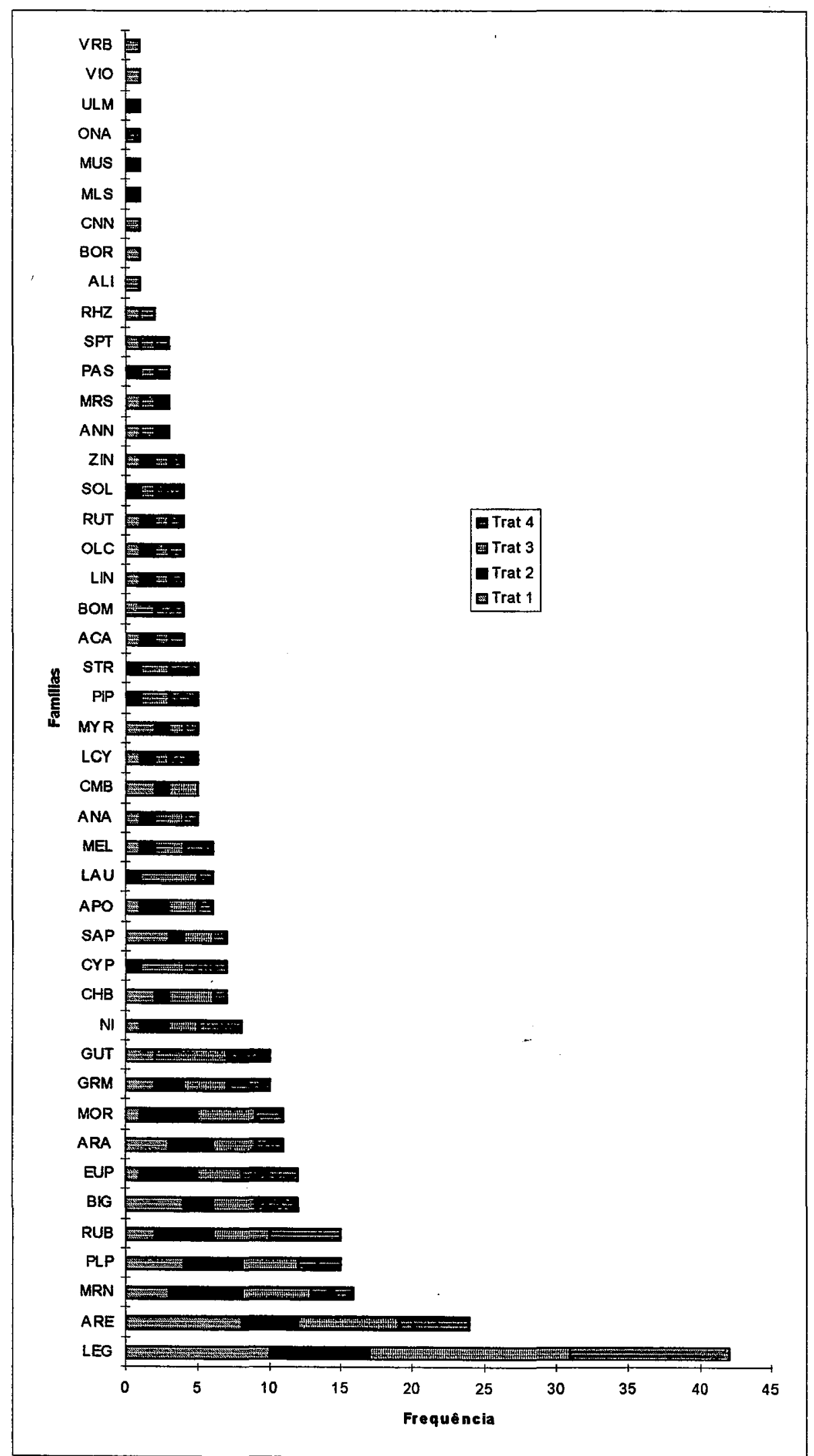

Figura 4: Distribuição das famílias botânicas identificadas no local de estudo e sua distribuição para cada tratamento. 


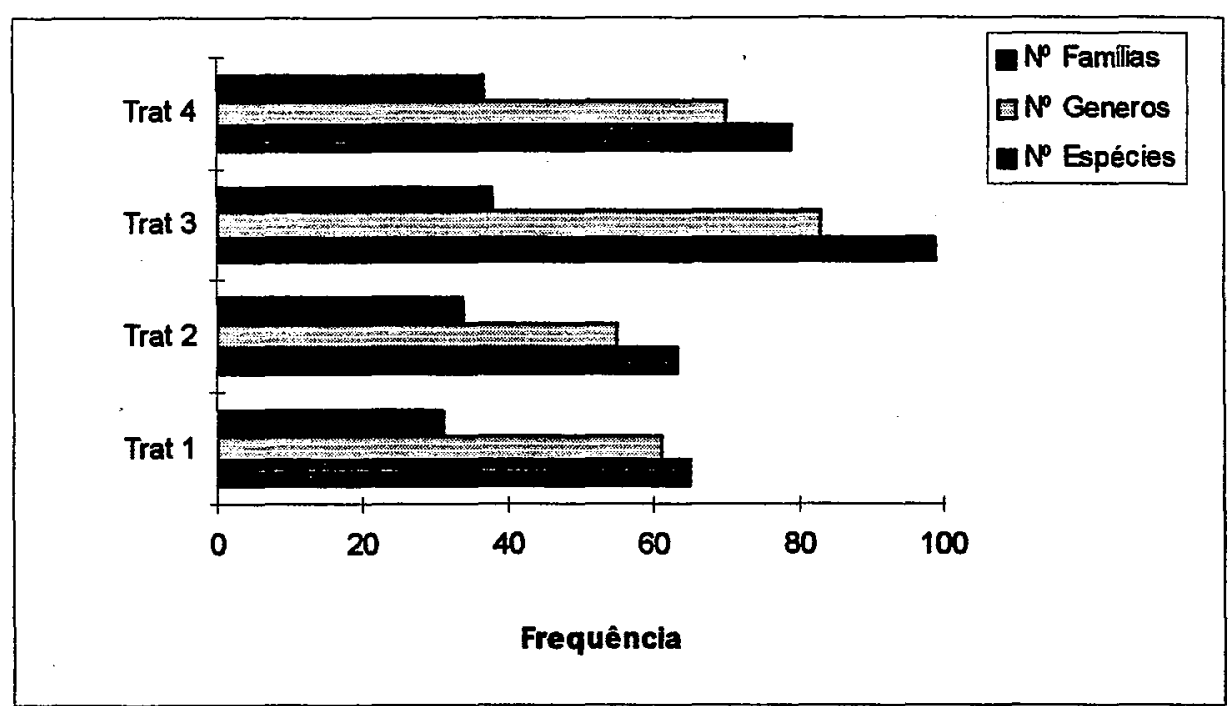

Figura 5: Proporção do número de famílias, gêneros e espécies em relação a cada tratamento.

3.2.2. Grupos de espécies: padrões de recrutamento em função da abundância e frequência relativas

Para as árvores, abundância e frequência foram maiores no tratamento 1, diminuindo nos outros tratamentos (Figura 6-A). Entretanto, é evidente uma tendência de recrutamento pelas espécies arbóreas mais exigêntes em luz. A mesma tendência é observada para os arbustos (Figura 6-A).

Um fato interessante é que a frequência e abundância de cipós se manteve constante, embora a composição das espécies variou em função da variação de luz para cada ambiente (Denslow, 1980; Putz, 1984) (Figura 6-A).

As palmeiras tiveram os valores de abundância e frequência diminuidos a medida que aumentou a entrada de luz, chegando no tratamento 4, a ter menos da metade dos valores em relação ao tratamento 1 (Figura 6-B). Os valores para o grupos de espécies de ervas e gramíneas obtiveram resultados esperados em relação às observações de campo, ou seja, houve um aumento nos locais mais abertos. As espécies de ervas apresentaram uma elevada porcentagem de abundância e frequência em todos os tratamentos, bem como, em relação ao demais grupos (Figura 6-B). 

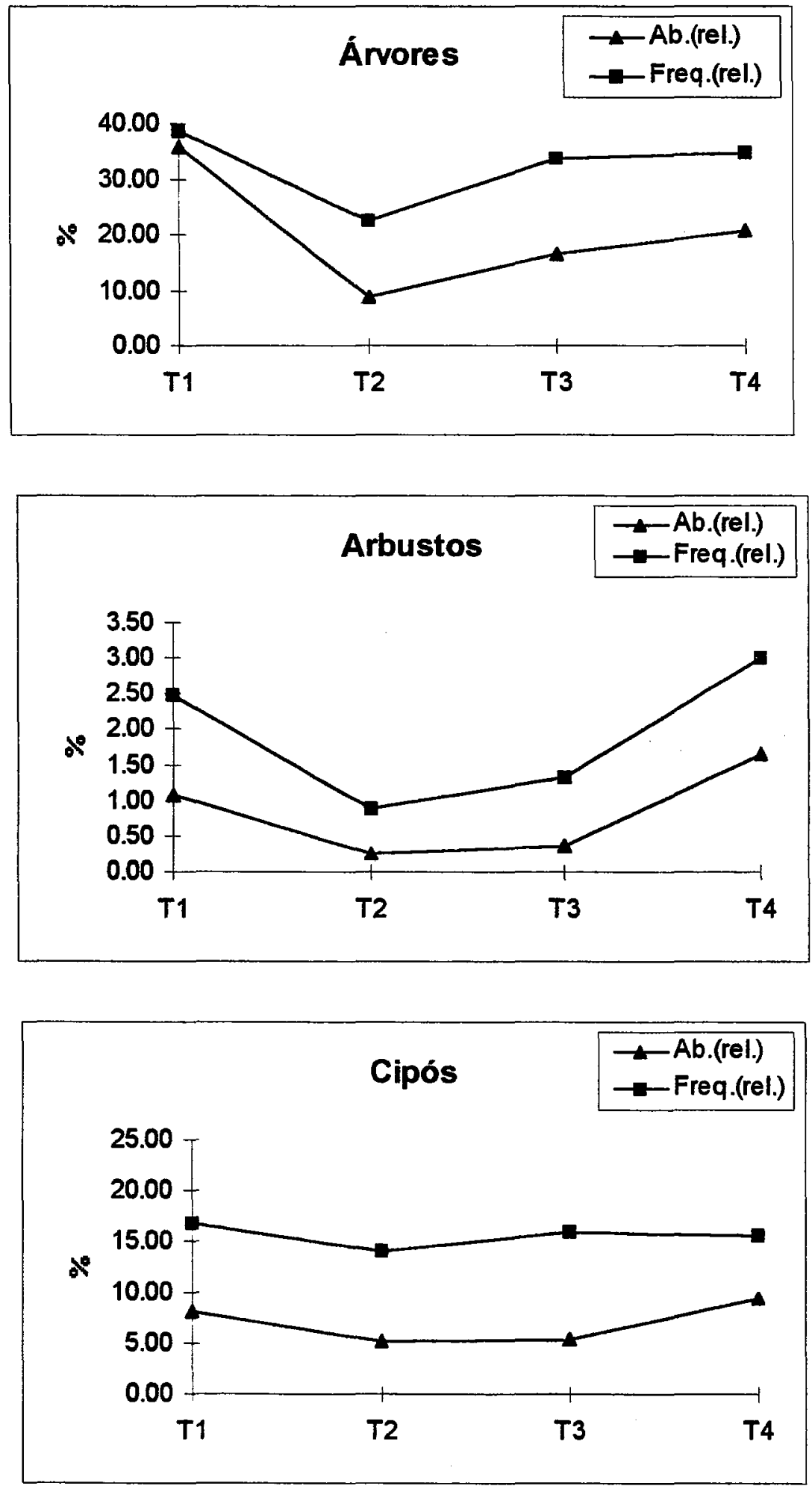

Figura 6: A - Abundância e frequência de: árvores, arbustos e cipós, nos quatro tratamentos. 

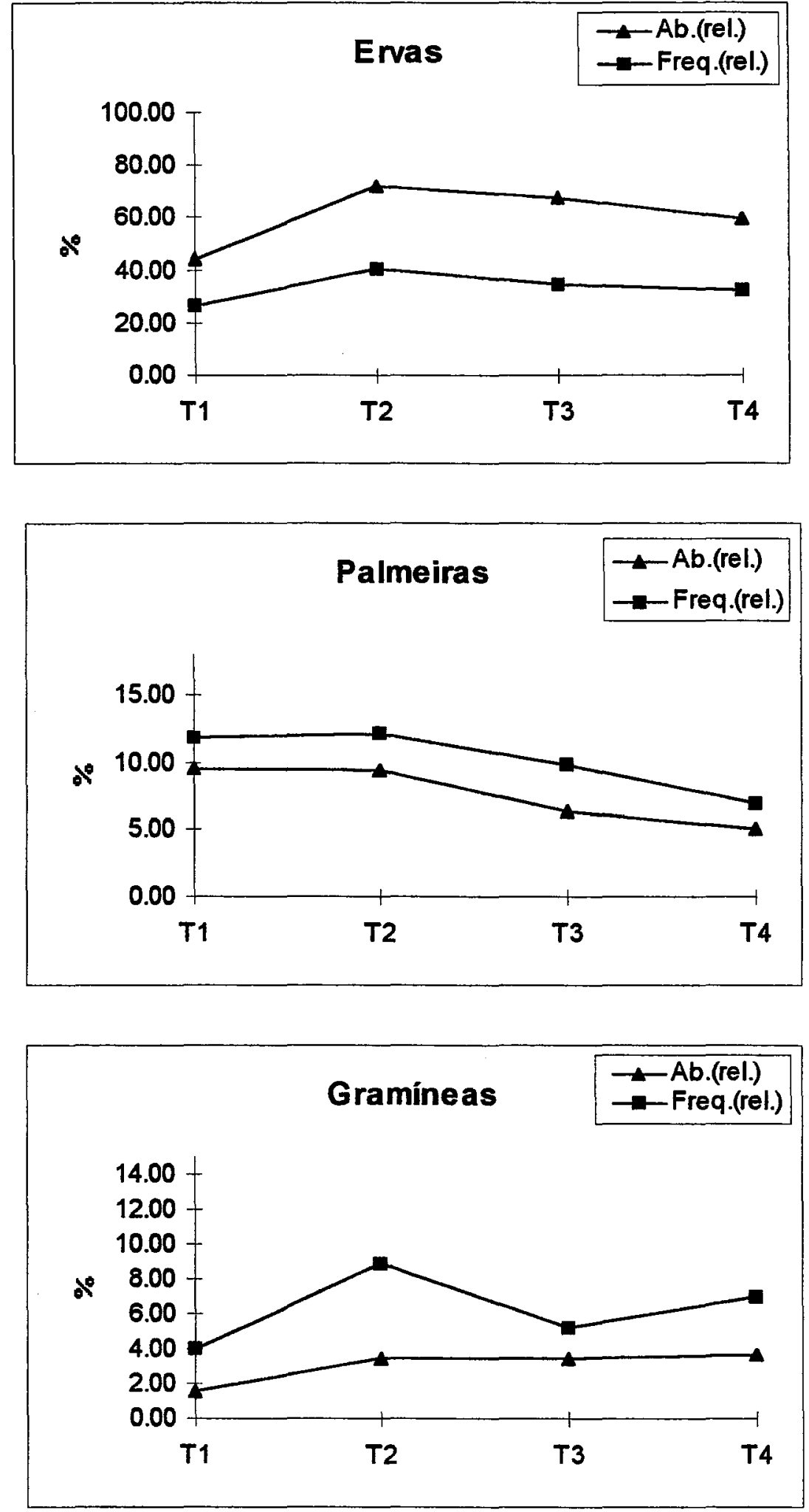

Figura 6: B - Abundância e frequência de: ervas, palmeiras e gramíneas, nos quatro tratamentos. 


\subsubsection{Indices de diversidade}

Os índices de riqueza (Margalef), de heterogeneidade (Shannon), e de similaridade (Jacquard), foram calculados com o objetivo de visualizar a dinâmica da regeneração natural entre os tratamentos. Não foi possível a comparação destes indices com florestas de várzea em semelhantes condições, por não haver disponibilidade na literatura de estudos deste tipo para várzeas na região amazônica.

Os indices de heterogeneidade levam em consideração tanto a regularidade como a riqueza de espécies, e se baseiam na abundância proporcional das espécies. $O$ indice de Shannon (Magurran, 1987) assume que os indivíduos são aleatoriamente amostrados de uma população infinitamente grande, e que todas as espécies estão representadas na amostra. Este índice atribui um peso maior às espécies raras.

Com relação aos tratamentos, 0 índice de shannon caracterizou os extremos (tratamentos 1 e 4). Nestes tratamentos, existem condições propicias para a ocorrência de espécies típicas (especialistas) de ambientes com bastante sombra (tratamento 1), ou de clareiras grandes (tratamento 4). Consequentemente, o número de individuos por espécie é proporcionalmente menor, devido às condições ecofisiológicas definidas, aumentando desta maneira, a sensibilidade do indice em questão (Tabela 2). 
Tabela 2: Relação dos índices de riqueza e heterogeneidade de espécies calculados para os vários tratamentos.

\begin{tabular}{|c|c|c|c|c|}
\cline { 3 - 4 } \multicolumn{2}{c}{} & $\begin{array}{c}\text { Índice de } \\
\text { Heterogeneidade }\end{array}$ & Indice de Riqueza \\
\hline Trat & $N^{\circ}$ Esp & Indiv./ha & Shannon & Margalef \\
\hline 1 & 65 & 25.064 & 2.76 & 6.32 \\
\hline 2 & 63 & 37.804 & 2.17 & 5.88 \\
\hline 3 & 99 & 50.609 & 2.68 & 9.05 \\
\hline 4 & 79 & 31.218 & 2.87 & 7.54 \\
\hline
\end{tabular}

Índices de riqueza tentam caracterizar a relação entre o número de espécies por um número determinado de indivíduos. No caso dos tratamantos, 0 indice de Margalef (Magurran, 1987) atribuiu um maior valor ao tratamento 3, que possui um maior número de espécies, mas que ao mesmo tempo, possui o maior número de indivíduos por área amostrada. Este se mostrou bem confiável, pois não atribui pesos muito altos às espécies mais comuns, e sim à comunidade como um todo, principalmente para as espécies com valores intermediários (Tabela 2 ).

Os indices de similaridade se baseiam no quanto duas comunidades são próximas com relação ao número de espécies. 0 indice de Jaccard (Magurran, 1987) utiliza dados qualitativos (presença/ausência de espécies). Foram avaliados duas situações: (i) com a presença das familias e (ii) com a ocorrência dos gêneros em relação a cada tratamento. Este coeficiente também se mostrou sensivel tanto para as familias (Tabela 3.1), como para os gêneros (Tabela 3.2), quando comparados os extremos (tratamentos 1 e 4). Este fato vem confirmar a existencia de uma relação entre um gradiente crescente de entrada de luz na floresta e a sua composição de espécies. 
Tabela 3.1: Valores do coeficiente de similaridade de Jaccard, obtidos pelo pelo procedimento SIMQUAL (Rohlf, 1990), utilizando-se matriz de presença (1) e ausência (0) de famílias nos quatro tratamentos.

\begin{tabular}{|c|c|c|c|c|}
\hline & Trat 1 & & & \\
\hline Trat 1 & 1.00 & Trat 2 & & \\
\hline Trat 2 & 0,62 & 1.00 & Trat 3 & \\
\hline Trat 3 & 017 & 0.73 & 1.00 & Trat4 \\
\hline trat 4 & 0.68 & 0.74 & 0.83 & 1.00 \\
\hline
\end{tabular}

Tabela 3.2: Valores do coeficiente similaridade de Jaccard, obtidos pelo pelo procedimento SIMQUAL (Rohlf, 1990), utilizando-se matriz de presença (1) e ausência (0) de gêneros nos quatro tratamentos.

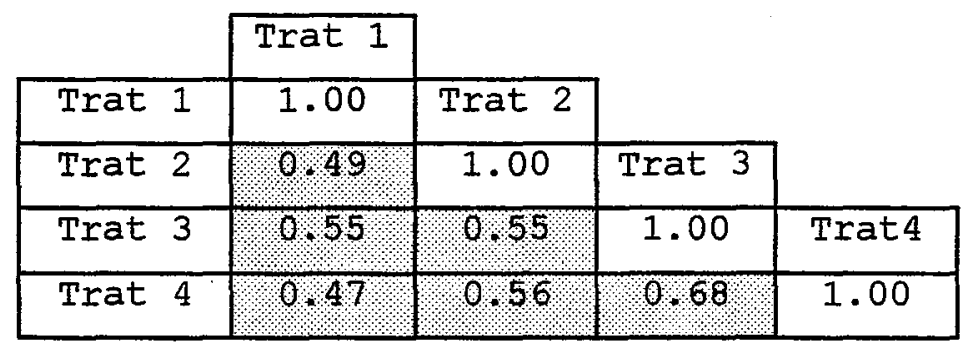

3.3. Influência das intensidades de exploração na composição das espécies

\subsubsection{Baixa intensidade de corte}

A abundância de cada espécie constitui um fator importante que deve ser considerado em uma análise da vegetação, através da relação espécie/abundância (Whittaker, 1965; Peet, 1974; Hubbell, 1979). Foi obtida uma curva de abundância relativa (diversidade versus dominância) através da plotagem em escala logarítmica do número de indivíduos por espécie, contra as espécies ordenadas em classes sequenciais de abundância.

Para os tratamentos 1 (sem exploração) e 2 (com baixa intensidade de corte) foram relacionadas as espécies consideradas mais comuns: (i) 3 espécies arbóreas Licania heteromorpha, Mora paraensis e Heisteria acuminata; (ii) 1 palmeira (Euterpe 
oleracea) e (iii) 6 espécies de ervas, sendo que 2 se destacaram Aphelandra acutifolia e Calathea cf. legrelleana.

Entre as espécies consideradas menos abundantes estão incluídas 11 espécies arbóreas, 2 cipós, 3 ervas e uma palmeira, para o tratamento 1. Para o tratamento 2 relacionam-se 12 árvores, 1 arbusto, 3 cipós e 1 erva. Dentre as árvores destacam-se Spondias mombin, Calycophylum spruceanum, Carapa guianensis e Symphonia globulifera.

\subsubsection{Média intensidade de corte}

Para o tratamento 3, considerado de média intensidade, foram encontradas 5 espécies mais abundantes. Neste caso, novamente as herbáceas Aphelandra acutifolia e Calathea cf. legrelleana, e como espécies arbóreas encontram-se Mora paraensis e calycophylum spruceanum, que nos tratamentos citados anteriormente, apareceu como uma das espécies memos comuns. Entre as espécies com abundância intermediária destacaram-se: Euterpe oleracea, Spondias mombin, Virola surinamensis, Symphonia globulifera, Carapa guianensis e Licania heteromorpha.

Dentre as espécies menos abundantes estão relacionadas 15 espécies arbóreas, 1 arbusto, 4 cipós, 2 espécies herbáceas e 2 palmeiras: Iriartea exorhiza e urucurí scheelea martiana.

\subsubsection{Alta intensidade de corte}

No tratamento de maior intensidade de corte, foram observadas 5 espécies arbóreas dominantes: Mora paraensis, Calycophylum spruceanum, spondias mombin, sickingia trinctoria e embaúba (Cecropia latiloba). Foram encontradas 2 espécies de cipós e 4 espécies herbáceas, entre elas novamente Aphelandra acutifolia e Calathea cf. legrelleana. Com relação às palmeiras foram identificadas 2 espécies: Euterpe oleraceae e Astrocaryum murumuru. Na relação de espécies mais abundantes encontrou-se ainda uma graminea: Lasiacis ligulata. 
$\mathrm{Na}$ lista de espécies menos abundantes estão incluídas 12 espécies arbóreas, destacando-se Carapa guianensis, Ceiba pentandra e seringueira Hevea brasiliensis. Para arbustos e ervas apenas uma espécie, cipós com 2 espécies, e palmeiras com 2 espécies: Geonome laxiflora e Schelea martiana.

Plotando-se a abundância e frequência relativas na sequência dos tratamentos para algumas espécies (Eiguras 7, 8 e 9), observou-se que é possivel fazer uma classificação quanto ao estágio sucessional de algumas delas. Espécies como limãozinho (Zanthoxylon rhoifolia), olho de pomba (Heisteria acuminata) e um tipo de tajá (Philodendron muricatum) são típicas de sombra.

Espécies como guarumã (Calathea ondulata), embaúba (Cecropia latiloba), pau mulato (Calycophylum spruceanum), e taperebá (Spondias mombin) são típicas de grandes clareiras.

Já espécies como pracuúba (Mora paraensis) e ucuúba (Virola surinamensis) apresentaram um equilíbrio quanto a sua ocorrência em toda a sequência dos tratamentos, apesar de apresentarem maiores valores para os locais com menos incidencia de luz.

As palmeiras como açaí (Euterpe oleracea) e buçú (Manicaria saccifera) também mostraram regularidade na sequência, mas também tendem ser espécies mais tolerantes à sombra (Figuras 7, 8 e 9). Nos exemplos de espécies citados, procurou-se representar todos os grupos (árvores, arbustos, cipós, ervas, gramíneas e palmeiras). As tendências de espécies e sua classificação quanto a grupos sucessionais, são de caráter preliminar. Pretende-se analisar mais a fundo os dados e futuramente sugerir com mais precisão uma classificação da fase inicial da regeneração das espécies de várzea quanto a sucessão. 

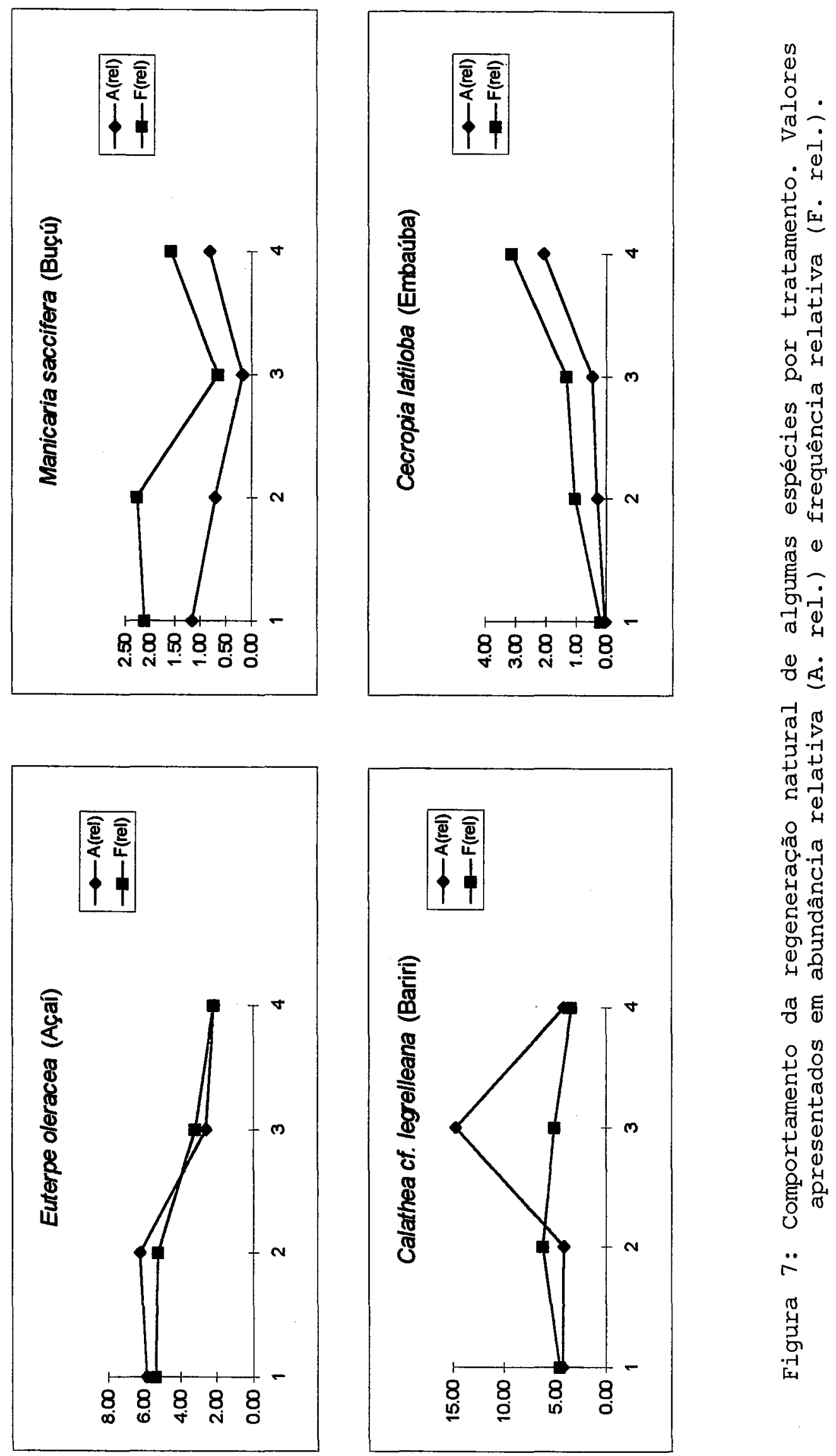

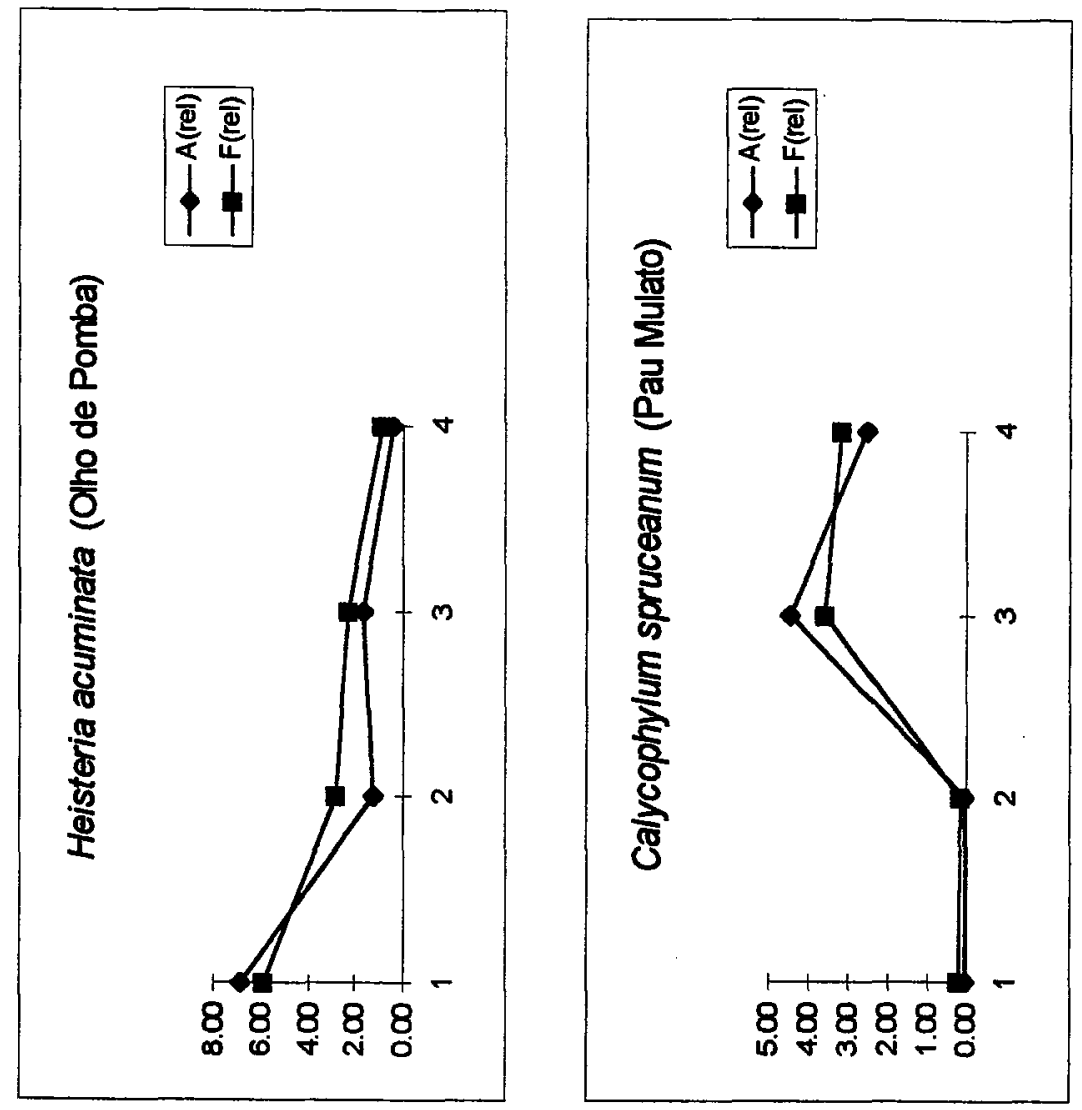

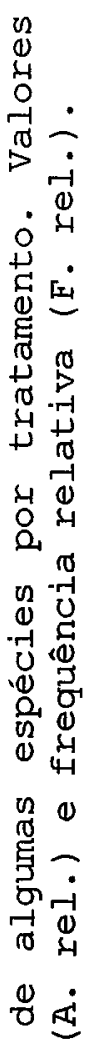

궁

式
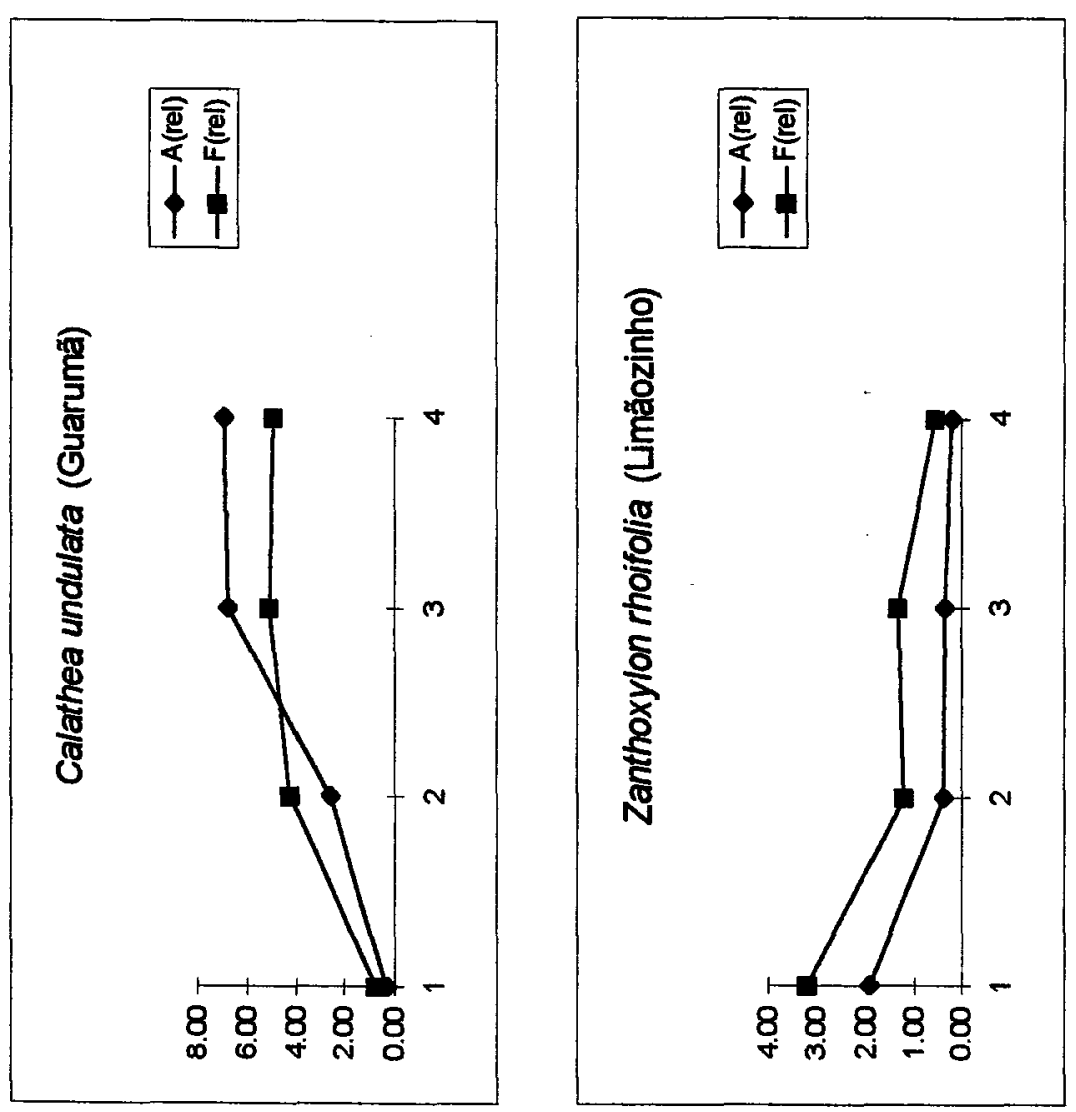

要

$\circ$ H

U.

(⿻)

崩

(1)

娄 $\frac{0}{0}$

ช

+ 음

⿷

穷

岑 会

영

U

$\ddot{\infty}$

告 

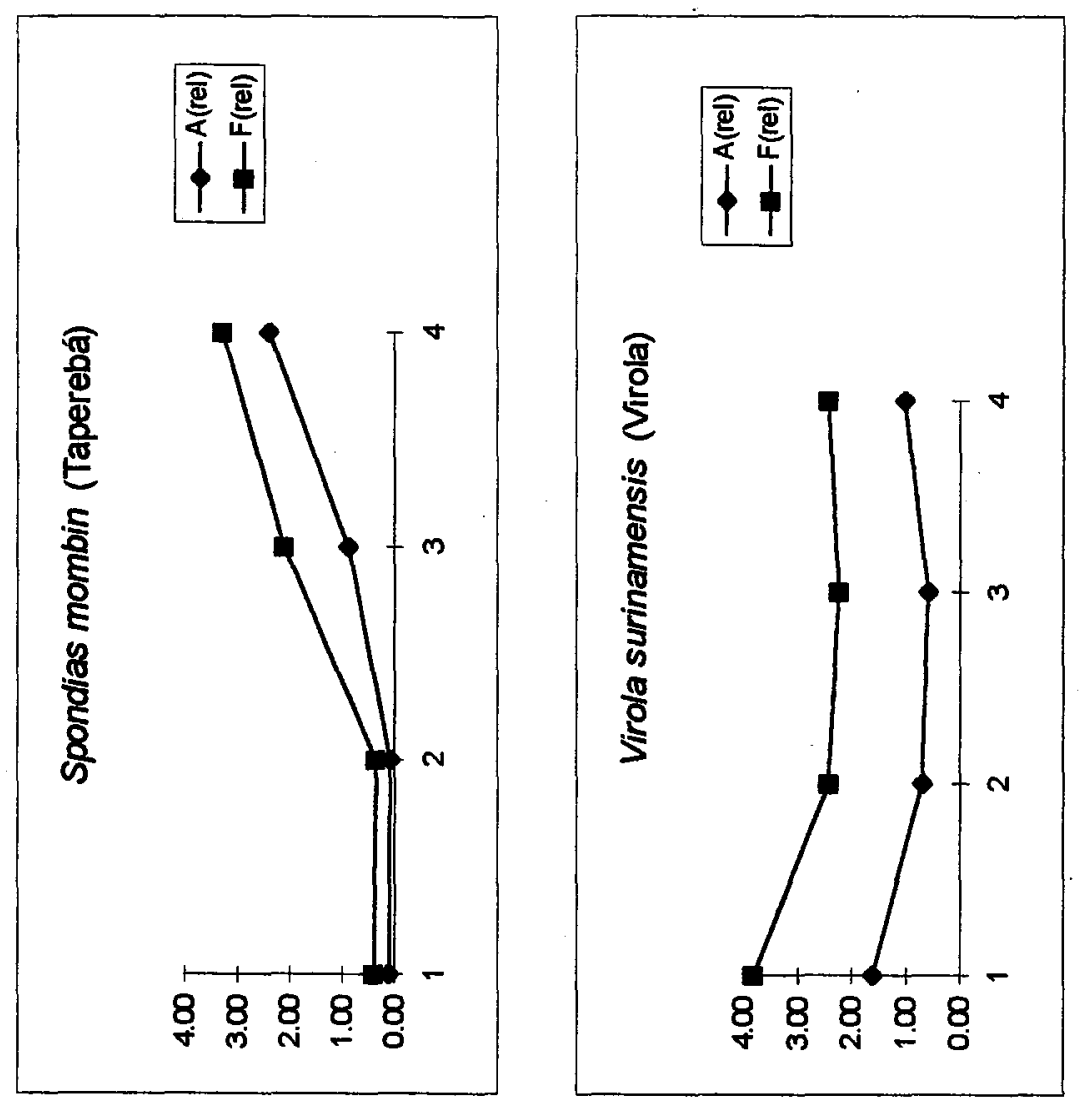

$n$
0
0
0
-1
0
$>$

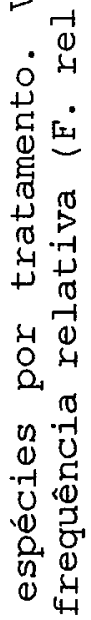

(2)

突

ه

ㅇํㅇ

年㝵
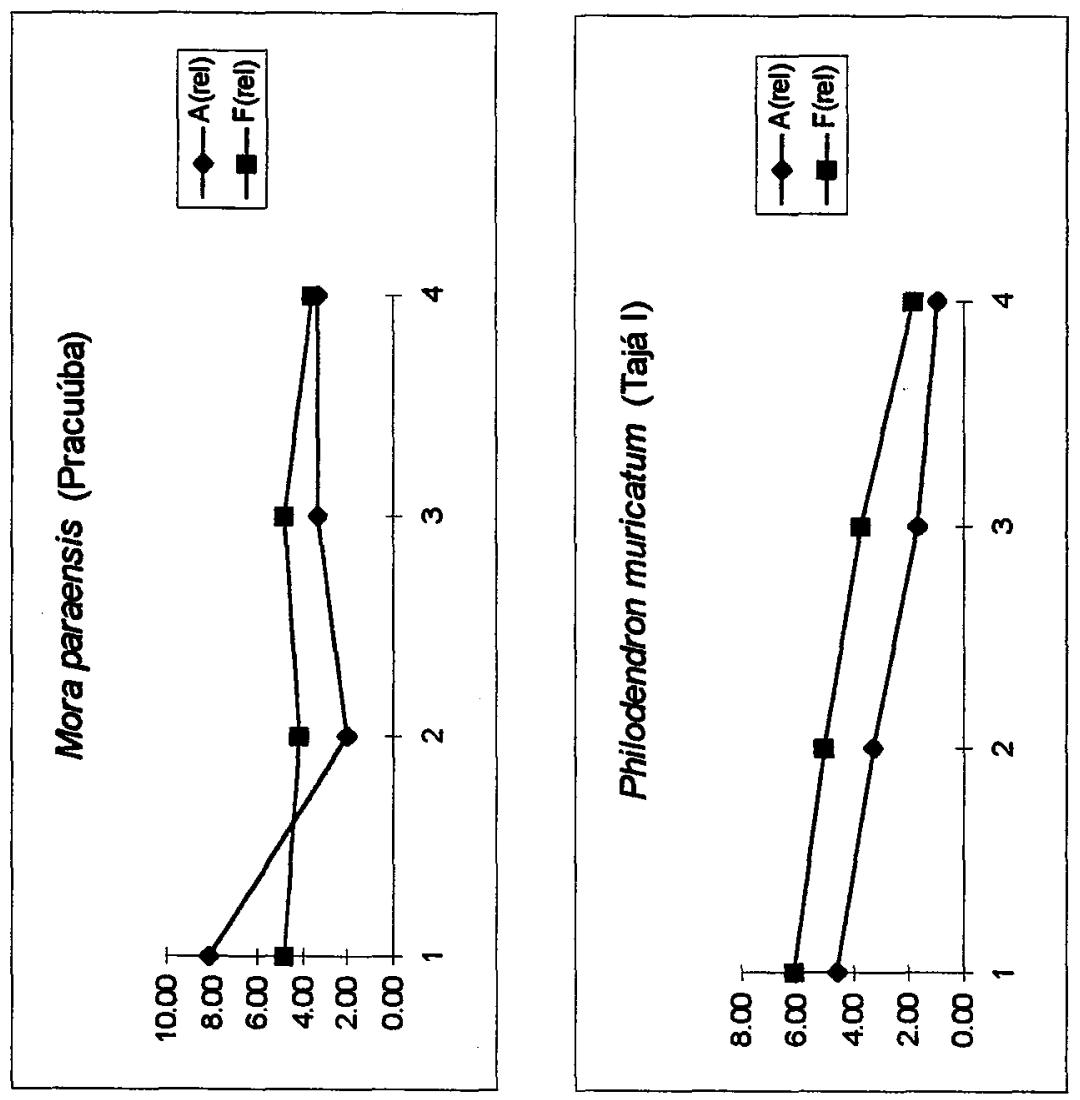

齿

20

U.

㟧

苋

氙

잉 붕

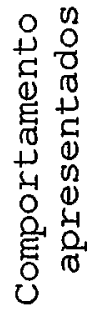

$\ddot{\sigma}$

苟 
4. Conclusão

As curvas de espécie/área mostraram uma tendência de estabilidade com o aumento da área amostrada, havendo suficiência de amostragem para todos os tratamentos.

As famílias Leguminosae e Arecaceae contribuiram com o maior número de espécies em todos os tratamentos.

As espécies coletadas nas parcelas de regeneração natural foram identificadas e posteriormente agrupadas em 6 grupos: árvores, arbustos, cipós, ervas, palmeiras e gramíneas, e calculadas a abundância e frequência relativas.

Houve um aumento do número de espécies $e$ do número de indivíduos a medida que aumentou a luz. Tanto $\circ$ índice de heterogeneidade (Shannon) como de riqueza de espécies (Margalef), foram sensiveis a estas mudanças, principalmente com relação aos extremos (tratamentos 1 e 4 ). O mesmo fato foi observado para 0 índice de similaridade de Jaccard.

As curvas de abundância relativa foram extremamente úteis para verificar a nível de tratamento, o comportamento das espécies em relação a características sucessionais.

Espécies como limãozinho (Zanthoxylon rhoifolia), olho de pomba (Heisteria acuminata), um tipo de tajá (Philodendron muricatum) são típicas de sombra.

Espécies como guarumã (Calathea ondulata), embaúba (Cecropia latiloba), pau mulato (Calycophylum spruceanum), e taperebá (Spondias mombin) são espécies típicas de grandes clareiras. Já espécies como pracuúba (Mora paraensis) e ucuúba (Virola surinamensis), apresentaram um equilibrio quanto a sua ocorrência em toda a sequência dos tratamentos, apesar de apresentarem maiores valores para os locais com menos incidencia de luz. As palmeiras, como açaí (Euterpe oleracea) e buçú (Manicaria saccifera), também mostraram regularidade na sequência, mas também tendem ser espécies mais tolerantes à sombra. 
Alder, D. 1992. Simple methods for calculating minimum diameter and sustainable yield in mixed tropical forest. In: wise management of tropical forests. Ed. F.R. Muller \& K.L. Adam. Oxford For. Institute. Oxford. p. 189-209.

Barros, P.L.C. 1986. Estudo fitossociológico de uma floresta tropical úmida no planalto de Curuá-Una. Amazônia Brasileira. Tese Doutorado. UFPR. Curitiba, PR. 147 p.

Baur, G.N. 1968. The ecological basis of rain forest management. Forestry Commission of New South Wales, Sidney. $499 \mathrm{p}$.

Botkin, D.B. \& Lee M. Talbot. 1991. Biological diversity and forests. World Bank Forest Policy Issues Paper. (Mimeo). 35 p.

Brokaw, N.V.I. 1987. Gap-phase regeneration of three pioneer tree species in a tropical forest. Journal of Ecology, 75:919.

Buschbacher, R.J. 1990. Natural forest management in the humid tropics: ecological, social, and economic considerations. Ambio, $19(5): 253-258$.

De Camino, R. \& Sabine Muller. 1993. Sostenibilidad de la agricultura y los recursos naturales: bases para estabelecer indicadores. IICA-GTZ. Serie de Programas: $38.133 \mathrm{p}$.

Denslow, J.L. \& Diaz, A.E.G. 1990. Seed rain to tree-fall gaps in the neoropical rain forest. Can. J. F. Res., 20:642-648.

Denslow, J.I. 1980. Gap partioning among tropical rainforest trees. Biotropica (Suppl.):47-55.

Denslow, J.L. 1987. Tropical rianforest gaps and tree species diversity. Ann. Rev. Syst., 18:431-51.

Dias, A.C. 1993. Estrutura e diversidade do componente arbóreo e a regeneração do Palmito (Euterpe edulis) em trecho de mata secundária, no parque estadual de Carlos Botelho, SP. Dissertação de Mestrado. ESALQ/USP. Piracicaba, SP. 126 p.

Evans, J. 1982. Plantation forestry in the tropics. Oxford University Press. London. $472 \mathrm{p}$.

Ewel, J. 1983. Succession. In: Tropical rain forest ecosystems, a struture and function. Ed. by F.B. Golley. Elsevier Scient. Publ. Co. Amsterdam. p. 217-23.

Ewel, J.; S. Gliessmann; M. Amadador; F. Benedict; C. Berish; R. Bermudez; B. Brown; R. Miranda \& N. Price. 1982. Leaf area, light tranmission, roots and leaf damage in nine tropical tropical plant communities. Agro-Ecosystems, 7: 305-326. 
Forget, P-M. 1994. Recuitment pattern of Vouacapoua americana (Caesalpiniacaeae), a rodent-dispersed tree species in French Guiana. Biotropica, 24(4):408-419.

Hartshorn, G. 1980. Neotropical forest dynamics. Biotropica (suppl.) : 23-30.

Hartshorn, G. 1989. Application of gap theory to tropical forest management: natural regeneration on strip clear-cuts in the Peruvian Amazon. Ecology, 70(3):567-69.

Hosokawa, R.T. 1986. Manejo e economia de florestas. FAO. Roma. $125 \mathrm{p}$.

Hubbell, S.P. 1979. Tree dispersion, abundance, and diversity in a tropical dry forest. Science, 203:1299-1309.

Hutchinson, I.D. 1986. The management of humid tropical forests to produce wood. In: Management of the forests of tropical america: prospects and technologies. Proceedings of a conference. Inst. of Tropical Forestry. Puerto Rico. 121-156 p.

Khan, M.I.; J.P.N. Rai \& R.S. Tripathi. 1986. Regeneration and survival of the tree seedlings and sprouts in tropical deciduous and sub-tropical forests of Meghalaya, India. Forest Ecol. and Management, 14:293-304.

Korning, J. \& Henrik Balslev. 1994. Growth rates and mortality patterns of tropical lowland tree species and the relation to forest structure in Amazonian Ecuador. $J$. of Tropical Ecology, 10:151-166.

Lamprecht, H. 1990. Silvicultura nos trópicos. GTZ. Eschborn. $342 \mathrm{p}$.

Lopes, J.M.A. 1993. Demografia e flutuações temporais da regeneração natural após uma exploração florestal: Flona Tapajós, PA. Dissertação de Mestrado. ESALQ/USP. Piracicaba, SP. $133 \mathrm{p}$.

Ludwig, J.A. \& Reynols, J.F. 1988. Statistical Ecology. A primer on methods and computing. J. Willey \& Sons, New York. $337 \mathrm{p}$.

Magurran, E. A. 1987. Ecological diversity and its measurement. Princeton Univ. Press. 179 p.

Martini, A.; Rosa N. \& C. Uhl. 1994. An attempt to predict which amazonian tree species may be threatened by logging activities. Enviromental Conservation, 21(2):152-162.

Morán, E.F. 1990. A Ecologia Humana das Populações da Amazônia. Vozes, Petrópolis, RJ. 367 p.

Oldeman, R.A.A. 1978. Architecture and energy exchange of dicotyledonous trees in the forest. In: P.B. Tomlinson \& M.H. Zimmermann, ed. Tropical trees as living systems. Cambridge University Press. New York. p. 535-60.

oosting, H.J. 1951. Ecologia vegetal. Aguilar. Madrid. 416 p. 
Panayotou, T. \& Peter S. Ashton. 1992. Not by timber alone: economics and ecology for sustaining tropical forests. Island Press. Whashington. 235 p.

Peet, R.K. 1974. The measurement of species diversity. Ann. Rev. Ecol. System., 5:285-307.

Peters, M.P. 1994. Sustainable harvest and non-timber plant resources in tropical mois forest: an ecological primer. WWF/The Nature Conservancy. New York. $45 \mathrm{p}$.

Putz, F.E. 1984. The natural history of lianas on Barro Colorado Island, Panama. Ecology, 65:1713-24

Rohlf, F.J. 1990. NTSYS-PC. Numerical taxonomy and multivariate analysis system, version 1.7 . State Univ. New York. Stony Brook. $156 \mathrm{p}$.

Ronald P.C. \& Jeffrey K. Smith. 1984. Applied statistics and SAS programming language. Elsevier Ed. Amsterdan. 187 p.

Southwood, T.R.E. 1978. Ecological methods. Chapmann \& Hall. London. $232 \mathrm{p}$.

synnott, T.J. 1992. The introduction of basic management into tropical forests. In: Wise management of tropical forests. Ed. F.R. Muller \& K.L. Adam. Oxford For. Institute. Oxford. p. $91-96$.

UhI, C \& I.C.G. Vieira. 1989. Ecological impacts of selective logging in the Brazilian Amazon: A case study from the Paragominas region of the state of Pará. Biotropica, $21(2): 98-106$.

Vásquez-Yanes, C. \& A. Orozco-Segovia. 1990. Ecological significance of light controlled seed germination in two contrasting tropical habitats. Oecologia, 83:171-75.

Veríssimo, A.; Barreto, P.; Mattos, M.; Tarifa, R. \& C. Uhl. 1992. Logging impacts and prospects for sustainable forest management in an old Amazonian frontier: the case of Paragominas. Forest Ecol. and Management, 55:169-199.

Veríssimo, A.; Barreto, P.; Tarifa, R. \& C. Uhl. 1995. Extraction of a high-value natural resource from Amazonia: the case of Mahogany. Forest Ecol. and Management, 72:39-60.

Weber, A.W. 1982. Minemonic three-letter acronyms for the families of vascular plants: a device for more effective herbarium curation. Taxon, 3(1):74-78/

Whitmore, T.C. 1978. Gaps in the forest canopy. In: P.B. Tomlinson \& M.H. Zimmermann, ed. Tropical trees as living systems. Cambridge University Press. New York. p. 639-55.

Whittaker, R.W. 1965. Dominance and diversity in land plant communities. Science, 147:250-60. 


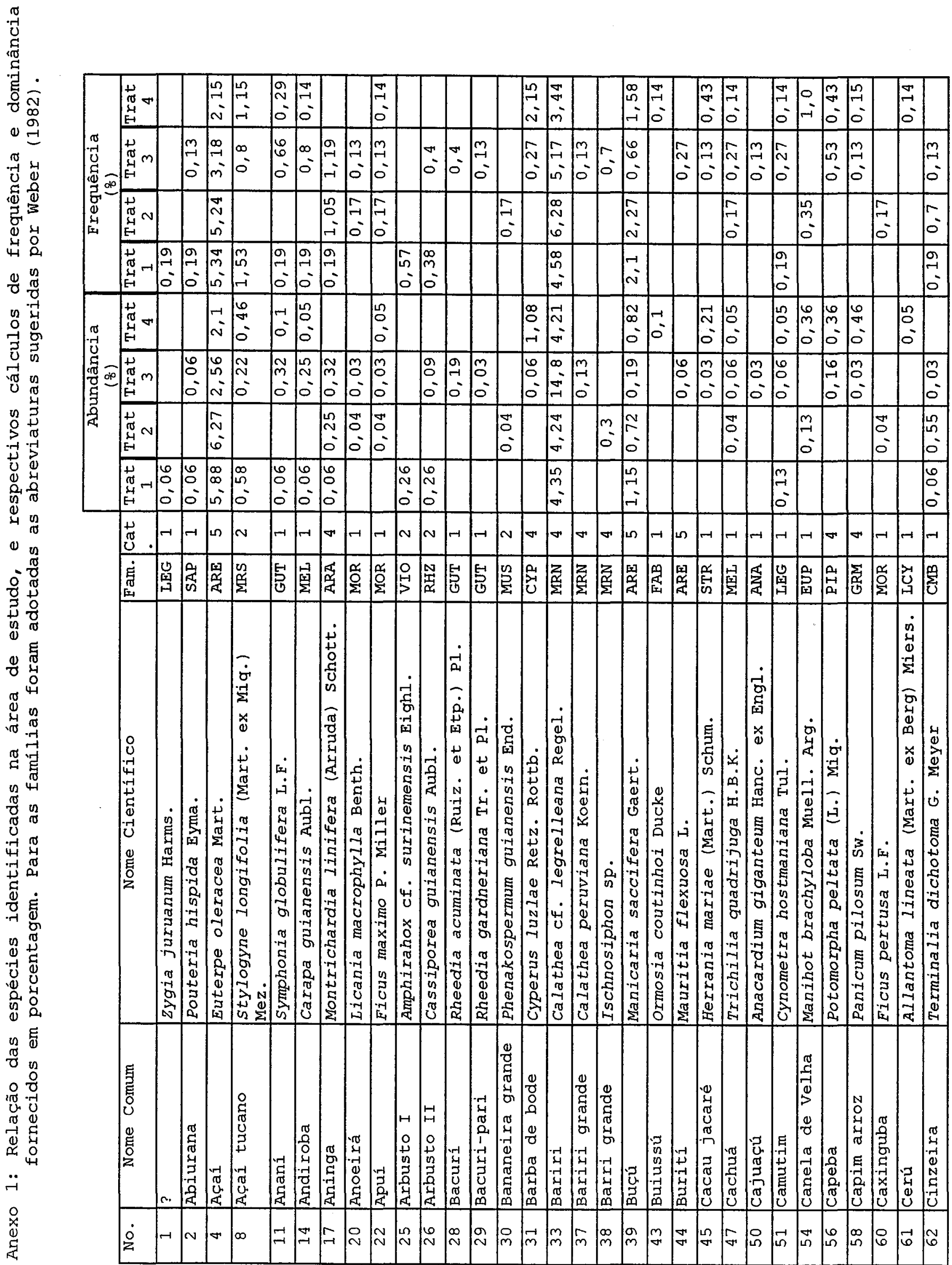




\begin{tabular}{|c|c|c|c|c|c|c|c|c|c|c|c|c|c|c|c|c|c|c|c|c|c|c|c|c|c|c|c|c|c|c|c|}
\hline & 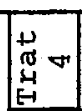 & $\begin{array}{l}a \\
N \\
N\end{array}$ & \begin{tabular}{|l|}
$\infty$ \\
$\infty$ \\
-1
\end{tabular} & & $\begin{array}{l}N \\
-i\end{array}$ & & \begin{tabular}{l|l} 
& -1 \\
- & 0 \\
$\vdots$ & $m$
\end{tabular} & & is & & & & & & \begin{tabular}{|l|} 
\\
0 \\
0 \\
0 \\
0
\end{tabular} & {$\left[\begin{array}{l}n \\
\sim \\
\sim\end{array}\right.$} & & $\mid \begin{array}{c}n \\
-1 \\
m \\
m\end{array}$ & & & & & & & $\left.\begin{array}{l}\infty \\
n \\
n \\
\sim\end{array}\right)$ & $\begin{array}{l}\approx \\
\approx \\
-i\end{array}$ & 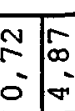 & & $\mid \begin{array}{l}\square \\
-1 \\
0\end{array}$ & & $\begin{array}{l}\nexists \\
-1 \\
0 \\
0\end{array}$ \\
\hline : & 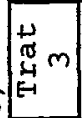 & $\begin{array}{l}0 \\
0 \\
-i\end{array}$ & \begin{tabular}{|l|} 
\\
$\infty$ \\
$-i$ \\
$-i$
\end{tabular} & & $\begin{array}{l}\hat{m} \\
m \\
i\end{array}$ & $\begin{array}{l}m \\
m \\
- \\
0\end{array}$ & \begin{tabular}{l|l}
$m$ & $n$ \\
& 0 \\
0 & \\
0 &
\end{tabular} & & $m_{-i}^{m}$ & \begin{tabular}{|l|} 
\\
$m$ \\
0 \\
0 \\
\end{tabular} & $\begin{array}{l}\pi \\
N \\
0\end{array}$ & $\mid \begin{array}{c}m \\
-1 \\
0\end{array}$ & 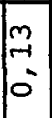 & & $\stackrel{N}{N}$ & $\vec{r}$ & $\stackrel{m}{m}$ & 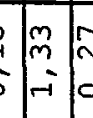 & & $\tilde{N}$ & & $\left|\begin{array}{l}m \\
\rightarrow \\
0\end{array}\right|$ & 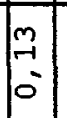 & & $\mid \begin{array}{l}0 \\
0 \\
-1\end{array}$ & $\begin{array}{l}\approx \\
\therefore-\end{array}$ & & \begin{tabular}{l|l}
5 \\
0 \\
0
\end{tabular} & $\because$ & $\begin{array}{l}m \\
n \\
0 \\
0 \\
0\end{array}$ & 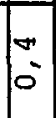 \\
\hline $\mid \begin{array}{l}0 \\
0 \\
4 \\
11\end{array}$ & 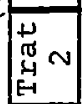 & $\begin{array}{l}a \\
0 \\
m\end{array}$ & $\begin{array}{l}\text { N } \\
\text { n } \\
0 \\
0\end{array}$ & & $\begin{array}{c}n \\
N \\
N\end{array}$ & & $\overrightarrow{7}$ & & in & & & & & $\vec{F}$ & $\left|\begin{array}{c}- \\
\infty \\
0 \\
0\end{array}\right|$ & & & - & & & $\begin{array}{l}f \\
\therefore\end{array}$ & & & \begin{tabular}{|l|l} 
& $N$ \\
\hdashline & 0 \\
0 & 0
\end{tabular} & \begin{tabular}{l|l} 
& $N$ \\
$n$ & 0 \\
0 & 0
\end{tabular} & & & $\begin{array}{ll}n \\
-1 \\
0\end{array}$ & & & $\begin{array}{l}n \\
-1 \\
0\end{array}$ \\
\hline & ${ }_{0}^{+}$ & & & & $\begin{array}{l}n \\
0 \\
m \\
m\end{array}$ & & $\begin{array}{l}\infty \\
\infty \\
n \\
-1\end{array}$ & 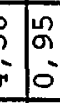 & $\begin{array}{l}\Omega \\
\alpha \\
0 \\
0\end{array}$ & & & & $\begin{array}{l}0 \\
2 \\
0 \\
\end{array}$ & & in & & & \begin{tabular}{c|c}
9 & 0 \\
-1 & 0 \\
0 & 0
\end{tabular} & & & & & & & $\mid \begin{array}{l}m \\
m \\
-i\end{array}$ & \% & 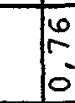 & \begin{tabular}{l|l}
0 & 9 \\
0 & -1 \\
0
\end{tabular} & & & $\begin{array}{l}\infty \\
m \\
0 \\
0\end{array}$ \\
\hline$\widehat{100}$ & 倠 & $\begin{array}{l}1 \\
0 \\
0 \\
0\end{array}$ & $\begin{array}{l}\mathbb{N} \\
0 \\
i \\
N\end{array}$ & & $\begin{array}{l}N \\
2 \\
0\end{array}$ & & \begin{tabular}{l|l}
$n$ & $N$ \\
0 & $N$ \\
0
\end{tabular} & & $\mid$\begin{tabular}{l}
0 \\
\hdashline \\
0
\end{tabular} & & & $\because$ & $\begin{array}{l}n \\
0 \\
0\end{array}$ & & 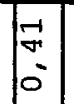 & & tr & $\begin{array}{l}a \\
\sim\end{array}$ & & & & & & & \begin{tabular}{l}
$\infty$ \\
$N$ \\
$-i$ \\
\hdashline
\end{tabular} & \begin{tabular}{l|l} 
\\
0 \\
0
\end{tabular} & \begin{tabular}{l|l}
\multirow{6}{c}{} & \multicolumn{2}{|c}{} \\
$\vdots$ & 0 \\
0 & 0
\end{tabular} & & $\mid \begin{array}{l}n \\
0 \\
0\end{array}$ & & $\begin{array}{l}2 \\
0 \\
0\end{array}$ \\
\hline $\mid \begin{array}{l}0 \\
-1 \\
\mathcal{E}\end{array}$ & 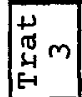 & $\begin{array}{l}\infty \\
m \\
0 \\
0\end{array}$ & \begin{tabular}{|l|} 
\\
$\infty$ \\
0 \\
0
\end{tabular} & \begin{tabular}{|l|} 
\\
$N$ \\
$\vdots$ \\
0
\end{tabular} & & \begin{tabular}{l|}
$\begin{array}{l}m \\
- \\
0\end{array}$ \\
\end{tabular} & 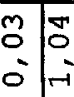 & & $m_{m}^{m}$ & $\begin{array}{l}m \\
0 \\
0 \\
0\end{array}$ & $\begin{array}{l}\vdots \\
\vdots \\
0\end{array}$ & $\begin{array}{l}m \\
0 \\
0\end{array}$ & $\begin{array}{l}3 \\
0 \\
0\end{array}$ & & $\begin{array}{l}0 \\
0 \\
0 \\
0\end{array}$ & ন & $\begin{array}{l}n \\
\\
v\end{array}$ & $\begin{array}{ll}5 \\
0\end{array}$ & & $\mid$ & & $\begin{array}{l}m \\
0 \\
0 \\
0\end{array}$ & $\left|\begin{array}{l}m \\
0 \\
0\end{array}\right|$ & & $\begin{array}{l}\vec{F} \\
\overrightarrow{0} \\
0\end{array}$ & $\begin{array}{l}5 \\
0^{\circ} \\
0^{\circ}\end{array}$ & $\begin{array}{l}-1 \\
0\end{array}$ & \begin{tabular}{l|l}
-1 & $\infty$ \\
0 & 0 \\
0 & 0
\end{tabular} & & $\begin{array}{l}9 \\
-1 \\
0\end{array}$ & $\begin{array}{l}m \\
-1 \\
0 \\
0\end{array}$ \\
\hline 莺 & $\begin{array}{ll} \\
\pi \\
\mathbb{4} \\
\xi-1\end{array}$ & $\mid \begin{array}{l}0 \\
-1 \\
-i\end{array}$ & $\begin{array}{l}A \\
-1 \\
0\end{array}$ & & $\begin{array}{l}-1 \\
\infty \\
0 \\
0\end{array}$ & & बू & & F & & & & & $\begin{array}{l}\infty \\
0 \\
0 \\
0\end{array}$ & $\left|\begin{array}{l}\vec{N} \\
\vdots \\
0\end{array}\right|$ & \begin{tabular}{l|l}
$\nabla$ & $I$ \\
0 & 0 \\
0 & 0
\end{tabular} & & m & & & $\begin{array}{l}\overrightarrow{0} \\
0 \\
0\end{array}$ & & & \begin{tabular}{|c|c}
$\infty$ & $m$ \\
0 & -1 \\
0 & 0 \\
\end{tabular} & \begin{tabular}{c|c}
$n$ & $m$ \\
\hdashline & $m$ \\
$\vdots$ & 0
\end{tabular} & & an & 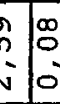 & & & $\begin{array}{l}\$ \\
0 \\
0\end{array}$ \\
\hline & 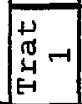 & & & & $\begin{array}{l}\pi \\
-i \\
-i\end{array}$ & & 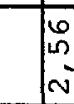 & $\begin{array}{ll}0 \\
\vdots \\
0\end{array}$ & $\begin{array}{l}M \\
m \\
0\end{array}$ & & & $\begin{array}{l}m \\
-1 \\
0\end{array}$ & & & $\begin{array}{l}0 \\
-1 \\
0\end{array}$ & & & $\mid \begin{array}{l}0 \\
0 \\
0 \\
0\end{array}$ & & & & & & & $\begin{array}{l}R \\
0 \\
0\end{array}$ & 告 & $\begin{array}{l}N \\
m \\
0\end{array}$ & \begin{tabular}{l|l}
5 & $m$ \\
$n$ & -1 \\
0 & 0
\end{tabular} & & & $\begin{array}{c}m \\
-1 \\
0 \\
0\end{array}$ \\
\hline
\end{tabular}

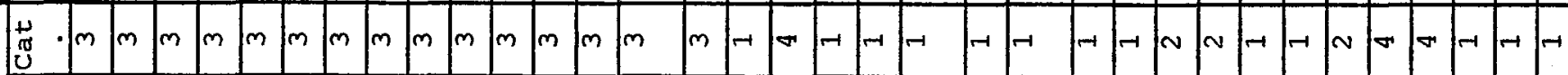
虙

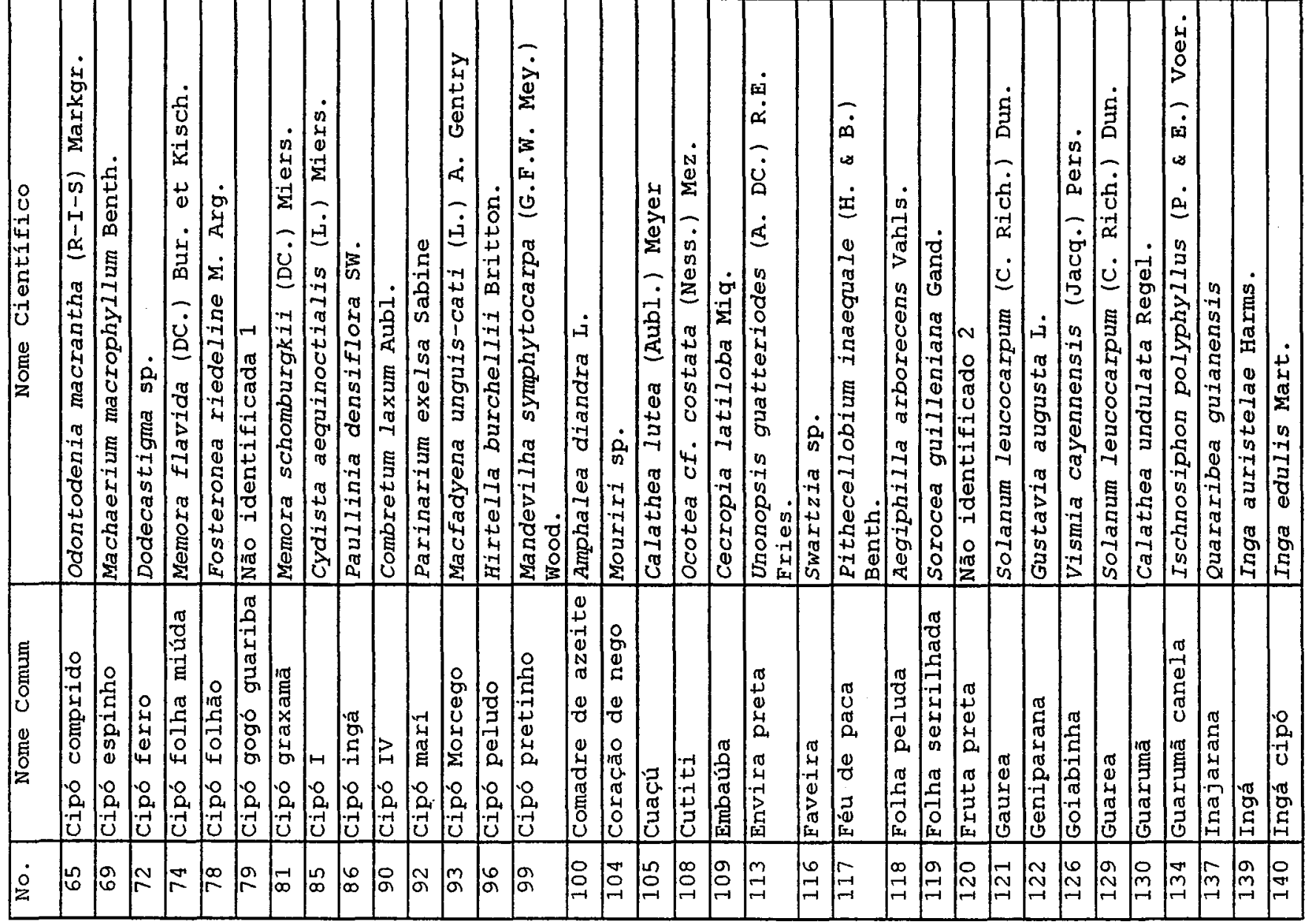




\begin{tabular}{|c|c|c|c|c|c|c|c|c|c|c|c|c|c|c|c|c|c|c|c|c|c|c|c|c|c|c|c|c|c|c|c|c|c|}
\hline \multirow{4}{*}{ 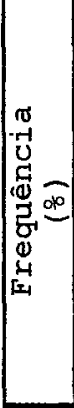 } & 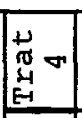 & & & & & 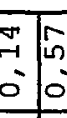 & & & & & {$\left[\begin{array}{l}m \\
\vdots \\
0 \\
0\end{array}\right.$} & 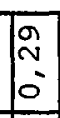 & & & $\sigma^{m}$ & & \begin{tabular}{|l|l} 
\\
$N$ \\
0
\end{tabular} & & & in & $\begin{array}{l}\hat{n} \\
\hat{n}\end{array}$ & & & & $\int_{-i}^{m}$ & & & $\stackrel{n}{n}$ & & & $\begin{array}{ll}5 \\
5 \\
0\end{array}$ & & $\begin{array}{l}N \\
0\end{array}$ \\
\hline & ${ }_{\pi}^{\pi} m$ & $\begin{array}{l}\infty \\
0 \\
0\end{array}$ & & & & \begin{tabular}{l|l}
0 & $\infty$ \\
6 & 0 \\
0 & 0
\end{tabular} & & & & 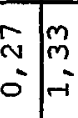 & & & $\begin{array}{l}\tilde{N} \\
\tilde{N} \\
0\end{array}$ & & & & $\left(\begin{array}{l}N \\
0 \\
0\end{array} \mid\right.$ & & & $\begin{array}{lll}m & - \\
-1 & -1 \\
0 & -1\end{array}$ & $\begin{array}{l}=1 \\
\therefore \\
\therefore\end{array}$ & \begin{tabular}{c|c}
0 \\
0 \\
\end{tabular} & $\underbrace{N}_{0}$ & & $\stackrel{m}{\because}$ & 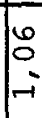 & & $\mid \begin{array}{l}\infty \\
n \\
n \\
m \\
m\end{array}$ & & $\begin{array}{l}m \\
- \\
0\end{array}$ & $\infty$ & & $\mid \begin{array}{l}0 \\
0 \\
-i\end{array}$ \\
\hline & 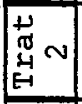 & & & & & & & & $\begin{array}{l}n \\
m \\
0 \\
0\end{array}$ & & & & $\begin{array}{l}5 \\
- \\
0\end{array}$ & & & \begin{tabular}{|l|}
$\infty$ \\
$\infty$ \\
0
\end{tabular} & $\begin{array}{l}F \\
\because \\
0\end{array}$ & & & {$\left[\begin{array}{l}\infty \\
0 \\
0\end{array}\right.$} & $\begin{array}{ll} & 0 \\
0 & 0\end{array}$ & & & & 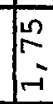 & $\begin{array}{l}N \\
N \\
N\end{array}$ & & $\begin{array}{c}-1 \\
0 \\
0\end{array}$ & & & 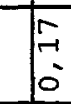 & & $\begin{array}{l}N \\
n \\
0 \\
0\end{array}$ \\
\hline & 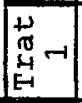 & & & & \begin{tabular}{|l|l} 
& \\
\hdashline & \\
0 & \\
0
\end{tabular} & \begin{tabular}{l|l}
$\qquad$ & 0 \\
-1 & 0 \\
-1
\end{tabular} & & & & 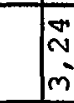 & & & & & & & $\begin{array}{ll}9 \\
-1 \\
0 \\
0\end{array}$ & & \begin{tabular}{|l|}
0 \\
$m$ \\
0 \\
0
\end{tabular} & $\vec{F}$ & $\Xi \sigma_{\infty}^{\infty}$ & & 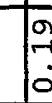 & N & $\mid \begin{array}{l}\infty \\
m \\
0 \\
0\end{array}$ & n & & $\mid \begin{array}{l}9 \\
-1 \\
0 \\
0\end{array}$ & \begin{tabular}{|l|l} 
& 0 \\
-1 & 0 \\
0 & 0
\end{tabular} & $\begin{array}{l}\infty \\
m \\
0 \\
0\end{array}$ & & $\begin{array}{l}9 \\
- \\
0 \\
0\end{array}$ & $\begin{array}{l}5 \\
0 \\
0\end{array}$ \\
\hline \multirow{4}{*}{ 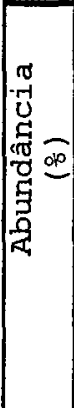 } & 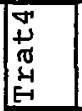 & & & & & \begin{tabular}{l|l} 
& 0 \\
0 & 0 \\
0 & 0
\end{tabular} & & & $\begin{array}{ll} \\
N \\
N \\
\end{array}$ & & $\begin{array}{l}-1 \\
m \\
0\end{array}$ & & & & $\begin{array}{l}n \\
-1 \\
-1 \\
0\end{array}$ & & $\begin{array}{l}-1 \\
0 \\
\end{array}$ & & & $\bar{n}$ & - & & & & {$\left[\begin{array}{l}\infty \\
\infty \\
0\end{array}\right.$} & $F$ & & $\begin{array}{l}\tilde{N} \\
\mathrm{n} \\
\mathrm{n}\end{array}$ & & & \begin{tabular}{l|l}
-1 & $\vec{N}$ \\
0
\end{tabular} & & $\begin{array}{l}0 \\
m \\
0\end{array}$ \\
\hline & $\mathbb{\pi}_{\substack{5 \\
\epsilon}} m$ & \begin{tabular}{|l|l} 
& \\
$\vdots$ & 0 \\
0 &
\end{tabular} & & & & \begin{tabular}{|l|l}
$N$ & $n$ \\
$\vdots$ & 0 \\
0 & 0 \\
\end{tabular} & & & $\begin{array}{l}0 \\
m \\
0 \\
\end{array}$ & \begin{tabular}{|l|l} 
& $n$ \\
$\vdots$ & $m$ \\
0 & 0
\end{tabular} & & & $\begin{array}{l}0 \\
\vdots \\
0\end{array}$ & & & $\begin{array}{l}2 \\
0 \\
0 \\
0\end{array}$ & $\begin{array}{l}\vdots \\
0 \\
0\end{array}$ & & & $\begin{array}{ll}m & 0 \\
0 \\
0\end{array}$ & $\begin{array}{ll}0 \\
0 \\
0\end{array}$ & \begin{tabular}{c|c}
0 & 0 \\
- & 0 \\
-1 & 0
\end{tabular} & & i & m & $T_{\infty}$ & & \begin{tabular}{l}
0 \\
\hdashline \\
$\cdots$
\end{tabular} & & $\begin{array}{l}m \\
0 \\
0 \\
0\end{array}$ & & & 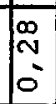 \\
\hline & \begin{tabular}{|l|l|} 
\\
\end{tabular} & & & & & & & & $\begin{array}{l}n \\
-1 \\
0 \\
0\end{array}$ & ${ }_{0}^{\infty}$ & & & $\begin{array}{l}0 \\
0 \\
0\end{array}$ & & & & $\begin{array}{l}\square \\
0 \\
0\end{array}$ & & & is & $\begin{array}{l}0 \\
0\end{array}$ & \begin{tabular}{l|l}
$y$ & 0 \\
$\vdots$ & 0 \\
& 0
\end{tabular} & & & ? & & & $\begin{array}{l}\square \\
0 \\
0 \\
0\end{array}$ & & & F' & & $\stackrel{m}{m}$ \\
\hline & $\underset{\sigma}{\mu}$ & & & & $\begin{array}{lll}0 & 0 \\
0 & 0 \\
0 & 0 \\
0 & 0\end{array}$ & $\hat{1}=5$ & & & & א్ & & & & & & 5 & 10 & & & o & $\frac{i}{n}$ & & 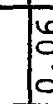 & $\mid \begin{array}{l}\infty \\
\infty \\
0 \\
0\end{array}$ & $\stackrel{m}{m}$ & & & $\mid \begin{array}{l}0 \\
0 \\
0 \\
0\end{array}$ & $\begin{array}{lll} & 0 \\
0 & 0 \\
0 & 0\end{array}$ & $\begin{array}{l}m \\
m \\
0\end{array}$ & & $\begin{array}{l}0 \\
0 \\
0\end{array}$ & $\begin{array}{l}0 \\
0 \\
0\end{array}$ \\
\hline
\end{tabular}

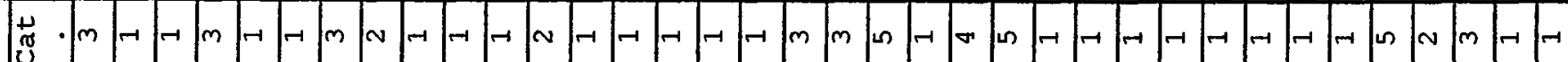
焉

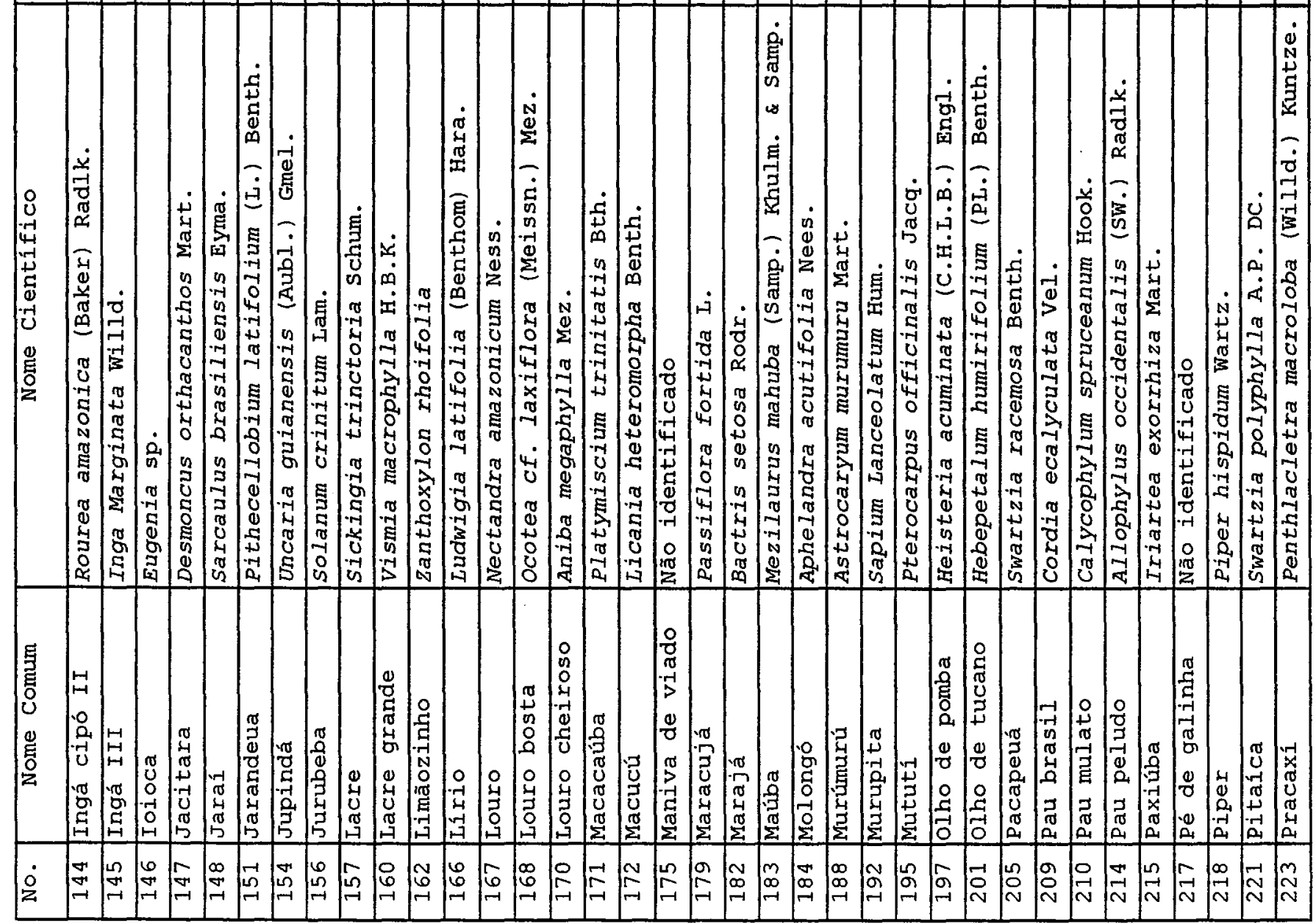




\begin{tabular}{|c|c|c|c|c|c|c|c|c|c|c|c|c|c|c|c|c|c|c|c|c|c|c|c|c|c|c|}
\hline \multirow{4}{*}{ 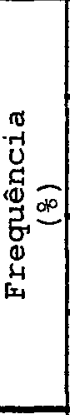 } & $\nabla$ & $\begin{array}{l}\infty \\
n \\
m \\
m\end{array}$ & $\begin{array}{l}T \\
-1 \\
0 \\
0\end{array}$ & $\left|\begin{array}{l}-1 \\
0 \\
m\end{array}\right|$ & $\left.\begin{array}{c}0 \\
N \\
-i\end{array}\right]$ & & & in & & $\begin{array}{l}1 \\
-1 \\
0 \\
0\end{array}$ & & $\begin{array}{l}\mp \\
\because \\
0 \\
0\end{array}$ & & & & & & & & & $\begin{array}{l}N \\
- \\
m\end{array}$ & & & \begin{tabular}{l|l}
3 & \\
5 \\
5 \\
0
\end{tabular} & & $\begin{array}{l}\text { I } \\
\vdots \\
i\end{array}$ \\
\hline & 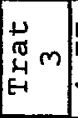 & $\begin{array}{l}N \\
+\end{array}$ & $\stackrel{\Sigma}{N}$ & 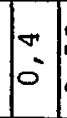 & $\left|\begin{array}{l}m \\
n \\
0 \\
0\end{array}\right|$ & & $\stackrel{m}{\rightarrow}$ & ${ }^{m}$ & $\begin{array}{l}0 \\
0 \\
0 \\
0 \\
0\end{array}$ & 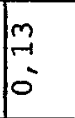 & & $\mid \begin{array}{l}n \\
N \\
0 \\
0\end{array}$ & & & \begin{tabular}{l|l}
$m$ & 0 \\
$n$ & 0 \\
$-i$ & 0
\end{tabular} & & $\vec{r}$ & $\stackrel{m}{m}$ & $\begin{array}{l}0 \\
n \\
-i\end{array}$ & $\begin{array}{l}\sim \\
-1 \\
\sim \\
N\end{array}$ & $\begin{array}{ccc}r & : \\
i & 0 & 0\end{array}$ & $\begin{array}{l}\hat{N} \\
0\end{array}$ & & $\begin{array}{l}0 \\
\infty \\
-i \\
-i\end{array}$ & & 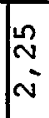 \\
\hline & 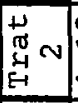 & $\begin{array}{ll} \\
\because \\
\therefore\end{array}$ & & $\begin{array}{l}n \\
m \\
0 \\
0\end{array}$ & $\begin{array}{l}N \\
\alpha \\
-i\end{array}$ & \begin{tabular}{|l|} 
\\
$\infty$ \\
0 \\
0 \\
\end{tabular} & $\begin{array}{l}1 \\
\infty \\
0 \\
0 \\
0\end{array}$ & $\begin{array}{l}1 \\
\infty \\
0 \\
0\end{array}$ & $\begin{array}{ll}m \\
m \\
0 \\
0\end{array}$ & & & & $\begin{array}{l}-1 \\
-1 \\
-1\end{array}$ & & & & \begin{tabular}{l|}
0 \\
0 \\
5
\end{tabular} & $\vec{S}$ & $\begin{array}{l}\hat{\alpha} \\
\hat{n} \\
\end{array}$ & $\begin{array}{l}n \\
m \\
0 \\
0\end{array}$ & & & & $\underset{-i}{N}$ & & In \\
\hline & 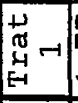 & & & \begin{tabular}{|l|}
0 \\
$m$ \\
0 \\
0
\end{tabular} & $\begin{array}{l}m \\
m \\
-i\end{array}$ & $\begin{array}{l}0 \\
-1 \\
0 \\
\end{array}$ & $\begin{array}{l}0 \\
0 \\
0 \\
0\end{array}$ & & & & & & & & & & & 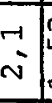 & 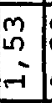 & $\infty$ & & & & $\begin{array}{l}n \\
i n \\
0 \\
0\end{array}$ & & \\
\hline & 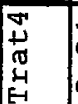 & \begin{tabular}{|l|}
$m$ \\
$m$ \\
$m$ \\
$m$
\end{tabular} & $\begin{array}{l}n \\
0 \\
0 \\
0\end{array}$ & $\mid \begin{array}{l}\approx \\
0 \\
-1\end{array}$ & & & & In & $\begin{array}{l}0 \\
0 \\
0 \\
0\end{array}$ & $\begin{array}{l}2 \\
0 \\
0\end{array}$ & & \begin{tabular}{|l|}
2 \\
0 \\
0
\end{tabular} & \begin{tabular}{l|} 
\\
$\square$ \\
$-i$ \\
\end{tabular} & \begin{tabular}{|l}
- \\
$N$ \\
$N$ \\
$N$
\end{tabular} & & & $\begin{array}{l}m \\
0 \\
-i\end{array}$ & $\begin{array}{l}\because \\
0\end{array}$ & \begin{tabular}{l|}
-1 \\
$m$ \\
0 \\
0
\end{tabular} & & \begin{tabular}{|c|}
$\vec{m}$ \\
$\dot{w}$ \\
$\bar{v}$
\end{tabular} & & & $\begin{array}{lll} & 0 \\
0 & 0 \\
\vdots & 0\end{array}$ & & $\left.\right|_{0} ^{m}$ \\
\hline & 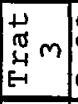 & \begin{tabular}{|l|} 
\\
$N$ \\
$m$
\end{tabular} & $\begin{array}{l}0 \\
\vdots \\
0\end{array}$ & $\begin{array}{l}m \\
\because \\
0\end{array}$ & \begin{tabular}{|c|} 
\\
-1 \\
0 \\
0
\end{tabular} & & & $\begin{array}{l}3 \\
0 \\
0\end{array}$ & $\begin{array}{l}N \\
N \\
0 \\
0\end{array}$ & $\begin{array}{l}3 \\
0 \\
0\end{array}$ & & $\begin{array}{l}1 \\
0 \\
0\end{array}$ & \begin{tabular}{|c|} 
\\
$\infty$ \\
$N$ \\
\end{tabular} & \begin{tabular}{|l|}
0 \\
0 \\
0
\end{tabular} & \begin{tabular}{|l|l}
$\begin{array}{l}n \\
m \\
0 \\
0\end{array}$ & \\
\end{tabular} & & \begin{tabular}{l|}
0 \\
0 \\
0 \\
$-i$
\end{tabular} & \begin{tabular}{l|}
0 \\
$\infty$ \\
0 \\
0
\end{tabular} & \begin{tabular}{|l|} 
\\
0 \\
0 \\
0 \\
\end{tabular} & & \begin{tabular}{ll}
\multirow{2}{*}{} \\
$\vdots$ \\
0
\end{tabular} & $\begin{array}{l}0 \\
\vdots \\
0 \\
0\end{array}$ & & $\begin{array}{l}\infty \\
-i\end{array}$ & & 綮 \\
\hline & $\begin{array}{l} \\
\substack{\pi \\
4} \\
-1\end{array}$ & & & $\begin{array}{l}\infty \\
0 \\
0 \\
0\end{array}$ & $\begin{array}{l}f \\
0 \\
0\end{array}$ & $\begin{array}{l}\stackrel{-}{N} \\
\vdots \\
0\end{array}$ & & & $\begin{array}{l}\vec{n} \\
\mathbf{N} \\
0 \\
0\end{array}$ & $\begin{array}{l}\sigma^{\prime} \\
0 \\
0\end{array}$ & & & $\begin{array}{l}\Omega \\
N \\
i\end{array}$ & $\overrightarrow{|r|}$ & & & $\begin{array}{c}-1 \\
m \\
m\end{array}$ & \begin{tabular}{l}
\multirow{N}{N}{} \\
$m$
\end{tabular} & \begin{tabular}{l|}
$m$ \\
$\vdots$ \\
0 \\
0
\end{tabular} & $\begin{array}{l}\infty \\
0 \\
0 \\
0\end{array}$ & $\begin{array}{l}1 \\
F \\
0\end{array}$ & & & 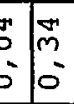 & & 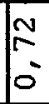 \\
\hline & 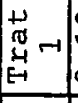 & & & $\left|\begin{array}{l}m \\
\because \\
0\end{array}\right|$ & $\mid \begin{array}{l}n \\
\forall \\
0\end{array}$ & $\begin{array}{l}0 \\
0 \\
0 \\
\end{array}$ & 0 & $\because$ & & & & & & \begin{tabular}{|l|}
$\overrightarrow{1}$ \\
0
\end{tabular} & & & $\vec{n}$ & $\begin{array}{l}0 \\
0 \\
-i \\
-i\end{array}$ & \begin{tabular}{l|}
$m$ \\
$\infty$ \\
0 \\
0 \\
0
\end{tabular} & $\begin{array}{l}m \\
\because \\
0\end{array}$ & & & & $\begin{array}{l}0 \\
N \\
0 \\
0\end{array}$ & & 6 \\
\hline & 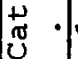 & -1 & $\sigma$ & $\sigma$ & $\nabla$ & $\sigma$ & $r$ & -1 & $m$ & -1 & $N$ & $\rightarrow$ & 6 & 6 & $\nabla$ & + & $\sigma$ & 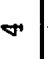 & $\nabla$ & -1 & $\sigma$ & $\nabla$ & & n & מ' & -1 \\
\hline & 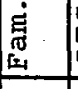 & \begin{tabular}{|l|}
0 \\
9 \\
$⿱ ㇒ 日$ \\
\end{tabular} & 含 & 品 & 落 & 号 & 悬 & 鲌 & 屬 & 面 & $\begin{array}{l}3 \\
0 \\
0\end{array}$ & \begin{tabular}{|l|} 
\\
0 \\
0
\end{tabular} & 罳 & 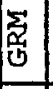 & $\left.\begin{array}{l}z \\
⿱ \\
⿱ \\
N\end{array}\right)$ & 龺 & 參 & 虹 & 起 & 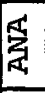 & Uि & 颔 & & 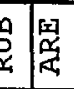 & & rat \\
\hline & 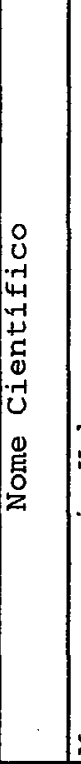 & $\begin{array}{l}0 \\
3 \\
4 \\
0 \\
0 \\
0 \\
0 \\
0 \\
\pi \\
4 \\
0 \\
0 \\
\pi \\
0 \\
0 \\
0 \\
2\end{array}$ & 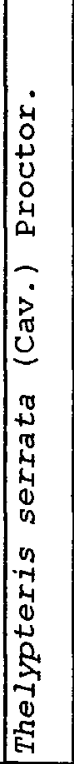 & 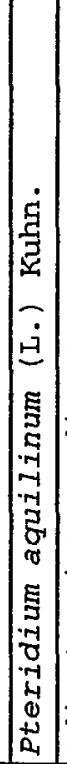 & 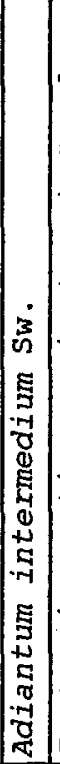 & 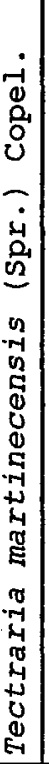 & 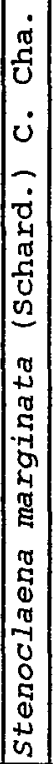 & 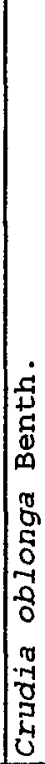 & 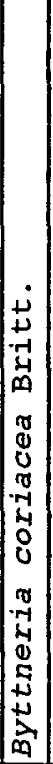 & 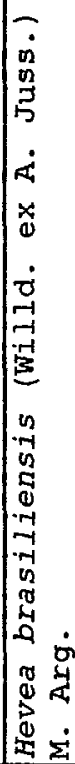 & 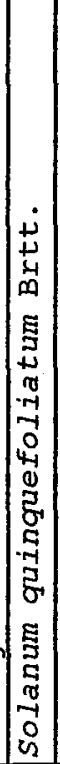 & 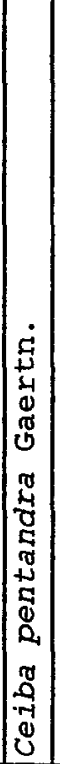 & 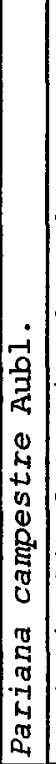 & 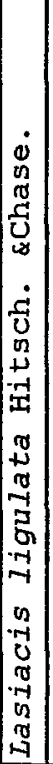 & 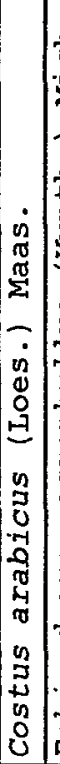 & 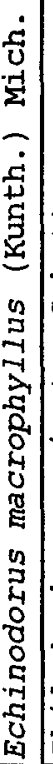 & 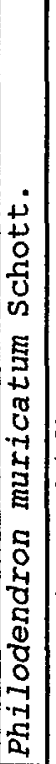 & 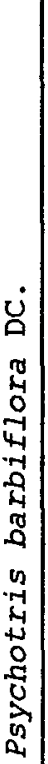 & 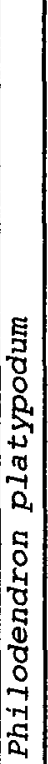 & 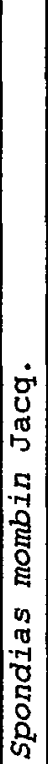 & 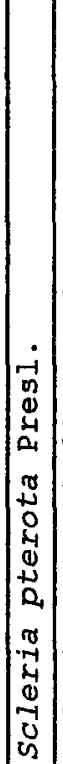 & 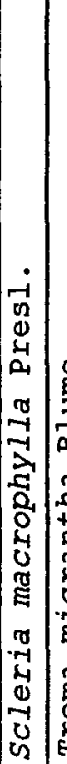 & 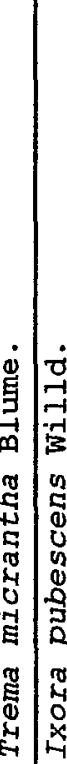 & 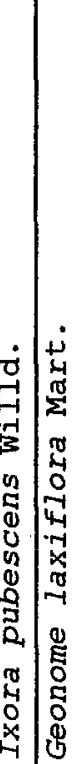 & & 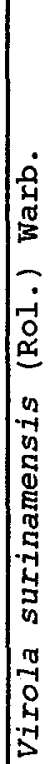 \\
\hline & $\begin{array}{l}0 \\
0 \\
0 \\
\\
\\
z\end{array}$ & $\left.\mid \begin{array}{l}\pi \\
0 \\
0 \\
\vdots \\
0 \\
0 \\
0 \\
0 \\
\alpha\end{array}\right]$ & 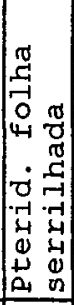 & 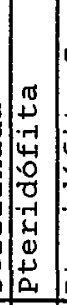 & $\mid \begin{array}{l}1-1 \\
0 \\
0 \\
-1 \\
-4 \\
0 \\
0 \\
-4 \\
4 \\
0 \\
0 \\
0 \\
0\end{array}$ & 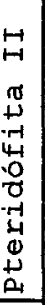 & 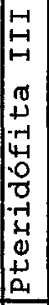 & 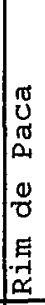 & 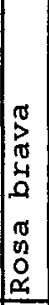 & 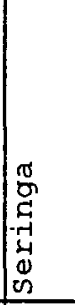 & 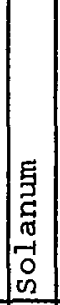 & 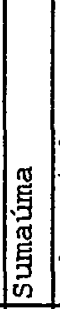 & 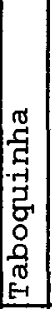 & 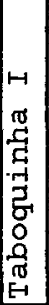 & 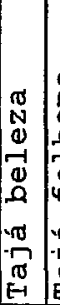 & & 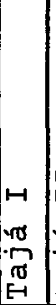 & 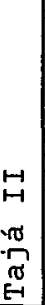 & 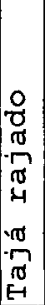 & 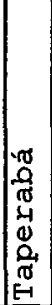 & $\mid \begin{array}{c}0 \\
0 \\
-4 \\
-4 \\
-4 \\
-4 \\
-4 \\
\forall-1\end{array}$ & 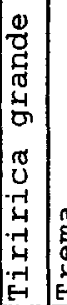 & & 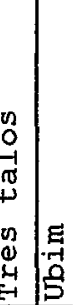 & 岱 & $\mid \begin{array}{l}\pi \\
-1 \\
0 \\
4 \\
-5 \\
-5\end{array}$ \\
\hline & r & $\stackrel{N}{N}$ & $\vec{N}$ & $m_{N}^{\infty}$ & $\stackrel{\sim}{m}$ & & & & & m & & No & & & & & & & & & $\begin{array}{l}\infty \\
\infty \\
\infty \\
N\end{array}$ & & & \begin{tabular}{l|l}
$\sigma$ & $\infty$ \\
$N$ & $\infty$ \\
$N$
\end{tabular} & 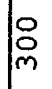 & m \\
\hline
\end{tabular}




\section{Capítulo IV}

\section{Impacto de diferentes intensidades de exploração numa floresta de várzea do estuário amazônico}

1. Introdução

1.2. O problema do manejo em florestas tropicais

- manejo de florestas tropicais pode ser definido como o manejo da floresta natural para a obtenção de produtos florestais, principalmente madeira (Baur, 1968; Lehmann, 1991). O termo floresta natural pode ser definido incluindo-se florestas altamente conservadas, florestas secundárias e fragmentos florestais (Goodland et al., 1991).

o manejo de florestas tropicais pode ter a forma de uma variedade de sistemas silviculturais. Estes envolvem o manejo em áreas remanescentes de florestas, ou em áreas de florestas bem conservadas (Evans, 1982; Hutchinson, 1987).

outras formas envolvem técnicas através das quais faixas inteiras de floresta são extraídas, deixando clareiras abertas na floresta, ou utilizam uma determinada área onde são exploradas seletivamente poucas espécies. Há ainda métodos que integram plantios de enriquecimento dentro do seu regime de manejo, enquanto outros implementam tratamentos silviculturais que auxiliam na regeneração natural de espécies desejadas (De Graaf, 1986; Hartshorn, 1987; Jonkers, 1987).

A forma tradicional de exploração de florestas tropicais implica que a floresta não é manejada sob bases sustentáveis, mas pelo contrário, é utilizada para maximizar um volume de madeira de alto valor num primeiro corte (Synnot, 1992; Verríssimo et al., 1995). Isto não significa que sucessivos cortes não podem ser feitos na mesma floresta no futuro, através da regeneração natural, possibilitando assim uma nova exploração no local previamente explorado. Entretanto, a composição das espécies e suas respectivas densidades são inevitavelmente alteradas, e este fato afeta sem dúvida o valor do segundo corte (Vanclay, 1992; 
Peters, 1989). A aplicação de tratamentos silviculturais não se justifica unicamente com base na resposta a curto prazo dos incrementos diamétricos. Mas também, o tratamento deve aumentar a rentabilidade do manejo através da produção mais rápida de madeira comercializável. Sendo assim, o tratamento silvicultural deve ser parte integral do manejo (Quirós \& Finegan, 1994).

\subsection{Hipóteses e predições}

- impacto provocado pela exploração intensiva de florestas tropicais pode provocar uma escala crescente de danos à medida que a retirada de árvores se intensifica (Johns, 1988). O dano causado através da queda das árvores selecionadas para a exploração, quando muito intenso, provoca a diminuição do número de espécies, e pode causar uma redução do incremento em volume e comprometer a qualidade da madeira da árvores remanescentes, prejudicando a continuidade de programas de manejo (Uhl \& Vieira, 1989; Kasenene \& Murphy, 1991; Wilcox, 1995). Serão consideradas as seguintes predições neste estudo:

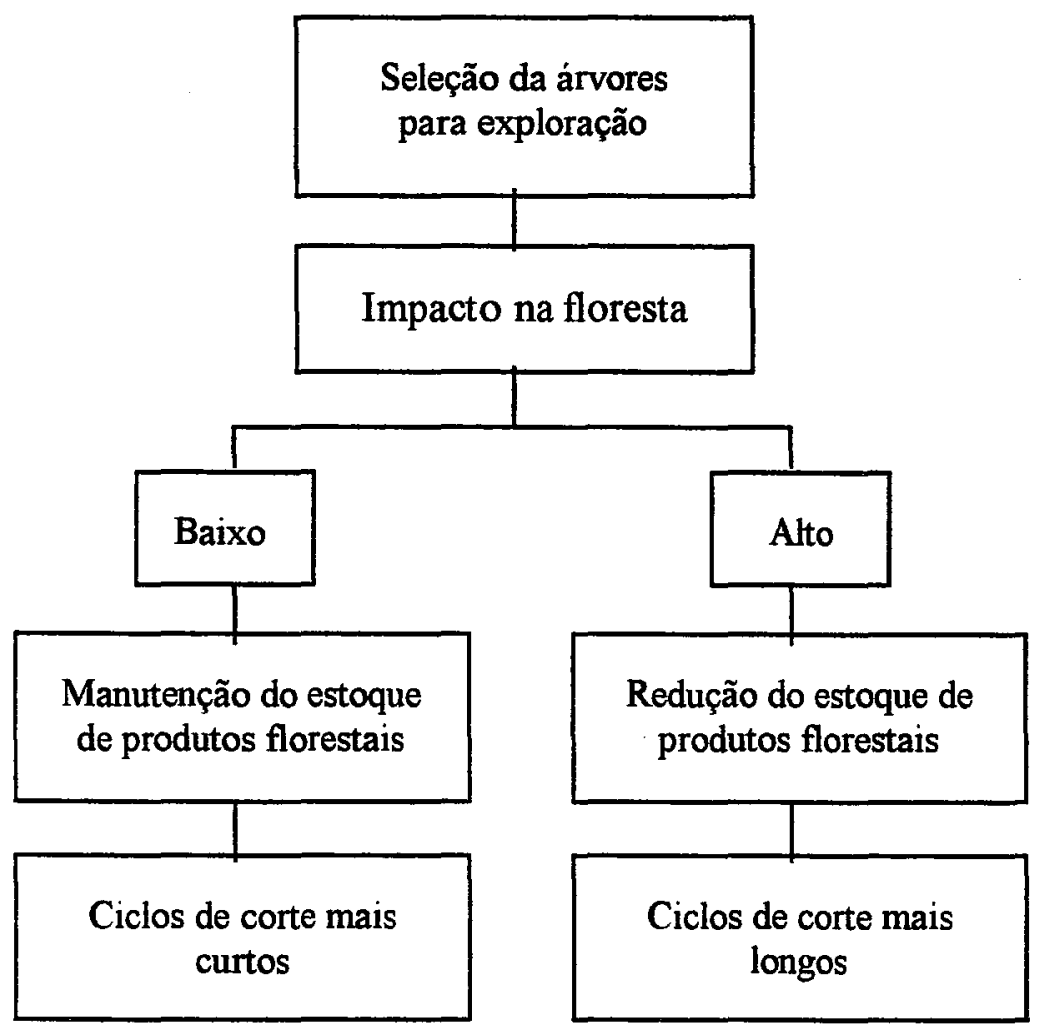




\subsection{Objetivos}

I. Procurar identificar as espécies arbóreas componentes da floresta de várzea em estudo, para caracterizar várias intensidades de exploração através do número de indivíduos, área basal e volume antes e depois da exploração.

II. Procurar obter dados referentes ao impacto causado pela exploração realizando um mapeamento das árvores que sofreram algum tipo de dano, como a ocorrência de árvores quebradas e tombadas e árvores mortas. Este cenário também será mostrado através da confecção de perfis idealizados da vegetação remanescente em cada tratamento.

III. Calcular indices de diversidade florística para verificar se a ocorrência de espécies após uma exploração foi afetada.

IV. Obter os custos de todas as fases envolvendo a exploração e observada a sua variação a medida que aumentou a intensidade de retirada das árvores. Será observado também qual o principal centro de custo de todas as operações.

2. Material e métodos

2.1. O local de estudo.

Vide descrição na seção 2 (pág. 3) e Figura 1 (pág. 4) do Capitulo I e Figura 4 do Capítulo II (pág. 29).

\subsection{Amostragem}

2.2.1. Tamanho e forma da amostragem

Foram utilizadas parcelas quadradas de 70 x 70 metros $(0,49 \mathrm{ha})$. Os critérios utilizados para o ajuste do tamanho das parcelas em campo obedeceram a seguinte ordem de prioridade:

(i) Área útil do experimento: as florestas de várzea do estuário amazônico são tipicamante recortadas por pequenos igarapés, que juntos formam uma extensa malha ao longo da floresta. Em função desta característica, as parcelas foram instaladas ao acaso (Figura II-4.2). A utilização de uma 
extensa área sem a ocorrência de igarapés foi inviabilizada, pois acarretaria uma grande perda de área experimental e comprometeria as análises estatisticas.

(ii) Eficiência dos tratamentos em relação aos fatores a serem estudados: Este trabalho visa $\circ$ acompanhamento de um experimento de manejo buscando obter dados de produtividade (o que viabiliza o uso de parcelas quadradas), e ao mesmo tempo acompanhar o efeito de cada intensidade de exploração ao longo do tempo. Portanto, as parcelas foram de caráter permanente e de forma quadrada.

(iii) operacionalidade do trabalho: A distância entre as parcelas foi entre $100-1000 \mathrm{~m}$, para criar uma borda minima de $100 \mathrm{~m}$ entre as parcelas, evitar a perda de tempo com 0 deslocamento de pessoal e equipamentos, e para facilitar a retirada de madeira.

parcelas

2.2.2. Relação entre o número de espécies e o número de

Inventários florestais feitos em florestas de várzea são limitados, quando comparados com estudos deste tipo em áreas de terra firme (Pires, 1973). Sendo assim, é importante caracterizar bem a parte amostral, em virtude da pouca quantidade de trabalhos disponiveis para comparação. Para a análise de suficiência da amostragem neste trabalho, foi utilizada a metodologia da curva espécie/área (Finol, 1971; Oosting, 1951) como também o cálculo da intensidade de amostragem ${ }^{1}$ (Péllico Neto, 1982).

$\overline{1}$ A intensidade de amostragem é obtida pela fórmula:

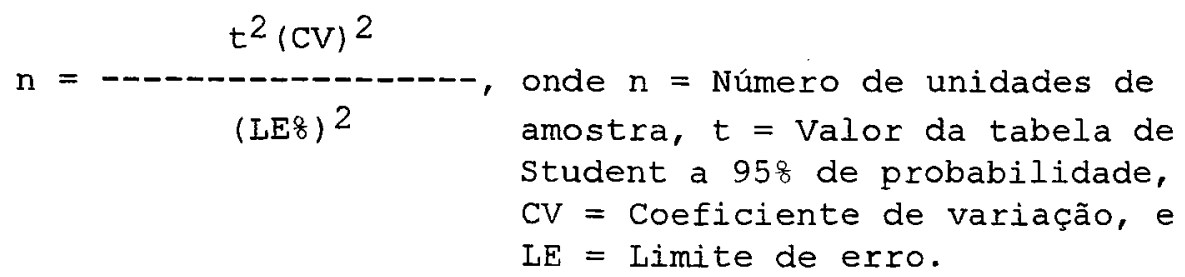


2.3. Inventário: coleta e identificação das espécies

A área total de cada parcela (0.49 ha) foi inventariada levando-se em consideração todos os indivíduos com DAP $\geq 10 \mathrm{~cm}$. Foram medidos o diâmetro e altura total de todas as árvores e altura comercial das árvores $\geq 40 \mathrm{~cm}$ de DAP. Nas árvores com sapopema, o diâmetro foi retirado logo acima da mesma (entre 2.5 a $3.5 \mathrm{~m}$ de altura). Cada árvore foi identificada, plaqueada e mapeada, para ajudar no planejamento de execução dos trabalhos de abertura da floresta, bem como para mapear os danos oriundos da exploração dentro das parcelas. Todo o material botânico foi coletado e identificado por técnicos do Departamento de Botânica do Museu Paraense Emílio Goeldi, em Belém, PA.

\subsection{Tratos silviculturais}

2.4.1. Seleção e marcação das árvores

Esta operação necessitou de alguns critérios, priorizandose os indivíduos à permanecer, principalmente os que estavam na sua fase pré-reprodutiva. Árvores jovens das espécies selecionadas foram conservadas na faixa entre 5 a $20 \mathrm{~cm}$ de DAP. Árvores porta-sementes ficaram distribuidas a uma distância razoável para garantir a dispersão de sementes (Viana, 1990). obedeceu-se tais critérios para estabelecer este primeiro tratamento silvicultural, ou primeiro refinamento, iniciando-se desta maneira um sistema policíclico de cortes ao longo dos anos, também conhecido como corte seletivo com limites de diâmetros (Bushbacher, 1990) ${ }^{2}$.

\subsubsection{Espécies selecionadas}

- sistema de manejo florestal baseado na regeneração natural deve ser relacionado com três variáveis ecológicas

2 Estima-se que este ciclo de corte poderá acompanhar futuros desbastes seletivos do plantio com virola. A prescrição destes cortes não será objetivo deste trabalho, mas poderá servir de base para 0 prosseguimento do futuro acompanhamento do mesmo. 
básicas: a) potencial para regeneração (determinado pela abundância de sementes e mudas); b) potencial para crescimento (determinado pelo aumento de luz e nutrientes); e c) potencial econômico (determinado pelo valor dos produtos produzidos como madeira para serraria, lenha, carvão e produtos não-madeireiros (Peters, 1994). Quando se refere à viabilidade de sementes, estas variam no tempo (dependentes da fenologia das espécies, potencial de germinação e predação), e no espaço (dependendo da quantidade e distribuição de matrizes, distância e forma da curva de dispersão, e sobrevivência das sementes em função da distância de dispersão) (Viana, 1990). A Tabela 1 mostra a relação das espécies de interesse econômico em florestas de várzea, que foram priorizadas nos critérios citados anteriormente.

Tabela 1: Relação das espécies selecionadas para o monitoramento da regeneração natural (Fonte: Rombold, $1991^{3}$, dados não publicados).

\begin{tabular}{|c|c|c|}
\hline Nome comum & $\begin{array}{c}\text { Fenologia } \\
\text { Floração - Frutificação }\end{array}$ & Uso local \\
\hline Andiroba & jul/ago - dez/mar & madeira, óleo \\
\hline Seringa & jul/ago - dez/fev & látex \\
\hline Açaí & $\mathrm{abr} / \mathrm{set}-\mathrm{out} / \mathrm{jan}$ & palmito, vinho \\
\hline Breu & nov/jan - mar/mai & madeira, resina \\
\hline Assacú & set/abr - dez/mai & madeira \\
\hline Sumaúma & jul/ago - ago/set & madeira \\
\hline Taperebá & ago/out - jan/mai & fruto comestível \\
\hline Mututi & dez/jan - fev/abr & lenha \\
\hline Ananí & $\operatorname{mar} / a b r-j u n-n o v$ & madeira, látex \\
\hline Ventosa & jan/mar - mai/jun & madeira \\
\hline Pau Mulato & jun/jul - out/nov & madeira \\
\hline
\end{tabular}

A escolha das demais espécies para a seleção e refinamento foi baseada em: i) disponibilidade de sementes na época do trabalho, ii) importância econômica regional, iii) índice de valor de importância de cada espécie, iv) taxa de crescimento, e v) práticas locais.

3 Dados obtidos do projeto "Programa Estuário"/Depto. de Botânica, Museu Goeldi, Belém, PA. 


\subsubsection{Exploração}

A prática de exploração em florestas de várzea não permite - uso de maquinaria pesada principalmente nas operações de arraste e transporte (Macedo \& Anderson, 1993). O processo é quase todo manual, utilizando-se apenas de um machado, sendo que em alguns casos, os madeireiros extrativistas utilizam uma motosserra apenas para as operações de derrubada e traçamento para a obtenção de toras (Silva, 1989; Mousasticoshvily Jr., 1992; Barros, 1995).

As árvores selecionadas foram derrubadas utilizando-se uma equipe de 5 homens: 1 engenheiro, 1 motosserista, 2 auxiliares com machado e 1 ajudante. Após a decisão do direcionamento da queda, cada árvore foi derrubada, medida a sua altura total, altura comercial, e diâmetro da copa. Logo em seguida foi cubada rigorosamente utilizando-se o método de smalian (Husch et al., 1972). Na ficha de campo também foi anotada a espécie, - número de toras e os indivíduos que sofreram algum tipo de dano com a sua queda dentro da parcela.

\subsubsection{Tratamentos}

Foram instalados 3 tratamentos com diferentes níveis de exploração.

Tratamento 1 (T1): Foram instaladas 4 parcelas de 0,49 ha na floresta original, sem nenhuma intervenção (testemunha).

Tratamentos 2 (T2), 3 (T3) e 4 (T4): Foram instaladas 4 parcelas de 0,49 ha na floresta original e logo após foi efetuado um corte de liberação, retirando aproximadamente 25 \& (T2), 50\% (T3) e 75\% (T4) da área basal das espécies préselecionadas existentes nas parcelas. Não foi efetuado um tratamento de corte raso, pois é um tipo de intervenção muito drástica, e não está de acordo com a legislação florestal em vigor. 


\subsection{Estrutura da floresta}

2.5.1. Composição florística

Para a avaliação da estrutura horizontal foram calculados os valores absolutos e relativos para abundância, dominância, frequência, indice de valor de importância e distribuição diamétrica de toda a comunidade inventariada (Jardim, 1984; Hosokawa, 1986).

\subsubsection{Indices de diversidade}

Foram selecionados para o cálculo da diversidade o indice de riqueza de Margalef, o indice de heterogeneidade de Shannon. Foi também calculado o índice de similaridade florística de Jacquard. Vide seção 2.5, Capítulo III (pág. 51).

o uso de indices de diversidade neste estudo tem como objetivo principal a avaliação do efeito dos tratamentos em relação ao número de espécies, bem como selecionar qual dos indices é mais eficiente.

\subsubsection{Perfis idealizados}

Para cada tratamento, foi selecionada uma parcela para a confecção de perfil e projeção das copas das árvores acima de 10 $\mathrm{cm}$ de DAP. Foi utilizada uma faixa de 70 x 10 metros, seguindo a metodologia de oosting (1951) e Hallé et al. (1978).

\subsection{Avaliação econômica}

Em todas as fases do estudo foram feitas observações com relação a mão-de-obra, pessoal e infra-estrutura utilizada. Foram tomados os custos das seguintes operações: (i) seleção e marcação das parcelas, (ii) levantamento topográfico, (iii) inventário, (iv) seleção das árvores para exploração, (v) exploração (derrubada, traçamento, e cubagem), (vi) limpeza, (vii) plantio e replantio, e (viii) conservação nos dois anos de acompanhamento 
das parcelas. Todos estes custos são fornecidos por tratamento e por hectare.

3. Resultados e discussão

\subsection{Inventário}

\subsubsection{Amostragem}

Para avaliar a suficiência de amostragem, foram utilizados dois procedimentos. Primeiro, o cálculo da intensidade amostral (n), utilizando-se os valores de área basal das 16 amostras inventariadas. Foram considerados um limite de erro de $10 \%$ e probabilidade de 958 ( $t$ tabelado $=2,131$ ). Obteve-se urn valor calculado de 4,37 amostras $(2,14 \mathrm{ha})$, que seriam necessárias para quantificar os valores de área basal neste tipo de floresta, e que corresponde a 27,3 웅 do total da área amostrada $(7,84$ ha). 0 coeficiente de variação observado foi de 9,88 (Tabela 2).

Segundo, com relação a ocorrência de espécies a partir de 10 cm de DAP, foram obtidas curvas espécie/área, levando-se em consideração um incremento de subparcelas de $100 \mathrm{~m}^{2}$ em função da área de cada parcela amostrada. A Tabela 3 mostra os valores mínimos encontrados para cada parcela. Houve uma estabilização do aparecimento de novas espécies entre 34 (mínimo, parcela 5) e 46 sub-parcelas de $100 \mathrm{~m}^{2}$ (máximo, parcela 13). Considerando-se a área amostrada como um todo $(7,84 \mathrm{ha})$, a incidência de novas espécies foi diminuindo até estabilizar a uma área amostrada de 6,37 ha, ou seja, 81,3\% da área total, o que corresponde a um número de 13 parcelas onde apareceram 80 espécies. Com o aumento de uma área de 1,47 ha, apenas duas novas espécies apareceram (Figura 1). 
Tabela 2: Relação da área basal ( $\mathrm{m}^{2} /$ parcelas de 0.49 ha) e resultados do número suficiente de parcelas.

\begin{tabular}{|c|c|c|}
\hline Parcela & A. Basal $\left(\mathrm{m}^{2} / 0.49 \mathrm{ha}\right)$ & Resultados \\
\hline 1 & 13.584 & \multirow{16}{*}{$\begin{array}{l}\text { média: } 12.87 \\
s: 1.26 \\
s^{2}: 1.60 \\
C V \frac{o}{8}: 9.82 \\
t\left(95 \frac{\circ}{0}, 15 \mathrm{~g} .1 .:\right. \\
2.131 \\
\mathrm{LE}: 10 \frac{}{8} \\
\mathrm{n}_{\text {calc }}: 4.37\end{array}$} \\
\hline 2 & 14.747 & \\
\hline 3 & 13.683 & \\
\hline 4 & 13.430 & \\
\hline 5 & 12.901 & \\
\hline 6 & 13.569 & \\
\hline 7 & 11.648 & \\
\hline 8 & 12.534 & \\
\hline 9 & 15.505 & \\
\hline 10 & 11.994 & \\
\hline 11 & 12.573 & \\
\hline 12 & 10.555 & \\
\hline 13 & 13.595 & \\
\hline 14 & 11.597 & \\
\hline 15 & 11.974 & \\
\hline 16 & 12.024 & \\
\hline
\end{tabular}

Tabela 3: Valores mínimos para amostragem em cada parcela de 0.49 ha, levando-se em consideração o aumento da área a cada $100 \mathrm{~m}^{2}$ (subparcelas de $10 \times 10 \mathrm{~m}$ ).

\begin{tabular}{|c|c|c|}
\hline Parcela principal & $N^{\circ}$ Sub-parcelas & $N^{\circ}$ Espécies \\
\hline 1 & 38 & 35 \\
\hline 2 & 42 & 35 \\
\hline 3 & 45 & 37 \\
\hline 4 & 37 & 34 \\
\hline 5 & 34 & 29 \\
\hline 6 & 39 & 30 \\
\hline 7 & 38 & 29 \\
\hline 8 & 45 & 27 \\
\hline 9 & 45 & 27 \\
\hline 10 & 45 & 36 \\
\hline 11 & 32 & 28 \\
\hline 12 & 40 & 26 \\
\hline 13 & 46 & 35 \\
\hline 14 & 37 & 22 \\
\hline 15 & 39 & 27 \\
\hline 16 & 42 & 30 \\
\hline
\end{tabular}




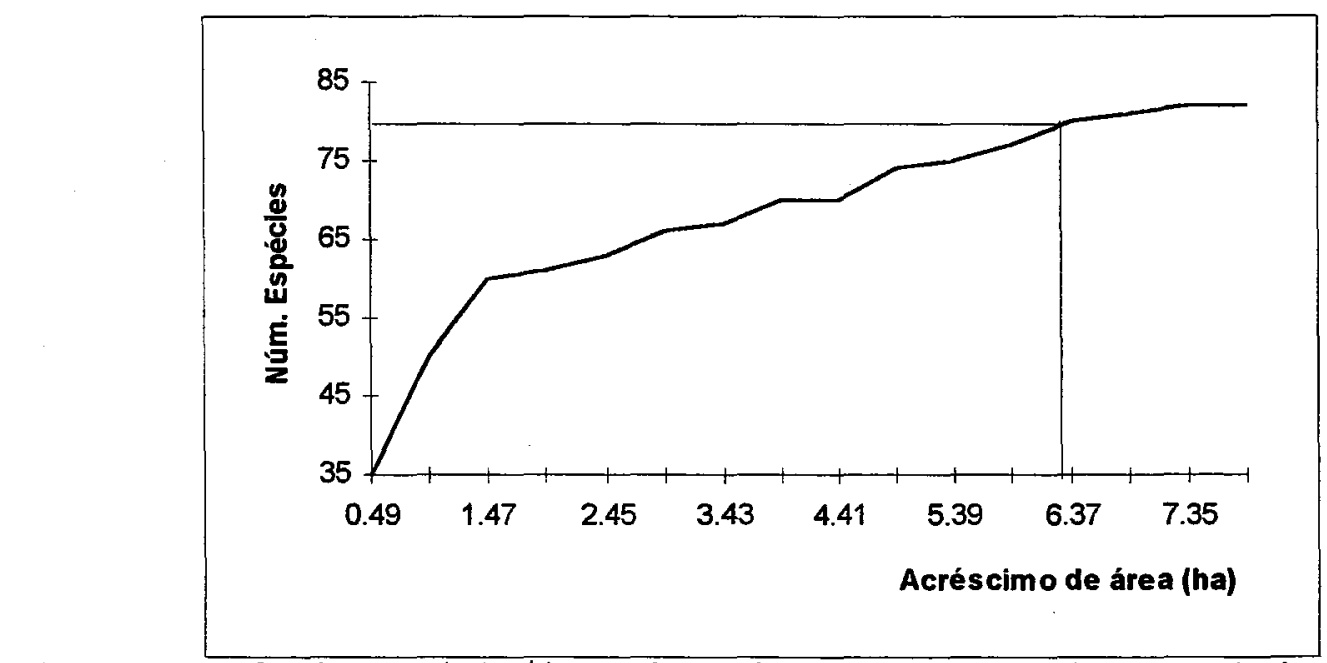

Figura 1: Relação espécie/área de todas as parcelas inventariadas para DAP $\geq 10 \mathrm{~cm}$.

3.1.2. Estrutura da floresta

No Anexo I são apresentados todas as espécies que ocorreram na área de estudo, constando a identificação dos nomes vulgares, nomes botânicos e familias. A familia mais predominante foi Leguminosae, com 19 espécies em 11 gêneros, destacando-se o gênero Inga. Foram totalizadas 30 famílias, 65 gêneros, e 80 espécies de plantas. Deste total, 3 espécies são palmeiras.

Também no Anexo I são apresentados os valores absolutos e relativos, respectivamente, de dominância, frequência, abundância, e índice de valor de importância (I.V.I). As espécies foram listadas em ordem decrescente de valores de I.V.I.

As 3 espécies mais abundantes no levantamento (Mora paranensis, Euterpe oleracea e Pentaclethra macrolobal somam $53,36 \%$, mais da metade do total da floresta. As palmeiras representam $34,96 \%$, mais de $1 / 3$ de toda a abundância nesta floresta de várzea, sendo que açaí (Euterpe oleracea) representa $56 \%$ deste valor. De todas as espécies inventariadas, Mora paraensis (pracuúba), E. oleracea (açaí), Pentaclethra macroloba (pracaxi), Manicaria saccifera (buçú), Astrocaryum murumuru (murumuru), Swartzia racemosa (pacapeuá), Trichilia quadrijuga (cachuá), e Carapa guianensis (andiroba) foram as 
únicas espécies a ocorrer em todas as 16 amostras inventariadas $(7,84 \mathrm{ha})$.

Com relação à dominância, $48.43 \frac{\circ}{0}$ de toda a área basal estimada para esta floresta pertence a uma única espécie, $M$. paraensis (pracuúba). A pracuuba é dominante em todas as classes diamétricas, e é a espécie que no momento ocupa a maioria do dossel da floresta. Esta espécie parece estar associada também com a grande ocorrência de pracaxí no subbosque. É muito comum a ocorrência deste tipo de dominância de uma única espécie nas floresta de várzea, visto que é um tipo de vegetação que vem sendo explorada a mais de 300 anos (Dr. Murça Pires, 19934, comunicação pessoal).

Em ordem de I.V.I., das 10 espécies ecologicamente mais importantes na estrutura e fisionomia da floresta, 2 palmeiras são de grande procura para economia local: açaí (produção de palmito), e buçú (palha para a cobertura das casas). Das 10 espécies mais importantes, pracuúba e andiroba têm grande procura pelas serrarias da região.

3.1.3. Diversidade de espécies em florestas de várzea amazônica: Futuras fontes de comparação

A floresta em estudo identifica-se muito com outras já estudadas em relação ao número de espécies, número de individuos e valores de área basal (Black et al., 1950; Pires \& Koury, 1958; Pires, 1972 e 1973). Entretanto, a grande maioria das comparações é feita utilizando-se resultados de áreas de terra-firme (Cruz, 1991). Com relação a estudos de diversidade de espécies na várzea, faltam dados para comparação (Ayres, 1993). Neste trabalho foram calculados indices de diversidade que poderão contribuir para futuras comparações com outros estudos. Utilizando-se todas as parcelas, obteve-se o cálculo para $\circ$ indice de heterogeneidade de Shannon $=2,78$ (Magurran, 1987 \& Pielou, 1975). Para caracterizar a riqueza de espécies foi utilizado o indice de Margalef $=14,21$.

4 Pesquisador do Departamento de Botânica, Museu Goeldi, falecido em 1995. 
Para a comparação entre parcelas, foi calculado o índice de similaridade florística de Jaccard (Rohlf, 1990), utilizandose uma matriz de presença (1) e ausência (0) em relação ao número de espécies. As parcelas apresentaram bastante semelhança independente dos tratamentos, visto que a grande maioria dos coeficientes estão entre 0,7 e 0,9 (Tabela 4).

A utilização de índices de diversidade foi importante na comparação do efeito dos diferentes níveis de exploração realizados neste trabalho (Seção 3.3).

Com relação a distribuição do número de espécies com o número de indivíduos (Magurran, 1987), foi observado um grande número de espécies mais raras, ou seja, para 53 espécies foi encontrado apenas um indivíduo. Observou-se também um grupo intermediário, com o número de indivíduos por espécie variando de 4 a 29, e finalmente, um grupo de espécies mais comuns, variando de 37 a 100 indivíduos por espécie (Figura 2). Pracuúba (Mora paraensis), pracaxí (Pentaclethra macroloba) e açai (Euterpe oleracea) fazem parte deste último grupo. Esta relação é muito útil para caracterizar a estrutura da floresta em relação à distribuição das suas espécies (Legendre \& Legendre, 1983; Pielou, 1984).

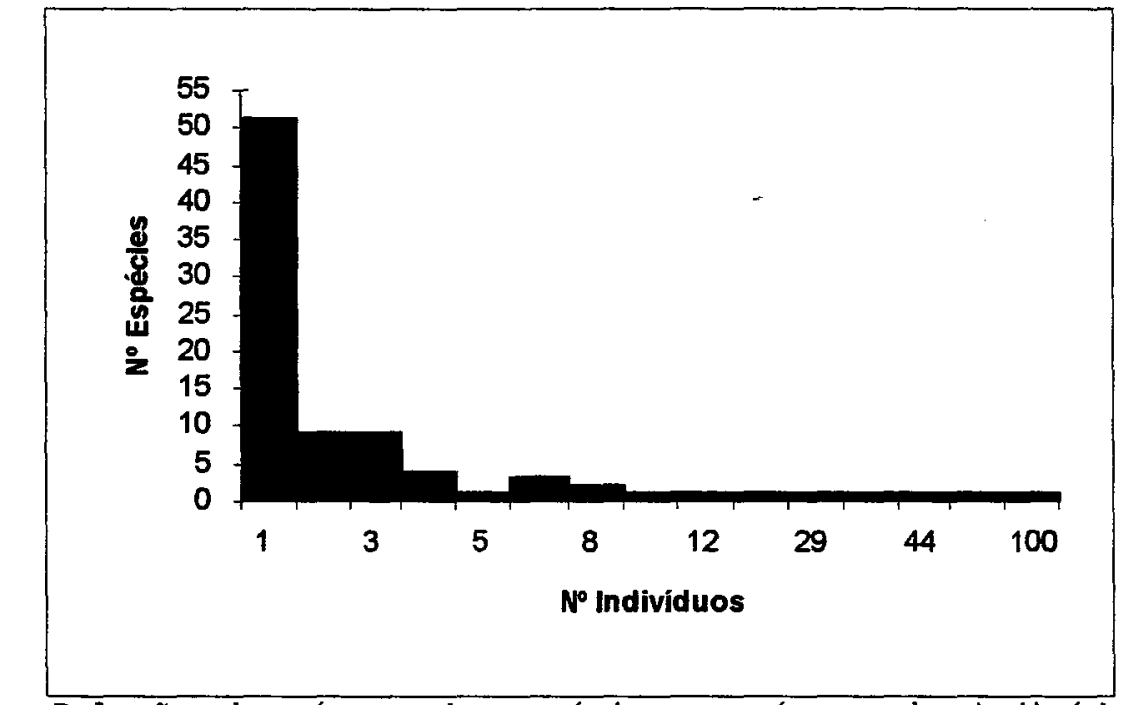

Figura 2: Relação do número de espécies e número de indivíduos para a floresta em estudo. O número de indivíduos por espécie tende a aumentar da esquerda para a direita. 
Tabela 4: Valores do coeficiente de similaridade de Jaccard, obtidos pelo procedimento SIMQUAL (Rohlf, 1990), para as parcelas dos tratamentos $1,2,34$, respectivamente.

\begin{tabular}{|c|c|c|c|c|}
\hline & $\mathrm{P} 2$ & & & \\
\hline P 2 & 1.00 & $\begin{array}{l}\mathrm{P} \quad 4 \\
\end{array}$ & & \\
\hline $\begin{array}{ll}\mathrm{P} & 4\end{array}$ & 0081 & 1.00 & $\mathrm{P} 12$ & \\
\hline $\mathrm{P} 12$ & 0.69 & 0.54 & 1.00 & $\mathrm{P} 16$ \\
\hline $\mathrm{P} 16$ & 0.48 & 0.51 & 0.73 & 1.00 \\
\hline
\end{tabular}

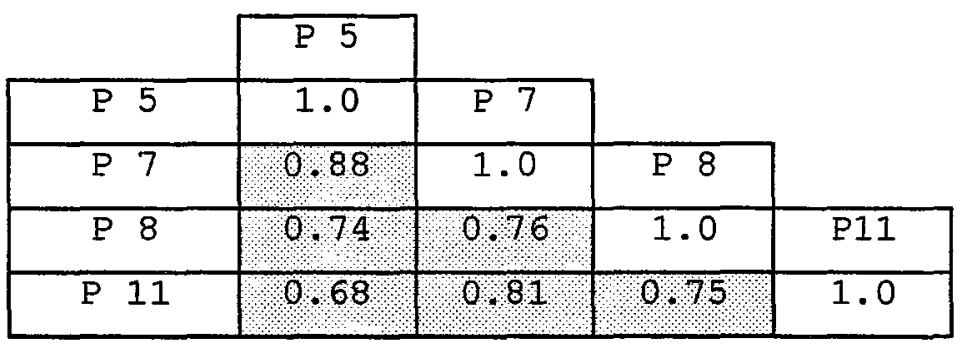

\begin{tabular}{|c|c|c|c|c|}
\hline & P 1 & & & \\
\hline P 1 & 1.00 & P 3 & & \\
\hline P 3 & 0.51 & 1.00 & P 9 & \\
\hline P 9 & 0.81 & 0.68 & 1.00 & P 16 \\
\hline P 15 & 0.81 & 0.55 & 0.91 & 1.00 \\
\hline
\end{tabular}

\begin{tabular}{|c|c|c|c|c|}
\hline \multirow{2}{*}{\multicolumn{5}{|c|}{$\mathrm{P} 6$}} \\
\hline & & & & \\
\hline P6 & 1.0 & P 10 & & \\
\hline P 10 & 0.70 & 1.0 & $\mathrm{P} 13$ & \\
\hline $\mathrm{P} 13$ & 0.68 & 0.81 & 1.0 & P 14 \\
\hline $\mathrm{P} 14$ & 0.92 & 0.64 & 0080 & 1.0 \\
\hline
\end{tabular}




\subsection{Tratos silviculturais}

\subsubsection{Exploração}

3.2.1.1. Distribuição diamétrica

Com os dados coletados no inventário florestal, a Tabela 5 contém os valores médios de número de individuos (n/ha), área basal ( $\mathrm{m}^{2} / \mathrm{ha}$ ) e número de espécies, antes da aplicação dos tratamentos. Não foram observadas diferenças significativas entre as médias à $95 \%$ de probabilidade pelo teste de Tukey (Ronald \& Smith, 1984), o que mostra homogeneidade entre todas as parcelas.

A seleção das árvores a serem retiradas para o desbaste foi feita na ordem decrescente das classes diamétricas (Figuras 3-A; 3-B). Houve um decréscimo acentuado na densidade dos indivíduos pertencentes as classes diamétricas superiores, principalmente nos tratamentos 3 e 4 . Para que houvesse precisão em relação à retirada da área basal, alguns indivíduos das classes mais inferiores (30 - $40 \mathrm{~cm}$, centro de classe 35) foram selecionados para complementar a somatória (Figuras 3-A; $3-\mathrm{B})$.

Tabela 5: Médias da área basal ( $\left.\mathrm{m}^{2} / \mathrm{ha}\right)$; número de indivíduos $(\mathrm{n} / \mathrm{ha})$; $e$ número de espécies, antes da execução dos tratamentos.

\begin{tabular}{|c|c|c|c|}
\hline Tratamento & \multirow{2}{*}{$\begin{array}{l}\text { A. Basal } \\
\left(\mathrm{m}^{2} / \mathrm{ha}\right)\end{array}$} & \multirow{2}{*}{$\begin{array}{c}\text { Erequência } \\
(n / h a)\end{array}$} & \multirow{2}{*}{$\begin{array}{l}\text { Número de } \\
\text { espécies }\end{array}$} \\
\hline & & & \\
\hline $\mathrm{T01}$ & 26.918 & 438.25 & 32 \\
\hline $\mathrm{T02}$ & 25.031 & 422.75 & 31 \\
\hline T03 & 27.938 & 423.75 & 35 \\
\hline T04 & 25.919 & 418.5 & 34 \\
\hline valor de F & 0,89 ns & $0,16 \mathrm{~ns}$ & $0,70 \mathrm{~ns}$ \\
\hline C.V. (8) & 10.07 & 10.22 & 14.7 \\
\hline Média & 26.4515 & 425.81 & 33 \\
\hline
\end{tabular}



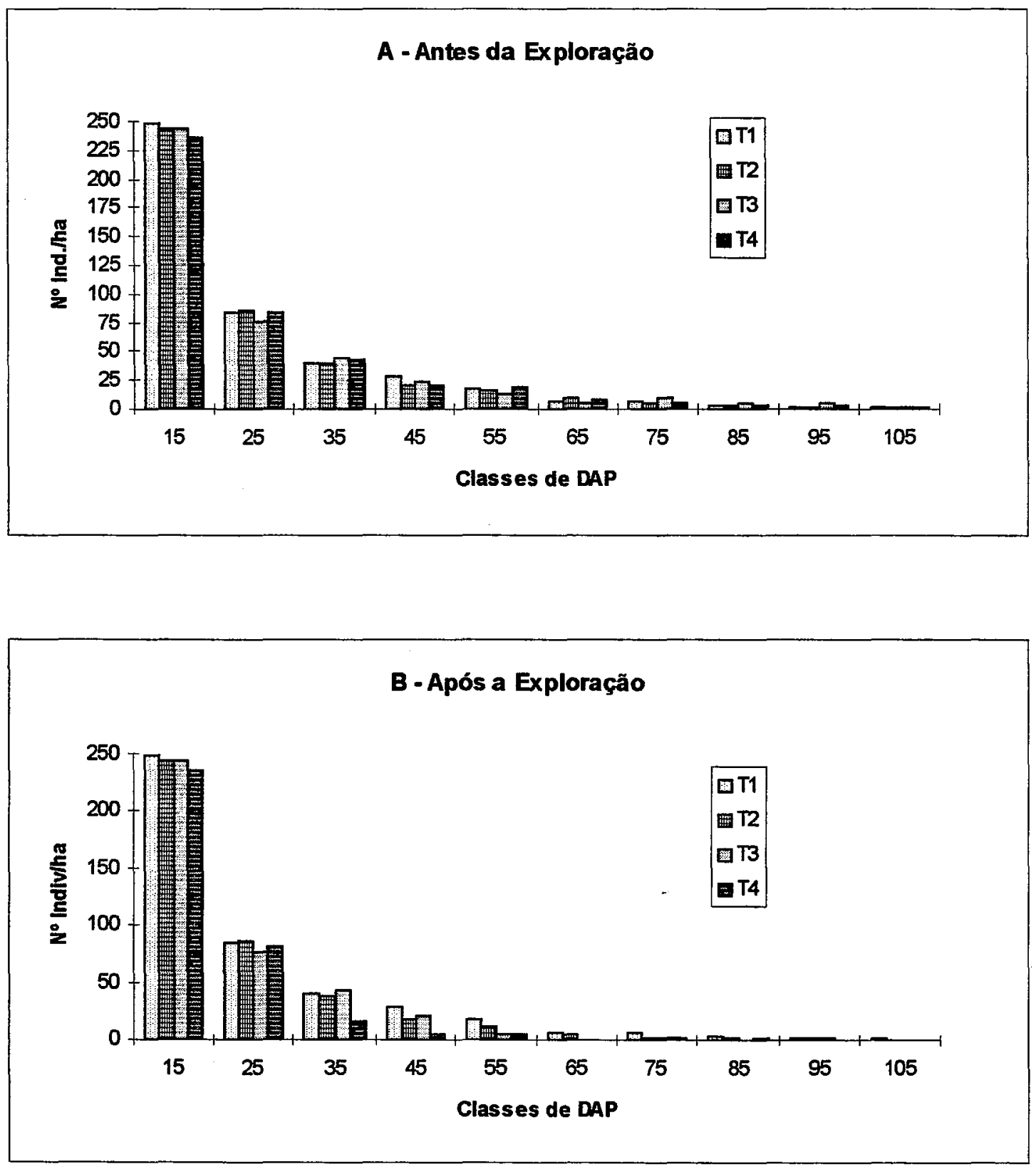

Figura 3: A - Número de indivíduos ( $\mathrm{n} / \mathrm{ha}$ ) por classe de DAP, antes da exploração; B - Número de indivíduos $(\mathrm{n} / \mathrm{ha})$ por classe de DAP, após a exploração. 


\subsubsection{2. Área basal}

A situação descrita acima refletiu na diferenciação entre os tratamentos, com relação ao efeito da retirada de área basal. Após a retirada das árvores selecionadas, foram detectadas diferenças significativas pelo teste de Tukey (95\% prob.), entre as médias dos tratamentos. Desta maneira, três condições distintas foram criadas com relação a abertura do dossel para a entrada de Iuz (Figura 4).

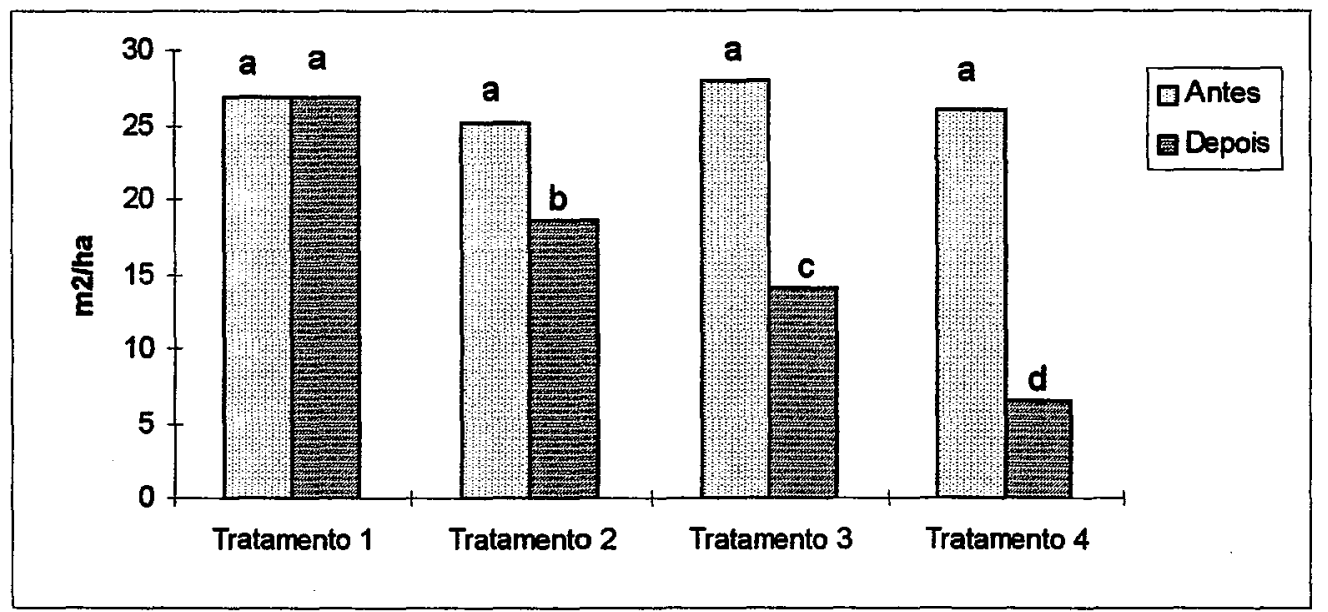

Figura 4: Análise de variância da área basal $\left(\mathrm{m}^{2} / \mathrm{ha}\right)$, antes e depois da aplicação dos tratamentos. Médias seguidas da mesma letra não diferem entre si (Tukey lines, a 958 de probabilidade).

\subsubsection{Volume}

Após a derrubada, foi efetuada uma cubagem rigorosa para - cálculo do volume comercial de cada árvore. Como era de se esperar, foram detectadas diferenças significativas entre as médias do volume comercial por hectare nos tratamentos, exceto para o tratamento 1 (testemunha), onde não ocorreu a exploração (Tabela 6). Foram encontradas árvores ocas em todos os tratamentos, inviabilizando a sua cubagem para aquelas árvores. Entretanto, este fato não influenciou no resultado final. 
Tabela 6: Médias do volume de madeira extraído por tratamento.

\begin{tabular}{|c|c|c|c|c|c|}
\hline & $\begin{array}{c}\text { Repetição } \\
1\end{array}$ & $\begin{array}{c}\text { Repetição } \\
2\end{array}$ & $\begin{array}{c}\text { Repetição } \\
3\end{array}$ & $\begin{array}{c}\text { Repetição } \\
4\end{array}$ & Médias \\
\hline Tratamento & $\begin{array}{l}\text { Volume } \\
\text { (m3/ha) }\end{array}$ & $\begin{array}{l}\text { Volume } \\
\text { (m3/ha) }\end{array}$ & $\begin{array}{l}\text { Volume } \\
\text { (m3/ha) }\end{array}$ & $\begin{array}{l}\text { Volume } \\
\text { (m3/ha) }\end{array}$ & $\begin{array}{l}\text { Volume } \\
\text { (m3/ha) }\end{array}$ \\
\hline $\mathrm{T} 2$ & 64.00 & 58.24 & 68.86 & 44.30 & 58.88 \\
\hline T3 & 113.78 & 105.55 & 69.60 & 83.60 & 93.13 \\
\hline $\mathrm{T4}$ & 136.26 & 124.49 & 152.69 & 134.01 & 136.86 \\
\hline F value & & & & & $27,81^{\star \star}$ \\
\hline C.V. (8) & & & & & 15.39 \\
\hline
\end{tabular}

\subsection{Danos em função da exploração}

A exploração de florestas tropicais tem-se constituído um problema com relação a racionalização dos impactos sobre as árvores remanescentes e regeneração natural, como também o barateamento dos custos envolvidos em todo o processo (Uhl \& Vieira, 1989).

A redução deste impacto está diretamente relacionado com a intensidade e porte das árvores a serem retiradas do local. Em florestas de várzea, apesar da impossibilidade da retirada de árvores com o auxílio de veículos de qualquer porte, e apesar do tamanho das árvores ser menor do que áreas de terra firme, o impacto está presente e representa também um problema para o seu manejo (Macedo \& Anderson, 1993).

Neste estudo de caso, as espécies a serem derrubadas foram selecionadas seguindo-se os critérios da seção 2.4.1.

Para a avaliação dos danos observados em cada tratamento, foi efetuado o mapeamento de cada árvore no campo (Figuras 5.1, 5.2, 5.3, e 5.4) observando-se os seguintes critérios: (i) mortas, (ii) danificadas (fuste e copa quebrados e árvores tombadas), 'e (iii) sem danos. Para melhor visualização dos impactos sobre a vegetação remanescente, também foram confeccionados perfis da vegetação para cada um dos tratamentos (Figuras 6.1, 6.2, 6.3, e $6.4)$. 


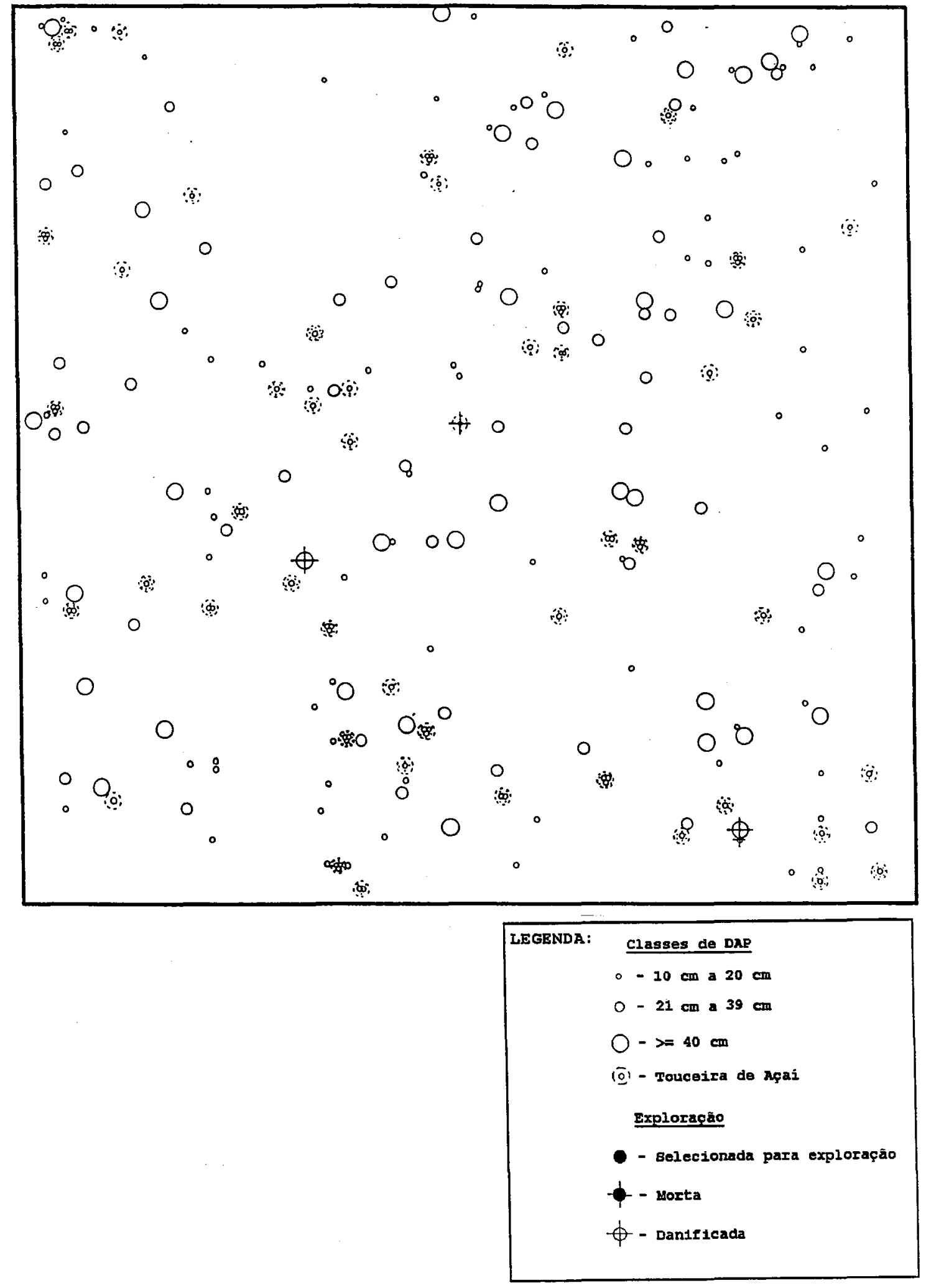

Figura 5.1: Mapa da distribuição espacial de todas as árvores inventariadas para o tratamento 1 (controle), parcela 12, como exemplo de área não explorada. 


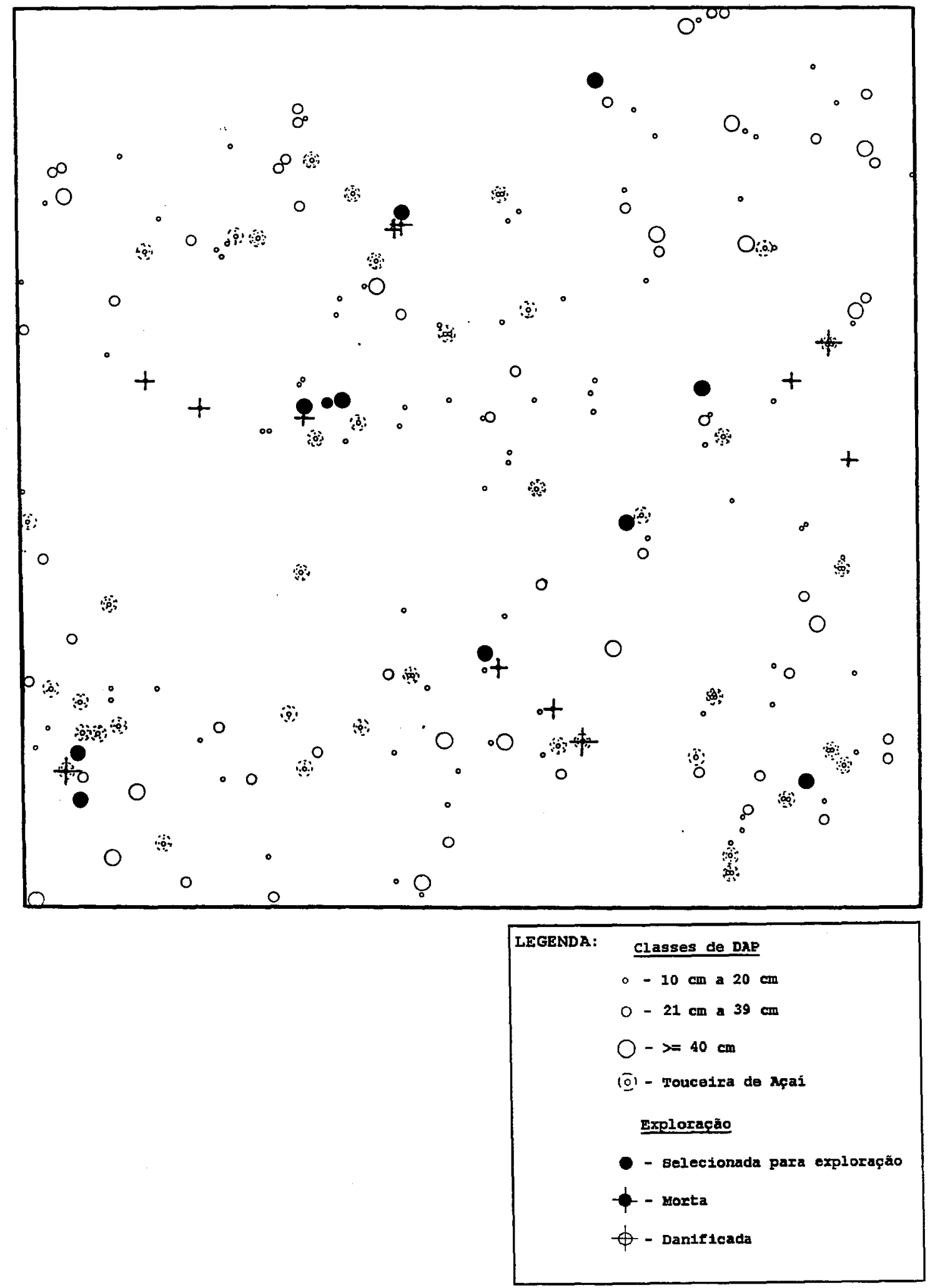

Figura 5.2: Mapa da distribuição espacial de todas as árvores inventariadas para o tratamento 2, parcela 8, como exemplo de retirada de 25 \& de área basal. 


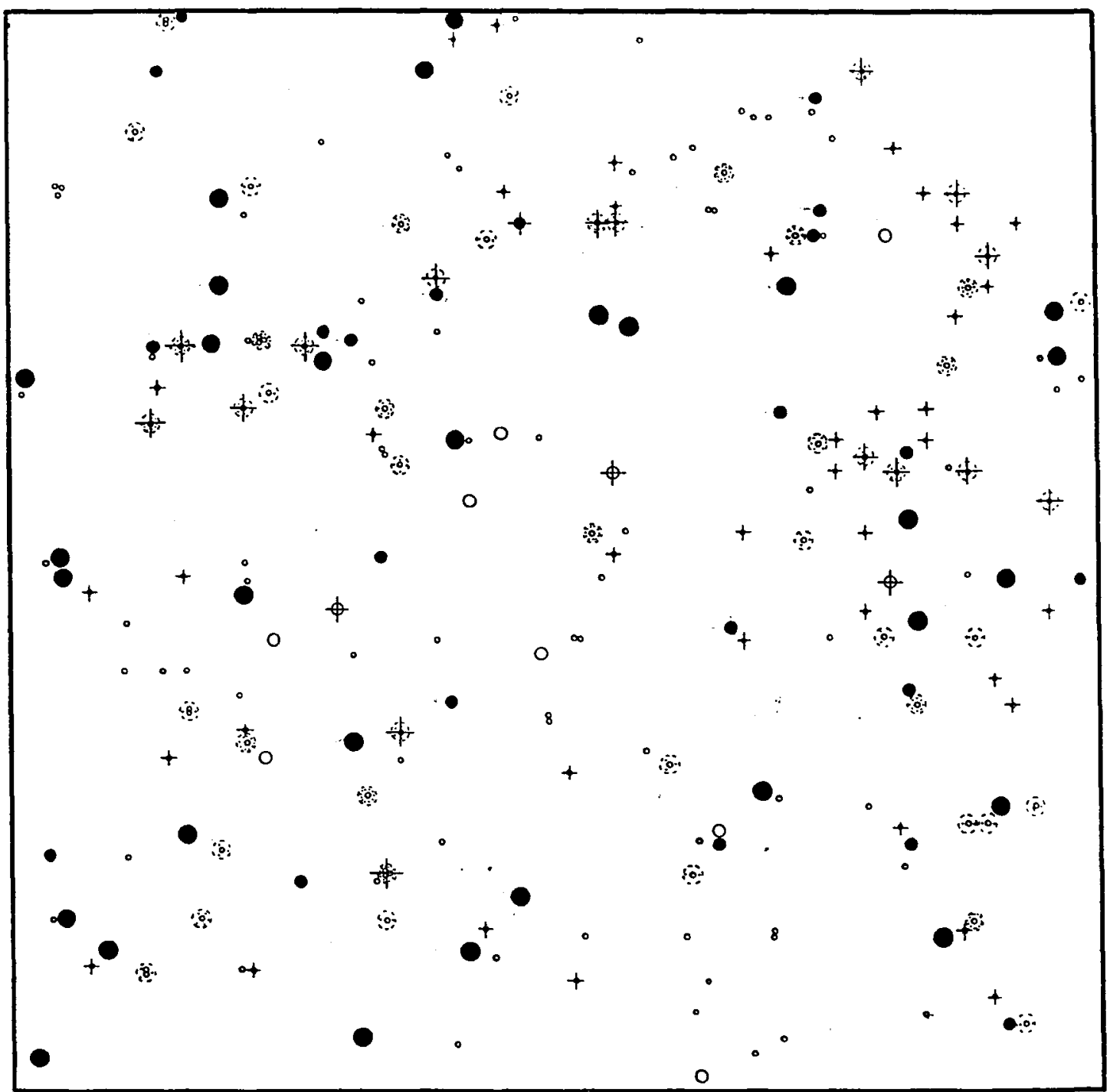

\begin{tabular}{|c|c|}
\hline LEGENDA : & $\begin{array}{l}\text { Classes de DAP } \\
0-10 \mathrm{~cm} \text { a } 20 \mathrm{~cm} \\
0-21 \mathrm{~cm} \text { a } 39 \mathrm{~cm} \\
O->=40 \mathrm{~cm} \\
|\bar{O}|-\text { Touceira de Açaí } \\
\text { Exploracaáo } \\
\text { - Belecionada para exploração } \\
\phi \text { - Morta } \\
\phi \text { - Dantricada }\end{array}$ \\
\hline
\end{tabular}

Figura 5.3: Mapa da distribuição espacial de todas as árvores inventariadas para o tratamento 3, parcela 9, como exemplo de retirada de 50 o de área basal. 


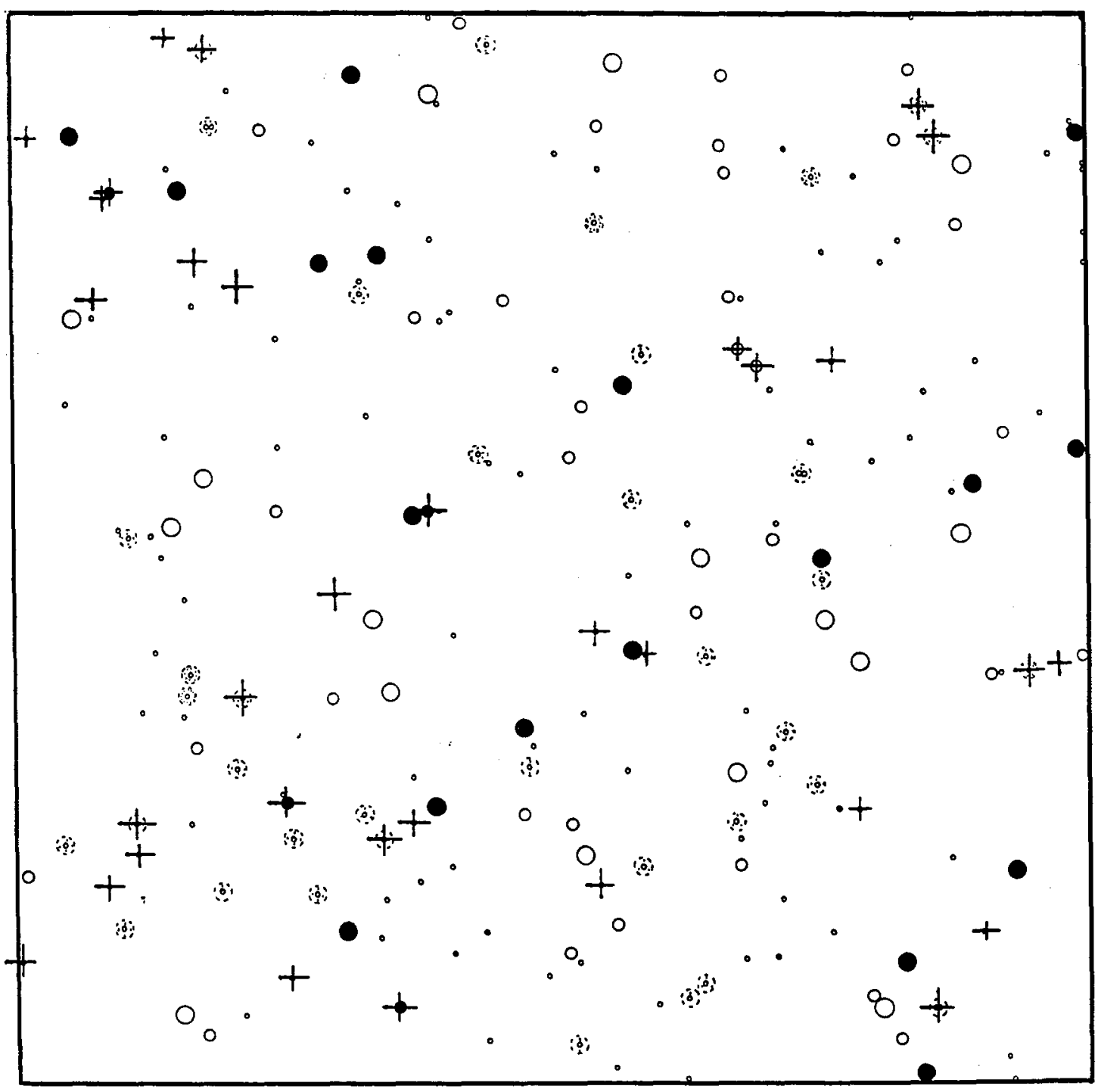

\begin{tabular}{|c|c|}
\hline LEGENDA: & $\begin{array}{l}\text { Clagses de DAP } \\
0-10 \mathrm{~cm} \text { a } 20 \mathrm{~cm} \\
0-21 \mathrm{~cm} \text { a } 39 \mathrm{~cm} \\
O->40 \mathrm{~cm} \\
\text { (O) - Touceira de Açai } \\
\text { Exploraçăo } \\
\text { - selecionada para exploração } \\
\phi-\text { Morta } \\
\phi \text { - Dan1ficada }\end{array}$ \\
\hline
\end{tabular}

Figura 5.4: Mapa da distribuição espacial de todas as árvores inventariadas para o tratamento 4, parcela 10, como exemplo de retirada de 75용 de área basal. 


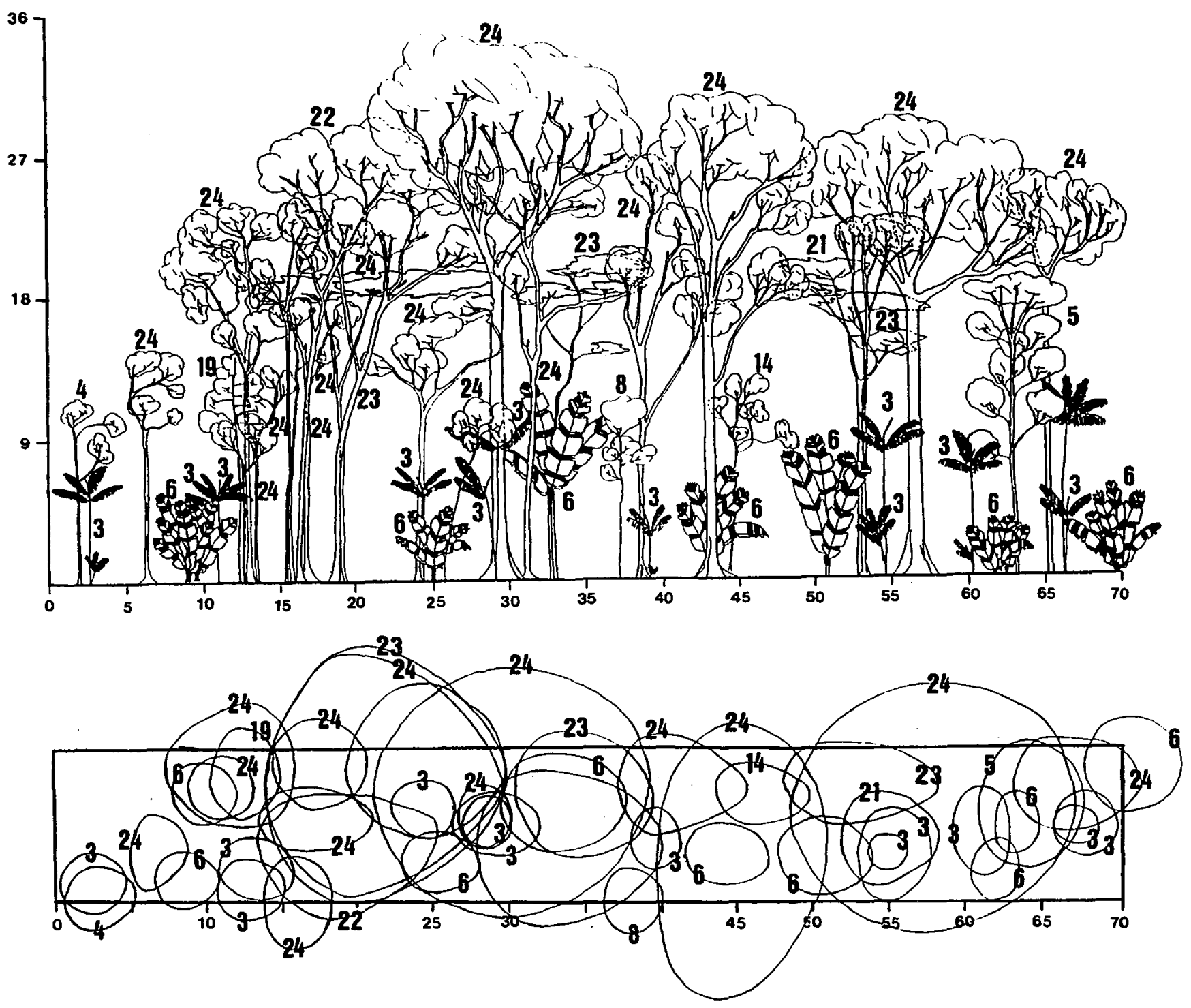

Figura 6.1: Perfil da vegetação, referente ao tratamento 1, parcela 12, como exemplo de área não explorada.3 = Euterpe oleracea Mart.; $4=$ Carapa guianensis Aubl.; 5 = Licania macrophyla Benth.; 6 = Manicaria sacifera Mart.; $8=$ Trichilia quadrijuga;14 = Pithecellobium cf. juruanum Harms.;19 = Maquira coriaceae Arg. (Kaist.) CC Berg.; $21=$ Pterocarpus officcinalis Jacq.; 22 = Swartzia racemosa Bth.; $23=$ Pentaclethra macroloba (Willd.) Kuntze; 24 = Mora paraensis Ducke. 

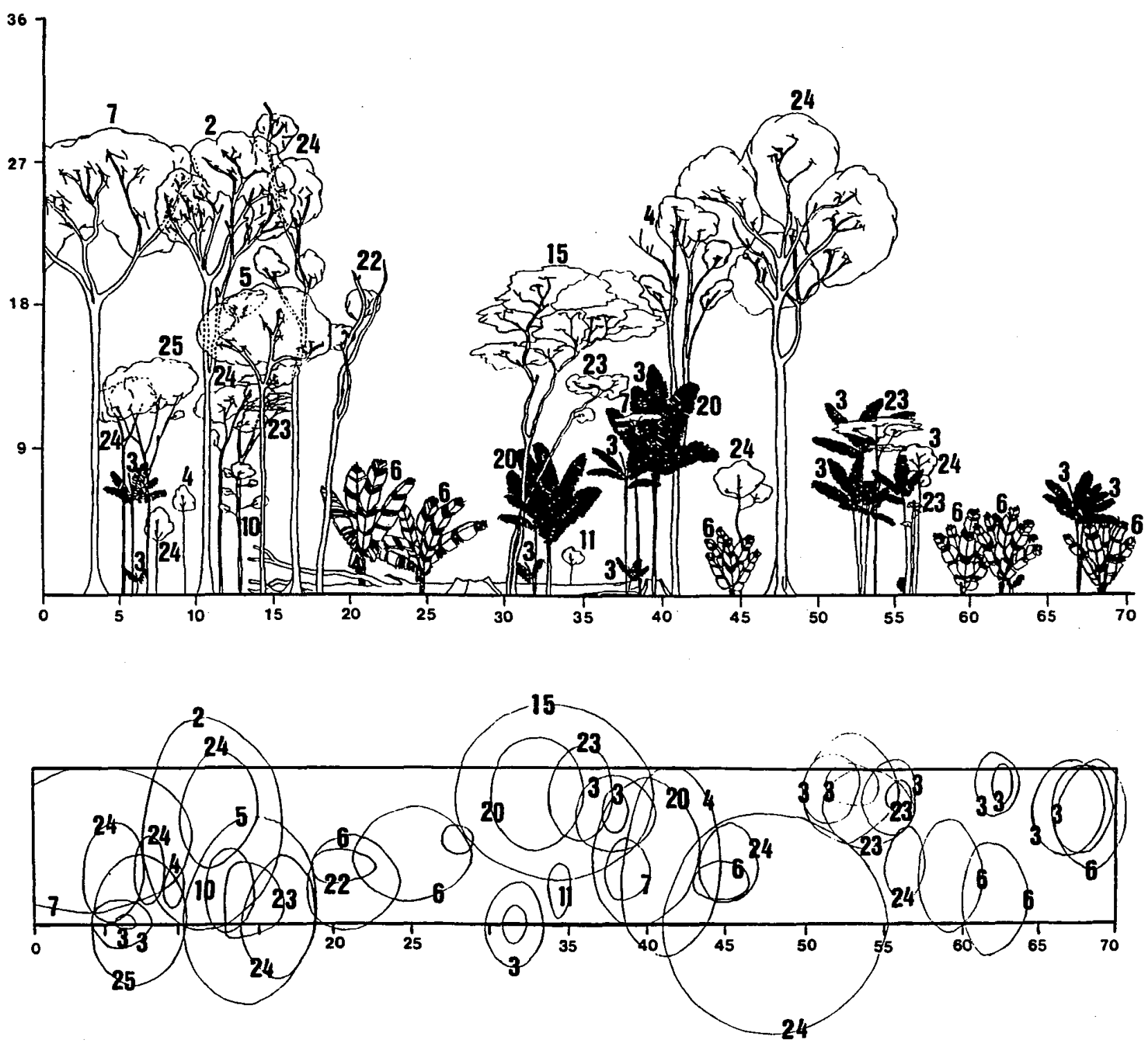

Figura 6.2: Perfil da vegetação, referente ao tratamento 2, parcela 8 , como exemplo de retirada de $25 \frac{8}{b}$ de área basal. $2=\mathrm{NI} ; 3$ = Euterpe oleracea Mart.; 4 = Carapa guianensis Aubl.; 5 = Licania macrophyla Benth.; 6 = Manicaria sacifera Mart.; $7=$ Ormosia coutinhoi; $10=$ Allantona Iineata (Mart. ex Berg.) Miers.; 11 = Gustavia augusta L.; 15 = Macrolobium pendulum Willd.; 20 = Astrocaryum murumuru Mart.; $22=$ Swartzia racemosa Bth.; 23 = Pentaclethra macroloba (Willd.) Kuntze; 24 = Mora paraensis Ducke; 25 = Crudia oblonga Bth.. 

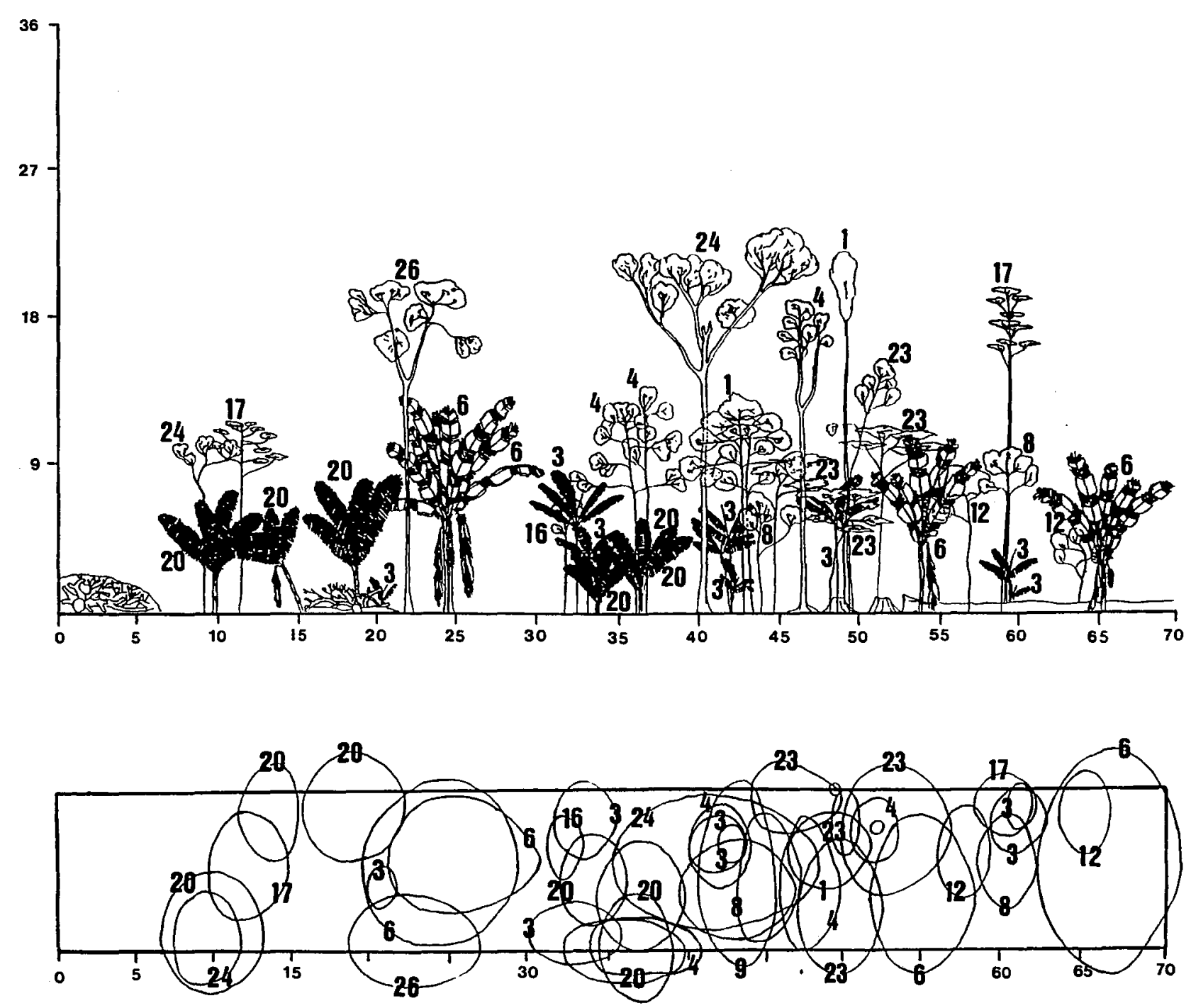

Figura 6.3: Perfil da vegetação, referente ao tratamento 3, parcela 9, como exemplo de retirada de $50 \%$ de área basal. 1 = Labatia macrocarpa Mart.; 3 = Euterpe oleracea Mart.; 4 = Carapa guianensis Aubl.; $6=$ Manicaria sacifera Mart.; $8=$ Trichilia quadrijuga; 9 = Anacardium giganteum Hanc. ex Berg.) Miers.; 12 = Inga tarapotensis Benth.; $16=$ Zanthoxylon rhoifolia; $17=$ Licaria mahuba (Sambi.) Kostern; $20=$ Astrocaryum murumuru Mart.; 23 = Pentaclethra macroloba (Willd.) Kuntze; 24 = Mora paraensis Ducke; 26 = Hevea brasiliensis M. Arg. 

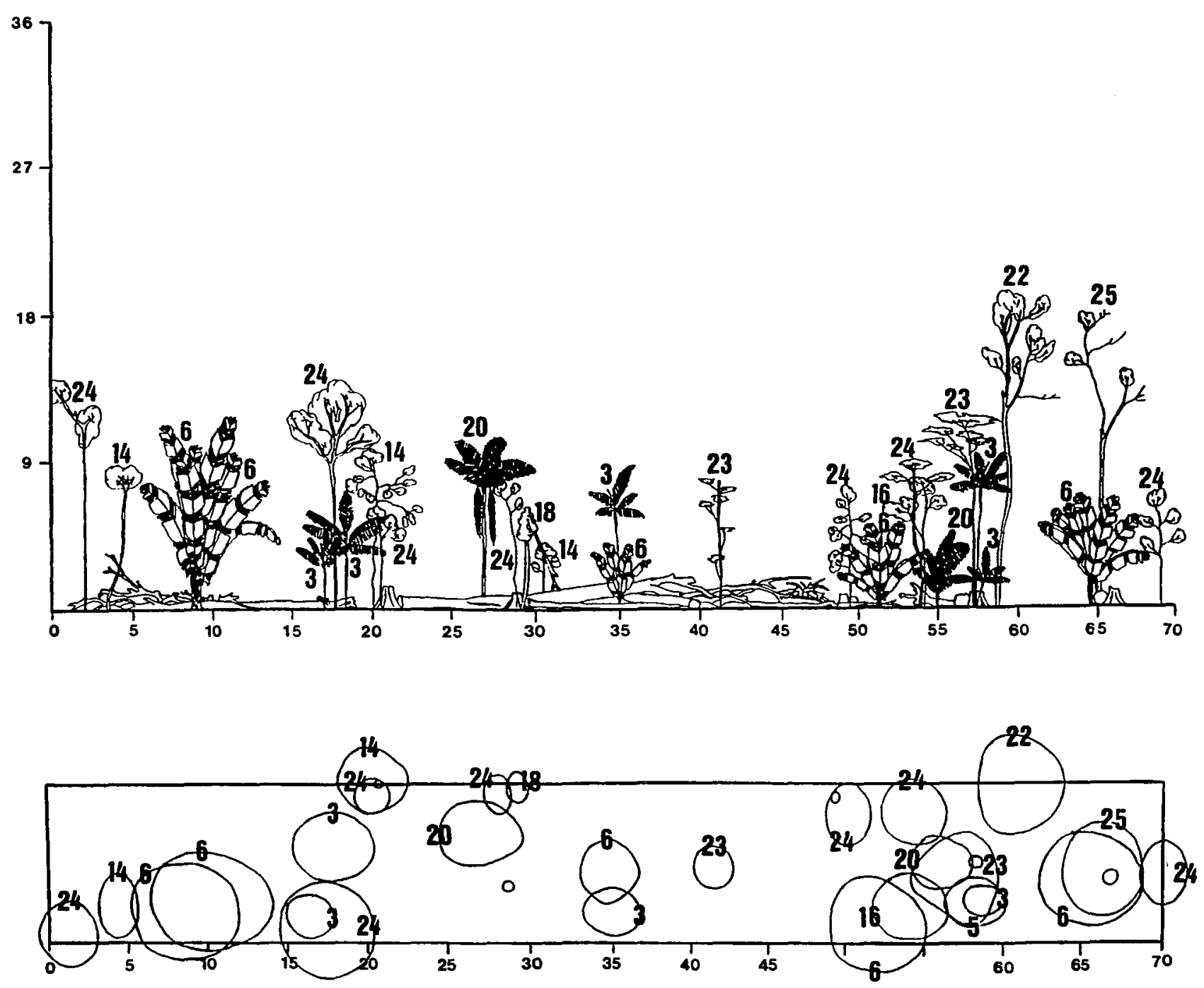

Figura 6.4: Perfil da vegetação, referente ao tratamento 4, parcela 10, como exemplo de retirada de 75 \% de área basal. $3=$ Euterpe oleracea Mart.; 5 = Licania macrophyla Benth.; 6 = Manicaria sacifera Mart.; 14 = Pithecellobium cf. juruanum Harms.; 16 = Zanthoxylon rhoifolia; $18=$ NI; 20 = Astrocaryum murumuru Mart.; 22 = Swartzia racemosa Bth.; $23=$ Pentaclethra macroloba (Willd.) Kuntze; $24=$ Mora paraensis Ducke; $25=$ Crudia oblonga Bth. 
Houve um aumento crescente no número de árvores exploradas entre os tratamentos, sendo observadas diferenças significativas $(\mathrm{P}<0.0001$ ) entre o número de árvores exploradas (Figura 7).

Com relação às árvores danificadas, foram observadas diferenças significativas $(P<0.0009)$ para 0 tratamento 2 em relação aos tratamentos 3 e 4, que não tiveram suas médias estatisticamente diferenciadas. Caso fossem consideradas todas as árvores danificadas --inclusive as exploradas -- foram encontradas diferenças significativas ( $\mathrm{P}<0.0001)$, caracterizando ainda mais - impacto a medida que há um aumento no número de árvores retiradas.

Com relação às médias para as àrvores que não foram danificadas, foram observadas diferenças significativas $(P<$ 0.002 ) para o tratamento 4 em relação aos tratamentos 2 e 3, que não diferiram entre si (Figura 7).

outro procedimento utilizado para avaliar $\circ$ impacto em função do aumento de árvores exploradas, e consequentemente árvores danificadas e mortas, foi $\circ$ cálculo de índices de diversidade. Houve a diferenciação com relação aos valores calculados entre os extremos, ou seja, tratamentos 1 e 4 para todos os indices (Tabela 7). Estes resultados mostram que alguns índices de diversidade podem ser sensiveis quanto à mudanças drásticas na composição de espécies em áreas exploradas, podendo se tornar indicadores de empobrecimento das florestas que foram intensamente exploradas em áreas tropicais.

Entretanto, muito cuidado dever ser tomado quando na interpretação dos mesmos. Com relação a este fato, duas considerações devem ser feitas. Primeiro, a espécie pracuúba (Mora paraensis), por ser a mais abundante e consequentemente a mais explorada, pois possui as árvores de maior porte, praticamente não foi afetada em relação a sua posição de espécie dominante. Segundo, a espécie açaí (Euterpe oleracea), por ser a segunda espécie mais abundante, e por ter sido uma das mais afetadas na exploração, não mudou seus valores de dominância. 
Ao afirmar que uma floresta é seriamente afetada na sua composição original de espécies, em função de altas intensidades de exploração -- sem o conhecimento profundo da sua estrutura -pode-se estar cometendo erros. É o caso de diagnosticar a vocação de certas florestas para a produção madeireira.

A utilização de índices de diversidade pode ser útil também para a classificação de sítios florestais com relação a uma maior ou menor capacidade produtiva, podendo suportar intensidades mais altas de exploração, enquanto que outros locais podem ser mais sensiveis para a produção de madeira, podendo ser utilizados como áreas aptas a extração de produtos não-madeireiros que causam menos impacto na vegetação.

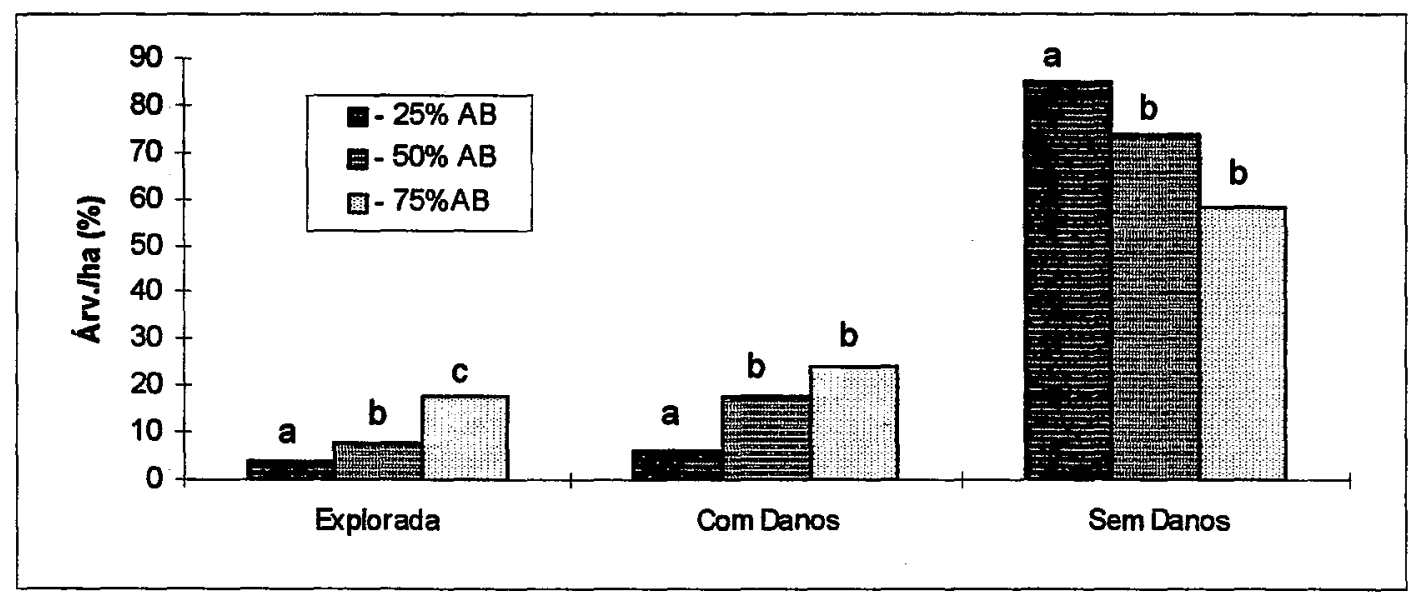

Figura 7: Médias em porcentagem de árvores exploradas, com danos e sem danos para cada tratamento. Médias com a mesma letra não diferem entre si a $95 \%$ de probabilidade. $A B$ refere-se à área basal. 
Tabela 7: Cálculo de índices de heterogeneidade e de riqueza para a caracterização do efeito da exploração em relação à diversidade de espécies na floresta (foram considerados para o cálculo apenas as árvores que não sofreram danos na exploração).

\begin{tabular}{|c|c|c|c|c|}
\cline { 4 - 5 } & \multicolumn{2}{c|}{ Indice de Heterogeneidade } & Índice de Riqueza \\
\hline Trat & $\mathbf{N}^{\text {o Esp }}$ & Indiv./ha & Shannon & Margalef \\
\hline 1 & 61 & 438 & 1.21 & 9.70 \\
\hline 2 & 54 & 378 & 1.14 & 8.93 \\
\hline 3 & 53 & 310 & 1.21 & 9.06 \\
\hline 4 & 47 & 252 & 1.11 & 8.32 \\
\hline
\end{tabular}

\subsection{Levantamento dos custos dos tratamentos}

A exploração com máquinas em florestas de várzea é bastante dificultada pela condição de ter solos inundados em grande parte do ano. Por causa deste fato, a utilização de mão-de-obra é mais intensa, conforme observado na tomada de custos de todas as operações que se sucederam neste trabalho. Este fator foi o que pesou mais em todos os tratamentos, exceto para o tratamento 1 , onde não foi realizada nenhuma operação de exploração. Para os tratamentos 2, 3 e 4 , os custos com mão-de-obra representaram $53.1 \%$, 54.68 e 58.4\%, respectivamente, em relação ao total com todas as operações realizadas (Figura 8 ).

Com relação ao item infra-estrutura, onde estão incluídos os gastos com material, praticamente não houve acréscimo à medida que aumentou a intensidade de exploração. Os gastos com equipamentos, como aquisição de machado e outros instrumentos manuais de trabalho e aluguel de motosserra, não influenciaram muito na somatória total, mas foi um dos ítens que mais pesou em termos de gastos.

- custos médios por metro cúbico por hectare para os tratamentos 2, 3 e 4 foram respectivamente: US\$6.37, US\$5.8 e US\$5.46. Vale lembrar que para o cálculo destes valores, não 
estão incluídos os gastos com o arraste e retirada das toras do interior da floresta até a serraria, ou seja, apenas para a 0 planejamento dfos trabalhos de inventário, seleção e derrubada.

No total para os tratamentos $1,2,3$ e 4, foram gastos por hectare para a derrubada, limpeza e plantio, respectivamente: US\$1,298.69; US\$1,665.28; US\$1,836.60; e US\$1,958.86 (Figura 8).

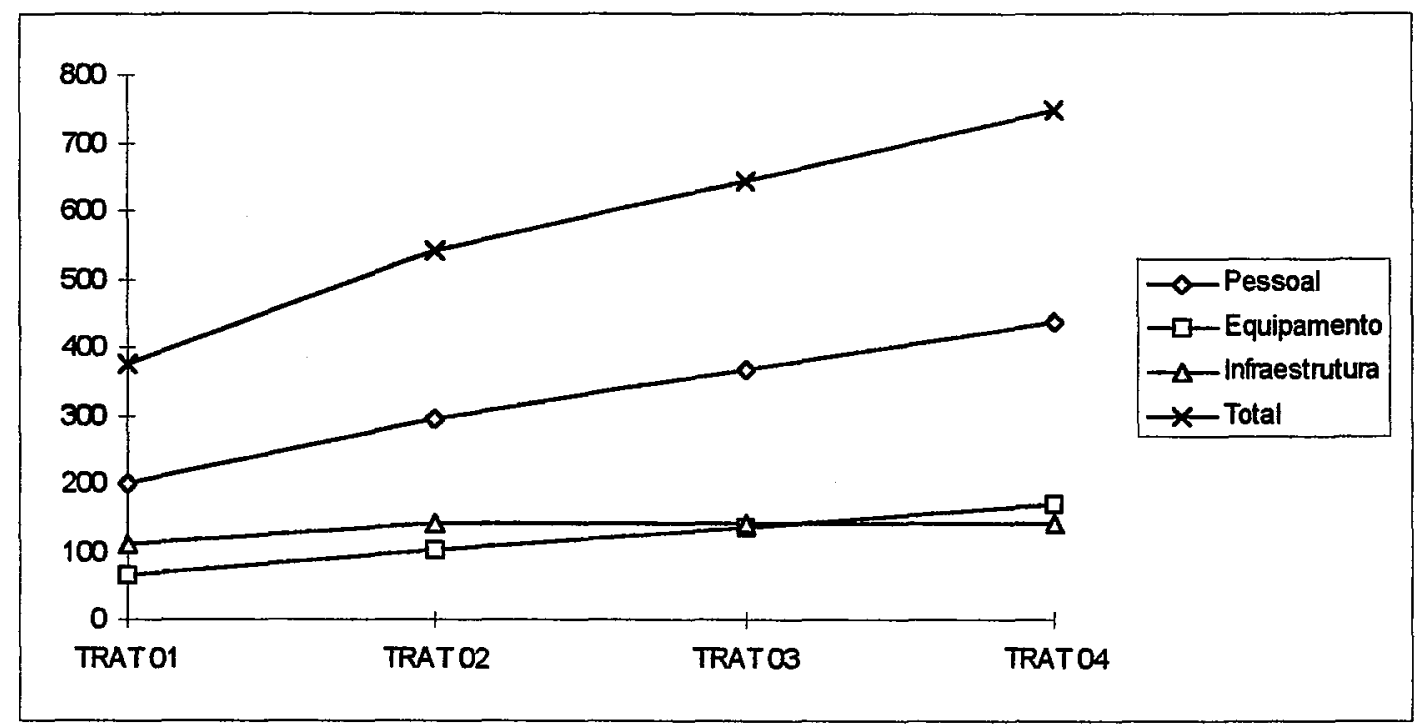

Figura 8: Relação de todos os itens e seus respectivos gastos para cada tratamento envolvendo o inventário, planejamento e derrubada. 
4. Conclusão

As espécies mais abundantes no local de estudo foram Mora paraensis (pracuúba), Euterpe oleracea (açaí) e Pentaclethra macroloba (pracaxí), que representaram 53,36\% da abundância de toda a floresta. Pracuúba e açaí são importantes economicamente na região como madeira serrada e para o corte de palmito, respectivamente.

Foi proposto um sistema policíclico de cortes seletivos a partir dos maiores diâmetros. Este sistema gerou grande impacto na floresta quando os tratamentos silviculturais foram muito intensos. Numa retirada de $75 \frac{\circ}{\circ}$ área basal com uma seleção prévia das árvores e direcionando da queda das copas, 24\% das árvores foram mortas e danificadas. Na operação de desbaste foram incluidas as árvores ocas para melhorar a qualidade da floresta remanescente.

Neste estudo, onde houve dominância de poucas espécies no extrato superior da floresta, o número de árvores mortas e danificadas não afetou a composição florística da mesma.

Foram retirados os seguintes valores de volume comercial por ha: (i) tratamento $2: 58.88 \mathrm{~m}^{3}$, (ii) tratamento $3: 93.13 \mathrm{~m}^{3}$, e (iii) tratamento $4: 136.86 \mathrm{~m}^{3}$.

$\mathrm{Na}$ avaliação dos custos, o item mão-de-obra foi o que pesou mais em todos os tratamentos, exceto para o tratamento 1, onde não foi realizada nenhuma operação de exploração. Para os tratamentos 2,3 e 4 , os custos com mão-de-obra representaram 53.18, 54.68 e $58.4 \%$, respectivamente, em relação ao total com todas as operações realizadas. Os custos médios por metro cúbico por hectare para os tratamentos 2, 3 e 4 foram respectivamente: US\$6.37, Us\$5.80 e US\$5.46. No total para os tratamentos $1,2,3$ e 4, foram gastos por hectare desde $\circ$ inventário até a derrubada, respectivamente: US\$375.00; US\$540.00; US\$644.00; e US\$747.00. 
5. Bibliografia

Ayres, J.M. 1993. As Matas de Várzea do Mamirauá. CNPq/Sociedade Civil Mamirauá. Brasilia, DF. Vol. 1. 123p.

Barros A.C. \& C. Uhl. 1995. Logging along the Amazon River and Estuary: Patterns, problems and potencial. Forest Ecol. and Management, 77: 87-105.

Baur, G.N. 1968. The ecological basis of rain forest management. Forestry Commission of New South Wales, Sidney. 499 p.

Black, G.A.; Dobzhansky, T.H. \& C. Pavan. 1950. Some attempts to estimate species diversity and population density of trees in amazonian forests. Botanical Gaz., 114:413-425.

Buschbacher, R.J. 1990. Natural forest management in the humid tropics: ecological, social, and economic considerations. Ambio, 19(5):253-258.

Cruz, E.C. 1991. Situação atual da silvicultura e do manejo florestal sustentado em áreas de várzeas rivular. In: 0 desafio das florestas tropicais. Simpósio. IUFRO/GTZ. Curitiba. p. 59-76

De Graaf, N.R. 1986; A silvicultural system for natural regeneration of tropical rain forest in suriname. Wageningen, Agricultural University. $250 \mathrm{p}$.

Evans, J. 1982. Plantation forestry in the tropics. Oxford University Press. London. $472 \mathrm{p}$.

Finol, U.H. 1971. Nuevos parametros a consideraise en el analisis estructural de las selvas virgenes tropicales. Rev. For. venezuelana, $18(25): 37-114$.

Goodland R.J.A.; Asibey, E.O.A.; Post, J.C. \& M.B. Dyson. 1991. Tropical Moist Forest Management: The urgency of transition to sustainability. In: Ecological Economics: The science and management of sustainability. Edited by R. Constanza. Columbia University Press. New York. p. 487-525.

Hallé, F.; R.A.A., Oldeman \& P.B. Tomlinson. 1978. Tropical trees and forests: An architectural analisys. New York. SpringerFerlag.

Hartshorn, G.S.; Simeoni, R. \& J.A. Tosi. 1987. Manejo para rendimiento sostenido de bosques naturales. In: Management of the forests of tropical america: prospects and technologies. Proceedings of a conference. Inst. of Tropical Forestry. Puerto Rico. 121-156 p.

Hosokawa, R.T. 1986. Manejo e economia de florestas. FAO. Roma. $125 \mathrm{p}$. 
Husch, B.C.; Miller, C.J. \& T.W. Beers. 1983. Forest mensuration. J. Wiley \& Sons., New York.

Hutchinson, I.D. 1987. The management of humid tropical forests to produce wood. In: Management of the forests of tropical america: prospects and technologies. Proceedings of a conference. Inst. of Tropical Forestry. Puerto Rico. 121-156 $\mathrm{p}$.

Jardim, F.C.S. 1984. Estrutura da floresta equatorial úmida da Estação Experimental de Silvicultura Tropical do INPA. Dissertação de Mestrado. Universidade federal do Paraná. Curitiba. $202 \mathrm{p}$.

Johns, A.D. 1988. Effects of "selective" timber extration on rain forest composition and some consequences for frugivores and folivores. Biotropica, $20(1)$ : 31-37.

Jonkers, W.B.J. 1987. Vegetation structure, logging damage and silviculture in a rain forest in suriname. Wageningen, Agricultural University. $172 \mathrm{p}$.

Kasenene J.M. \& P.G. Murphy 1991. Post-logging tree mortality and major branch losses in Kibale forest, Uganda. Forest Ecol. and management, 46: 295-307.

Legendre I. \& Legendre, P. 1983. Numerical Ecology. Elsevier. Amsterdam. $419 \mathrm{p}$.

Lehmann, M.P.G. 1991. Managing tropical forest in Costa Rica: The Portico Project. Master dissertation. University of Florida, Gainesville. $98 \mathrm{p}$.

Macedo, D.S. \& A.B. Anderson, 1993. Early ecological changes associated with logging in an amazonian floodplain. Biotropica, $25(2): 151-163$.

Magurran, E. A. 1987. Ecological diversity and its measurement. Princeton Univ. Press. $179 \mathrm{p}$.

Mousasticoshvilly Jr., I. 1992. Comercialização e industrialização de virola no estuário amazônico. Dissertação de Mestrado. Universidade Federal do Paraná. Curitiba. 140 p.

Oosting, H.J. 1951. Ecologia vegetal. Aguilar. Madrid. 416 p.

Pellico Neto, S. 1982. Inventário florestal. CAEF, UFPR. Mimeografado. $110 \mathrm{p}$.

Peters, C.M.; Gentry, A.H. \& R. Mendelsohn. 1989. Valuation of an Amazonian rainforest. Nature, 339: 655-666.

Peters, M.P. 1994. Sustainable harvest and non-timber plant resources in tropical mois forest: an ecological primer. WWF/The Nature Conservancy. New York. $45 \mathrm{p}$.

Pielou, E.C. 1975. Ecological diversity. John Willey \& Sons. New York. $156 \mathrm{p}$. 
Pielou, E.C. 1984. The interpretation of ecological data. A primer on classification and ordination. J. Wiley \& Sons. New York. $263 \mathrm{p}$.

Pires, J.M. \& Koury, H.M. 1958. Estudo de trecho de mata de várzea próximo a Belém. Inst. Agronômico do Norte. Bol. Téc., 36: 344 .

Pires, J.M. 1972. Estudo dos principais tipos de vegetação do estuário amazônico. Tese de Doutourado. ESALQ/USP. Piracicaba. $183 \mathrm{p}$.

Pires, J.M. 1973. Tipos de vegetação da Amazônia. In: Museu Paraense Emílio Goeldi, Belém, PA. O Museu Goeldi nos anos do sesquicentenário. Publicação avulsa, 20: 179-202.

Quirós D. \& B. Finegan. 1994. Manejo sustentable de un bosque natural tropical en costa Rica. CATIE. Serie Técnica, $225(9): 25 \mathrm{p}$.

Rohlf, F.J. 1990. NTSYS-PC. Numerical taxonomy and multivariate analysis system, version 1.7. State Univ. New York. Stony Brook. $156 \mathrm{p}$.

Ronald P.C. \& Jeffrey K. Smith. 1984. Applied statistics and SAS programming language. Elsevier Ed. Amsterdan. 187 p.

Silva, J.N.M. 1989. The behavior of the tropical rain forest of the brazilian Amazon after logging. Doctoral Dissertation. oxford. $303 \mathrm{p}$.

Synnott, T.J. 1992. The introduction of basic management into tropical forests. In: Wise management of tropical forests. Ed. F.R. Muller \& K.L. Adam. Oxford For. Institute. Oxford. p. $91-96$.

Uhl, C \& I.C.G. Vieira. 1989. Ecological impacts of selective logging in the Brazilian Amazon: A case study from the Paragominas region of the state of Pará. Biotropica, $21(2): 98-106$.

Vanclay, J. 1992. Species richness and productive forest management. In: Wise management of tropical forests. Edited by F.R. Miller \& K.L. Adam. Oxford forest Institute. Oxford. p. $1-10$.

Veríssimo, A.; Barreto, P.; Tarifa, R. \& C. Uhl. 1995. Extraction of a high-value natural resource from Amazonia: the case of Mahogany. Forest Ecol. and Management, 72:39-60.

Viana, V.M. 1990. Seed and seedling avaiability as a basis for management of natural forest regeneration. In: Alternatives to deforestation: Steps toward to sustainable use of the Amazon rain forest. A.B. Anderson, Editor. Columbia University Press. New York. p. 97-115.

Wilcox, B.A. 1995. Bosques tropicalez y diversidad biológica: los riegos de la pérdida y degradación de los bosques. Unasylva, $181(46): 43-49$. 


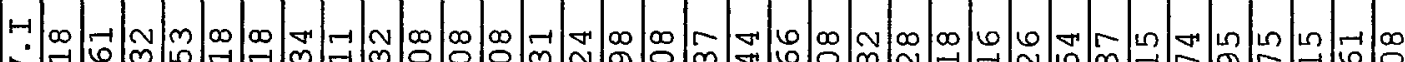

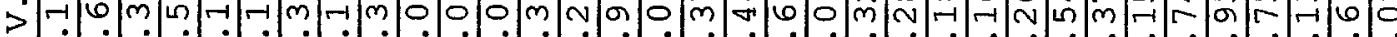
i

a

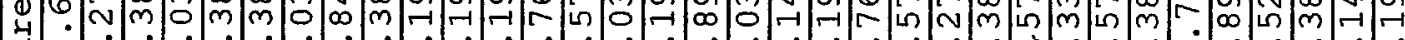

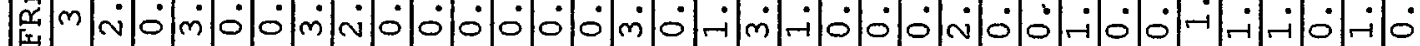

$-\prod_{\pi}$

-

(n)

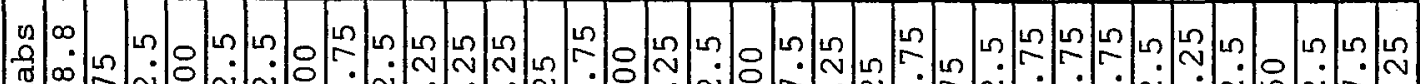

2

$+$

F (1)

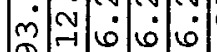

-

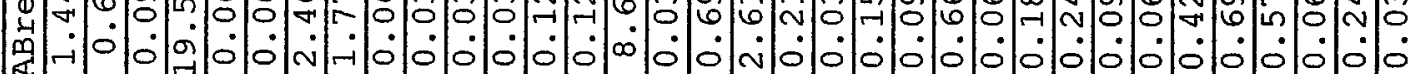

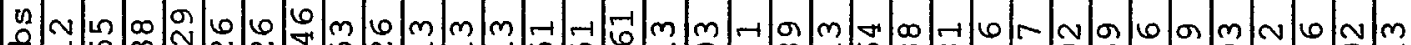

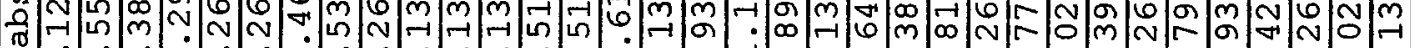
罢

结

을

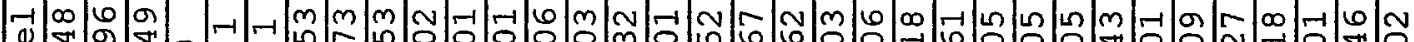
म厶

$\pi$

1

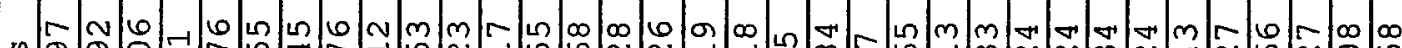

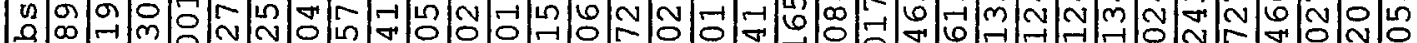

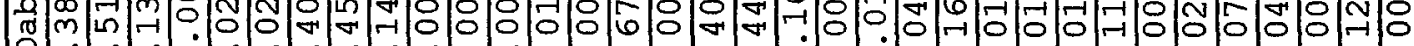

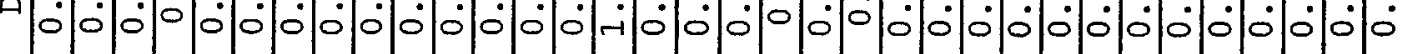

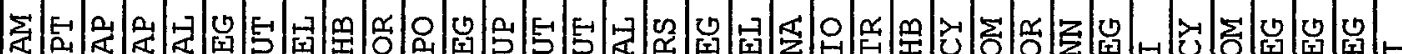

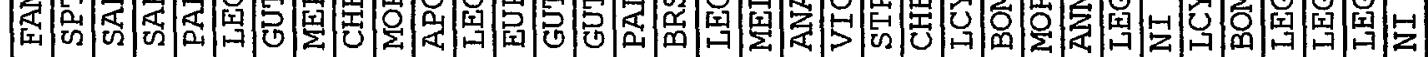

in

0

\&

O

in

要

究

is

密 응

点

(2)

-

$\stackrel{0}{0}$

ป)

in ${ }^{24}$

光

0 讨

U.

穴

D 0

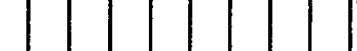

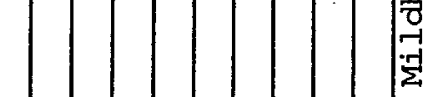

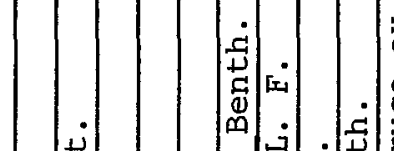

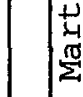

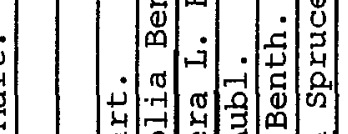

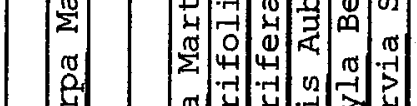

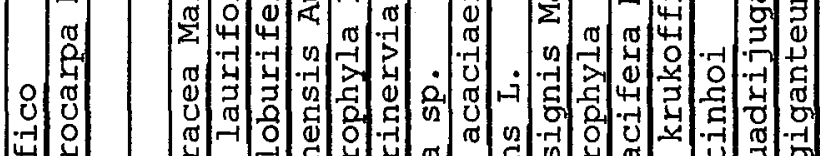

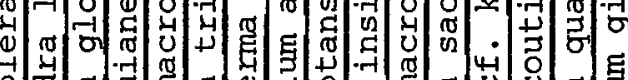

건

प्丶

.

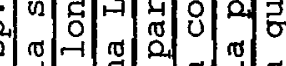

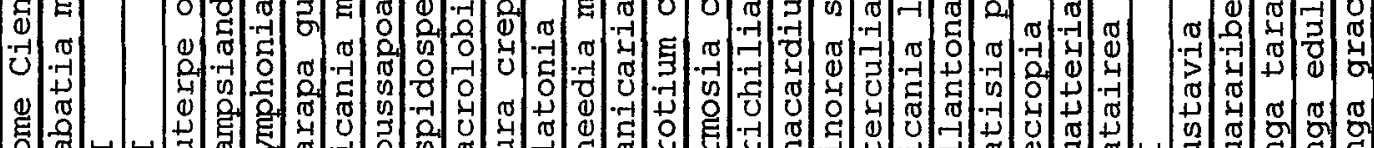

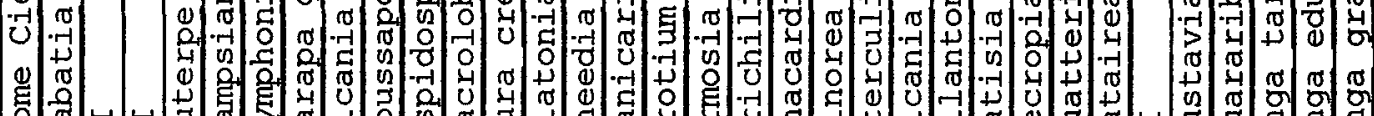

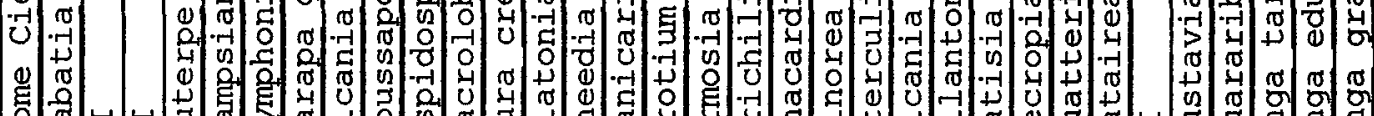

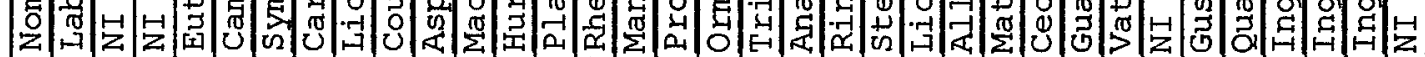

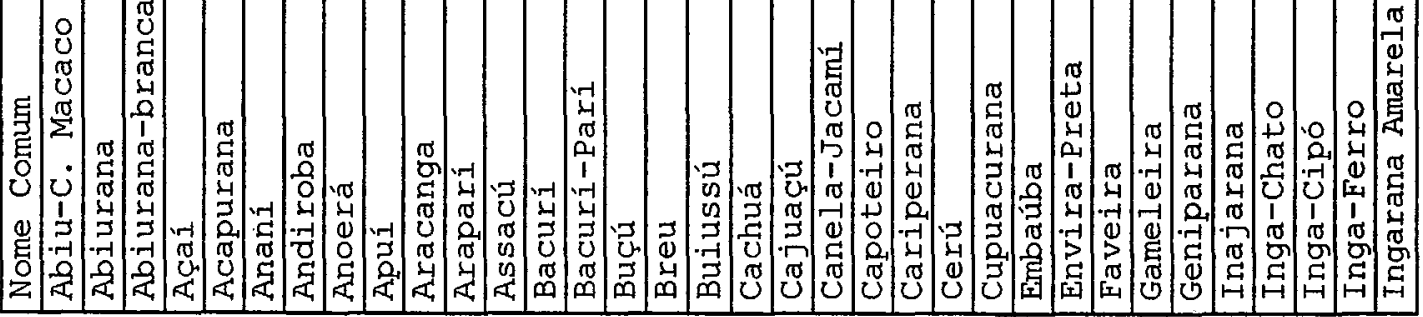




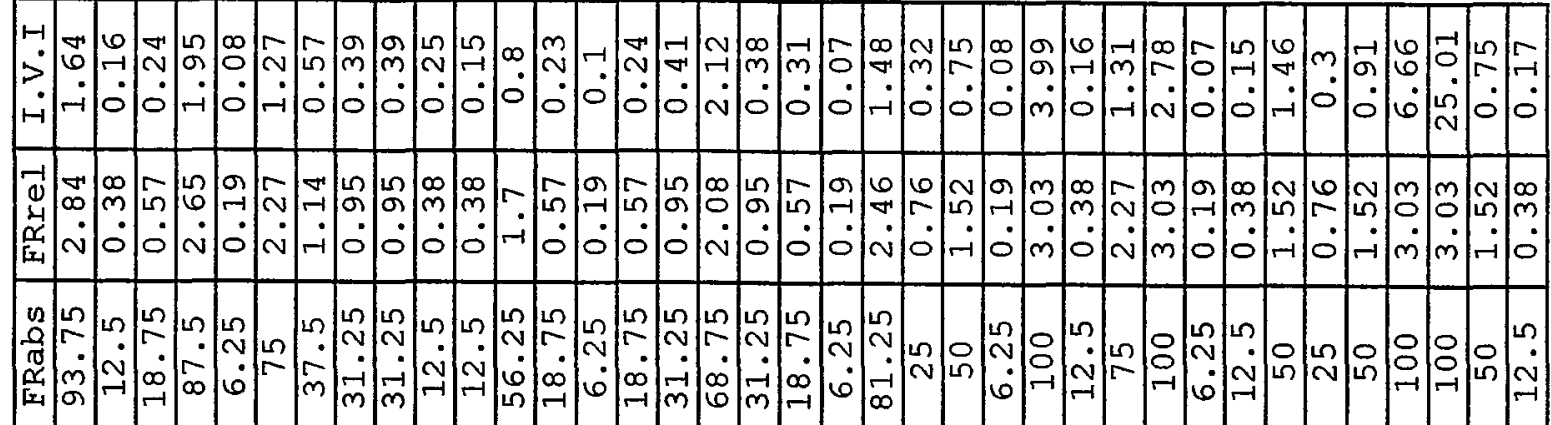

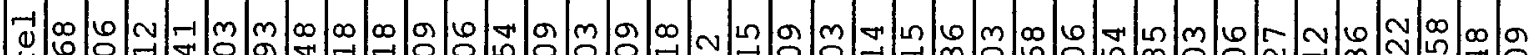

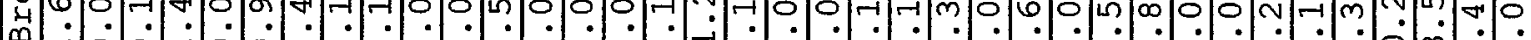
自

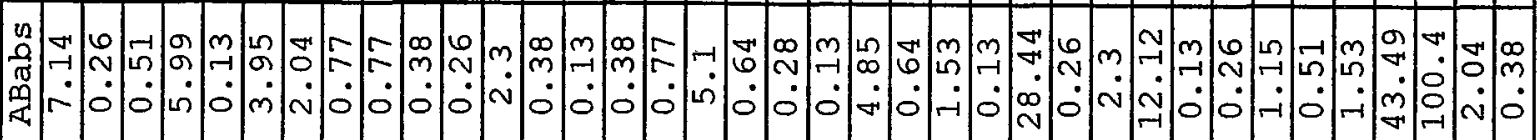

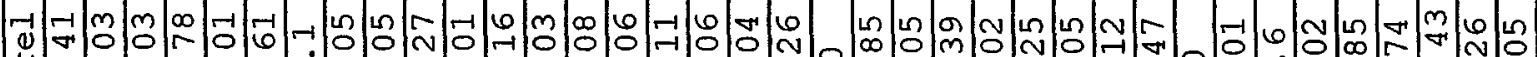

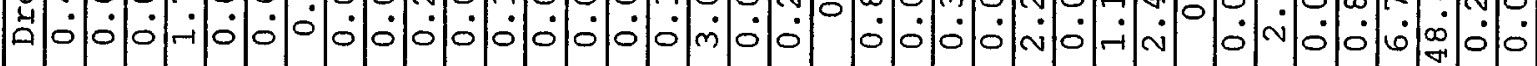

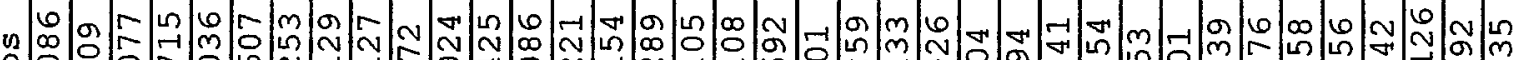

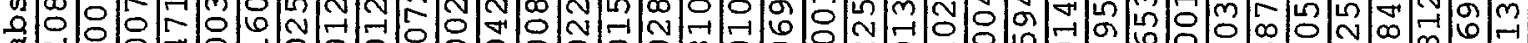

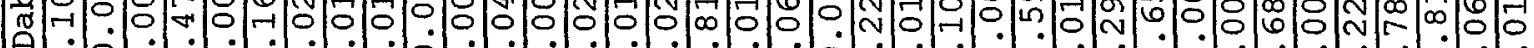

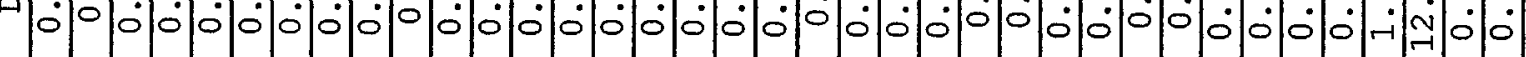

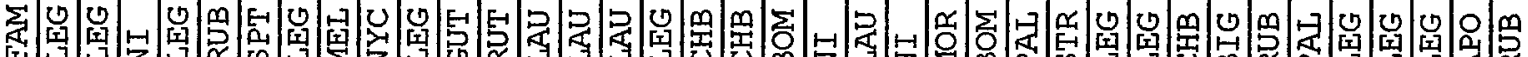

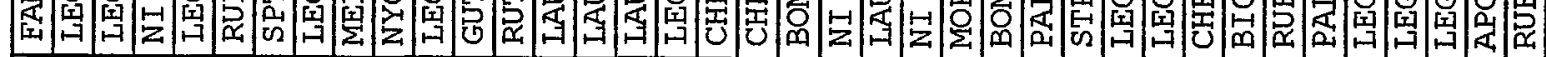

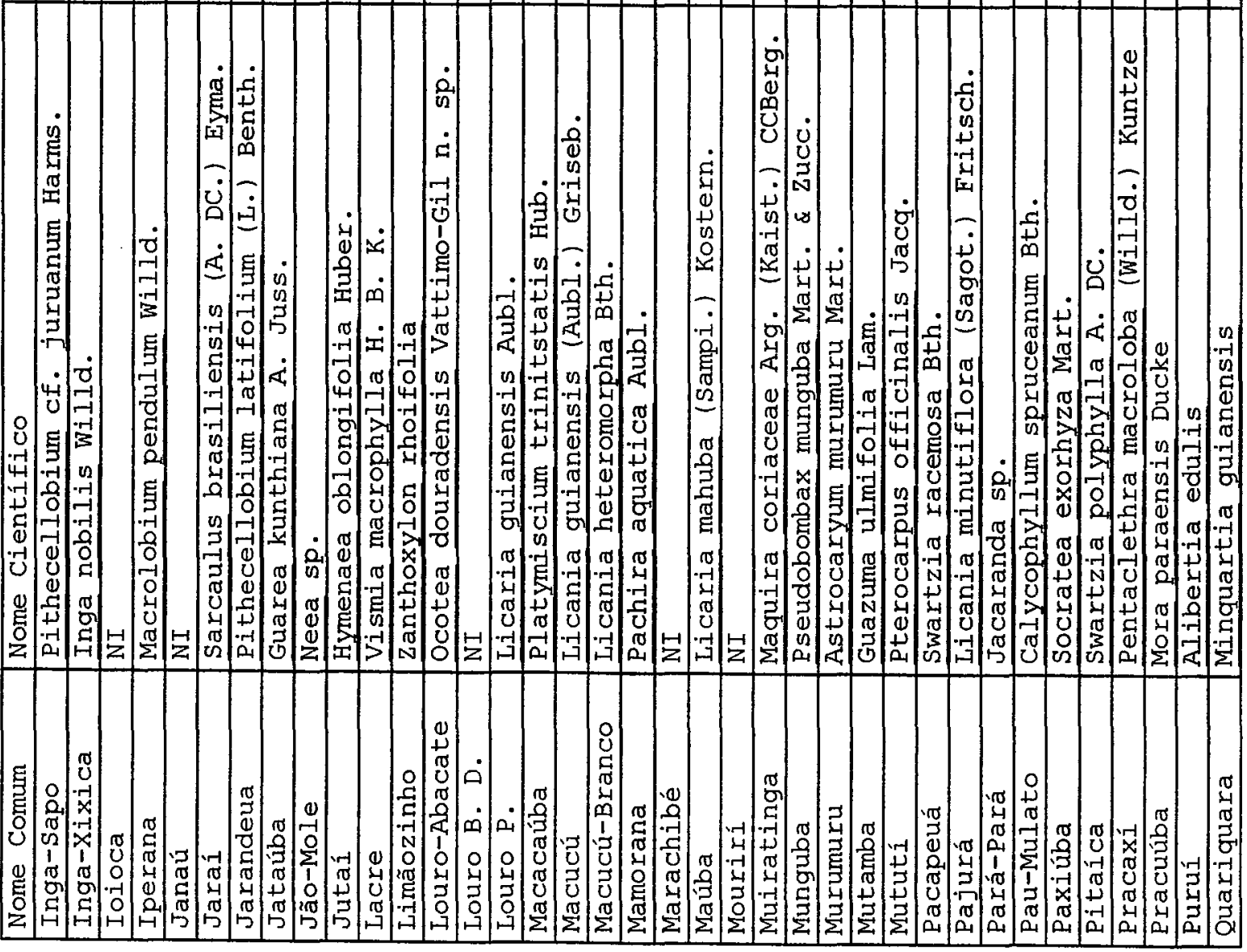




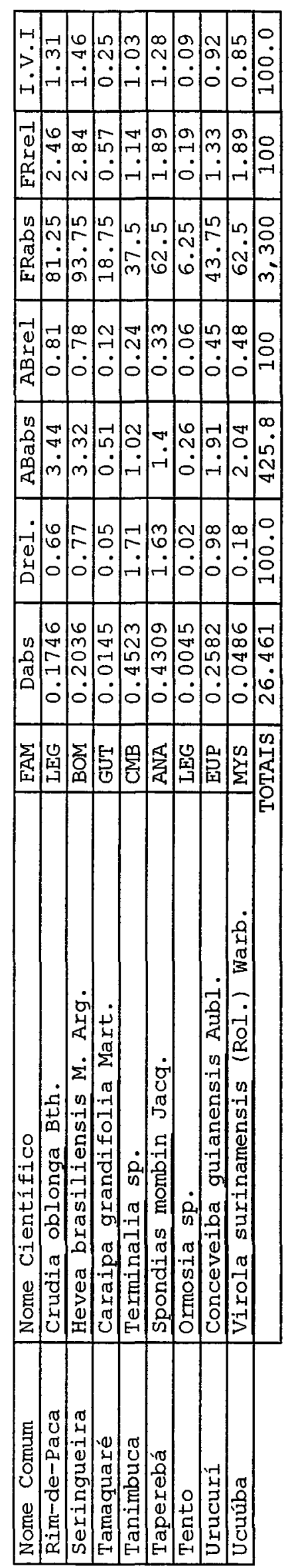

